UNIVERSIDADE DE SÃO PAULO

ESCOLA DE ENFERMAGEM

FLÁVIA FIRMINO

EFICÁCIA DA CELULOSE OXIDADA REGENERADA NO CONTROLE DO

SANGRAMENTO DE FERIDAS NEOPLÁSICAS MALIGNAS DECORRENTES DE

CÂNCER DE MAMA: ENSAIO CLÍNICO RANDOMIZADO

SÃO PAULO

2019 


\section{FLÁVIA FIRMINO}

\section{EFICÁCIA DA CELULOSE OXIDADA REGENERADA NO CONTROLE DO SANGRAMENTO DE FERIDAS NEOPLÁSICAS MALIGNAS DECORRENTES DE CÂNCER DE MAMA: ENSAIO CLÍNICO RANDOMIZADO}

Versão corrigida da Tese apresentada ao Programa de Pós-Graduação em Enfermagem na Saúde do Adulto - PROESA - da Escola de Enfermagem da Universidade de São Paulo para obtenção do título de Doutor em Ciências

Área de concentração: Enfermagem na Saúde do Adulto

Orientadora: Profa ${ }^{a}$ Dr ${ }^{a}$. Vera Lúcia Conceição de Gouveia Santos (EE-USP)

\section{VERSÃO CORRIGIDA}

A versão original encontra-se disponível na Biblioteca da Escola de Enfermagem da Universidade de São Paulo e na Biblioteca Digital de Teses e Dissertações da Universidade de São Paulo.

São Paulo 
AUTORIZO A REPRODUÇÃO E DIVULGAÇÃO TOTAL OU PARCIAL DESTE TRABALHO, POR QUALQUER MEIO CONVENCIONAL OU ELETRÔNICO, PARA FINS DE ESTUDO E PESQUISA, DESDE QUE CITADA A FONTE.

Assinatura:

Data:

\section{Catalogação na Publicação (CIP)}

\section{Biblioteca "Wanda de Aguiar Horta"}

\section{Escola de Enfermagem da Universidade de São Paulo}

\section{Firmino, Flávia}

Eficácia da celulose oxidada regenerada no controle do sangramento de feridas neoplásicas malignas decorrentes de câncer de mama: ensaio clínico randomizado / Flávia Firmino. São Paulo, 2019

$142 \mathrm{p}$.

Tese (Doutorado) - Escola de Enfermagem da Universidade de São Paulo.

Orientadora: Prof. ${ }^{\mathrm{a}}$ Dr. ${ }^{\mathrm{a}}$ Vera Lúcia Conceição de Gouveia Santos

Área de concentração: Enfermagem na Saúde do Adulto

1. Neoplasias mamárias. 2. Ensaio clínico controlado randomizado. 3. Ferimentos e lesões. 4. Enfermagem oncológica. 5. Cuidados paliativos. I. Título.

Ficha catalográfica elaborada por Fabiana Gulin Longhi Palacio (CRB-8: 7257) 


\section{Dedicatória}

Aos profissionais de saúde, de qualquer lugar do mundo que, com suas mãos, mentes e corações, nos caminhos do ensino e da pesquisa, contribuem para a assistência às mulheres acometidas pelo câncer de mama. 


\title{
Agradecimentos
}

\author{
À Profa Doutora Vera Lucía Conceícão de Gouveía Santos, \\ que me orientou no desenvolvimento deste estudo e, neste \\ caminhar, enríqueceu-me com seus conhecimentos, sua \\ crítica, seu posicionamento e tantas outras questões \\ inerentes ao mundo do ensino, da pesquisa... e da vida. Para \\ além desta tese, meus agradecimentos por tornar realidade \\ a Enfermagem em Estomaterapia no Brasil.
}

A todos os pacientes que participaram deste estudo. Minha eterna gratidão, respeito e compromisso pelas histórias atrás de cada ferida sangrante.

Às enfermeiras dos Hospitais de Câncer III e IV do Instituto Nacional de Câncer, pelo auxílio no recrutamento dos pacientes do estudo.

Às técnicas de enfermagem do Serviço de Pronto-Atendimento (SPA) do Hospital de Câncer IV - INCA Cristina Fonseca, Patrícia da Luz, Marisete Ruas, pelo otimismo que me depositaram nos momentos mais difíceis desta coleta de dados.

À enf. Vilma Gárcia Monteiro, que foi minha chefe direta na maior parte do tempo no desenvolvimento deste estudo; pela compreensão e apoio concreto.

A todas as enfermeiras do Serviço de Internação Hospitalar do HC IV - que dividiram entre si a carga de trabalho durante meu necessário período de ausência.

Aos colegas de trajetória comum da EEUSP: Juliano Santos, Carime Flórido, Sônia Benavente, Ramon Oliveira, Juliana Chaves, pela parceria, cumplicidade e discussões profícuas inerentes ao mundo dos alunos.

A todos os colegas do Grupo de Pesquisa em Estomaterapia da Escola de Enfermagem da Universidade de São Paulo - EEUSP. 
Aos funcionários da Biblioteca da EEUSP, por facilitarem o caminhar dos alunos nos momentos mais importantes.

Ao Instituto Nacional de Câncer José Alencar Gomes da Silva, pelo fornecimento doe material e exames inerentes ao estudo.

À Coordenação de Aperfeiçoamento de Pessoal de Nível Superior - CAPES e ao PROESA, pelo patrocínio de minha participação no 15 th World Congress of the European Association for Palliative Care, em Madri, e da visita técnica ao Hospital de Manacor, Ilhas Baleares, e por subsidiarem a tradução do artigo de revisão sistemática oriundo desta pesquisa.

A amigos queridos: Maurício Ramos, Sérgio e Valéria, Sueli Benato, Anelise Fonseca e Eunice Lima pela parceria, pelos abraços, incentivos e colaboração.

A meu marido Márcio Jacques de Moraes, pelo caminhar junto, pelo incentivo, pelo amor...

E, finalmente... à minha família: Roberta Gonçalves, minha mãe; aos irmãos Rafael Firmino, Andréa Chagas, Ana Carolina Firmino, pelo apoio incondicional.

Ainda com intenso sentimento, agradeço a meu pai, Elson Firmino, que partiu no decurso do desenvolvimento deste estudo... sem tempo de saber de minha gratidão, sem tempo de saber que estava tão perto de concluir este estudo... Mas deixou comigo suas palavras de incentivo. 
"Olhe para as estrelas e nãa para as seus pés. Tente entender a que vacê vê e imagine a que faz a universa existir. Seja curiasa." 
Nome: Flávia Firmino

Título: Eficácia da celulose oxidada regenerada versus alginato de cálcio no controle do sangramento de feridas neoplásicas malignas decorrentes de câncer de mama: ensaio clínico randomizado

Tese apresentada ao Programa de Pós-Graduação em Enfermagem na Saúde do Adulto da Escola de Enfermagem da Universidade de São Paulo para obtenção do título de Doutora em Ciências.

Aprovado em:

Banca Examinadora

Orientadora: Profa. Dra.

Instituição:

Assinatura:

Prof. Dr. Instituição:

Julgamento:

Assinatura:

Prof. Dr. Instituição:

Julgamento: Assinatura:

Prof. Dr. Instituição:

Julgamento: Assinatura:

Prof. Dr. Instituição:

Julgamento: Assinatura:

Prof. Dr. Instituição:

Julgamento: Assinatura: 
Firmino F. Eficácia da celulose oxidada regenerada versus alginato de cálcio no controle do sangramento de feridas neoplásicas malignas decorrentes de câncer de mama: ensaio clínico randomizado [tese]. São Paulo: Universidade de São Paulo, Escola de Enfermagem; 2019.

\section{RESUMO}

Introdução: Feridas neoplásicas malignas (FNM) apresentam sangramento decorrente da angiogênese tumoral ou do rompimento de vasos sanguíneos adjacentes. Ainda hoje, a hemostasia tópica é orientada pela opinião de especialistas tendo como curativo padrão o alginato de cálcio (AC). A celulose oxidada regenerada (COR) é um hemostático cirúrgico e também está indicada para hemostasia em FNM. Não há fortes evidências sobre o emprego destes na hemostasia clínica de FNM. Objetivo geral: Avaliar a eficácia da COR versus o AC no controle do sangramento de FNM decorrente de câncer de mama. Método: Ensaio clínico randomizado, estratificado, paralelo, controlado, aberto, unicêntrico, conduzido entre outubro de 2017 e agosto de 2018, recrutando pacientes no Instituto Nacional de Câncer - INCA. Selecionaram-se 13 mulheres ao grupo AC e 15 ao grupo COR com FNM sangrantes, decorrentes de câncer de mama, com idade igual ou superior a 18 anos. Os principais critérios de exclusão foram: presença de sangramento arterial, comorbidades hematológicas e participação anterior no mesmo estudo. As principais variáveis dependentes foram: obtenção de hemostasia, tempo total para hemostasia (TTH), ressangramento e quantidade de produtos hemostáticos utilizados. As principais variáveis independentes foram: número de plaquetas, coagulograma estadiamento do tumor, da FNM e do sangramento. A hipótese afirmou haver diferença média de 5 minutos na utilização da COR comparada ao AC. A intervenção consistiu na aplicação dos produtos, de acordo com a randomização (por envelopes opacos) e contagem do TTH, precedida de coleta de sangue, aferição de sinais vitais e avaliação da ferida e sangramento. $O$ desfecho primário foi o TTH e os secundários: proporção de mulheres que alcançaram hemostasia até 20 minutos; hemostasia aos 3, 5 e 10 minutos, ressangramento e quantidade de hemostáticos. Aplicou-se estatística descritiva para as variáveis nominais e ordinais, por meio de frequências absolutas; para as contínuas: média e desvio-padrão. Os desfechos foram avaliados pelo modelo de riscos de Cox, curva Kaplan Meier e teste Long-rank, para o TTH. O estudo foi aprovado pelos Comitês de Ética em Pesquisa do INCA (Parecer número: 2.2286.120) e da Escola de Enfermagem da Universidade de São Paulo - EEUSP (Parecer número: 2.286.120). Resultados: O TTH apresentou mediana 30,4 (IC 95\%: 21,7 - limite superior impreciso) no grupo AC e mediana 30,1 (IC 95\%: 18,6 189) no grupo COR, sem significância estatística $(p=0,894)$. Aos 3 minutos, $92 \%$ (12/13) pacientes do grupo AC alcançaram a hemostasia e $85 \%(12 / 14)$ no grupo COR. No 5o minuto, os resultados se mantiveram em ambos os grupos e no $10^{\circ}$ minuto, $100 \%$ (13/13) alcançaram a hemostasia no grupo AC e $93 \%(13 / 15)$ no grupo COR. Houve dois ressangramentos no grupo COR. Foram gastos 16 hemostáticos no grupo AC e 36 no grupo COR. Não houve danos/efeitos adversos. Conclusões: Não houve evidência de diferença de eficácia hemostática entre os grupos. Sugerem-se novos estudos com amostras maiores. 
Palavras-chave: Hemostáticos. Neoplasias das mamas. Ensaio Clínico Controlado Aleatório. Ferimentos e Lesões. Enfermagem Oncológica. Enfermagem de Cuidados Paliativos na Terminalidade da Vida. 
Firmino F. Efficacy of oxidized regenerated celulose versus calcium alginate in the control of bleeding from malignant wounds in breast cancer: a Randomized Clincal Trial [thesis]. São Paulo: "Universidade de São Paulo, Escola de Enfermagem"; 2019.

\section{ABSTRACT}

Introduction: Malignant wounds (MW) present bleeding due to tumor angiogenesis or the rupture of adjacent blood vessels. Topical hemostasis is recommended by expert opinion. Regenerated oxidized cellulose (ROC) and alginate calcium (AC) are indicated for surgical hemostasis and there is no robust evidence for its use in the control of MW bleeding. Overall objective: To evaluate the efficacy of ROC versus AC in the control of bleeding in malignant wounds due to breast cancer. Method: A randomized, stratified, parallel, controlled, open, unicentric clinical trial was conducted from October 2017 to August 2018, recruiting patients at the National Cancer Institute - INCA. We selected 13 women for the control group and 15 for the ROC group, with bleeding MW due to breast cancer, aged 18 years or older. The main exclusion criteria were: presence of arterial bleeding or contraindication to topical hemostasis, hematological comorbidities and previous participation in the same study. The main dependent variables were: hemostasis, total time for hemostasis (TTH), rebleeding and amount of hemostatic products used. The main independent variables were: number of platelets, coagulogram, and tumor, MW and bleeding staging. The hypothesis stated that there was an average difference of five minutes in the use of ROC compared to the standard dressing. The intervention consisted of random (using opaque envelopes) administration of the products and TTH counting, preceded by blood collection, vital signs measurement and evaluation of the wound and bleeding. The primary endpoint was TTH; secondary endpoints were: proportion of women who achieved hemostasis before 20 minutes, hemostasis at three, five and 10 minutes, rebleeding and amount of hemostatic dressings used. Descriptive statistics were applied for nominal and ordinal variables, by means of absolute frequencies; for the continuous ones: mean and standard deviation. The endpoints were evaluated using the Cox risk model, Kaplan Meier curve and Longrank test for the TTH. The study was approved by the Research Ethics Committees of INCA (Opinion number: 2.2286.120) and the School of Nursing of the University of São Paulo - EEUSP (Opinion number: 2.286.120). Results: TTH was median of 30.4 (95\% Cl: 21.7 - imprecise upper limit) in the AC group and median of 30.1 (95\% $\mathrm{Cl}: 18.6-189)$ in the ROC group. The mean difference between the groups was 0.5 minutes, with no statistical significance $(p=0.897)$. At 3 minutes, $92 \%(12 / 13)$ patients in the AC group and $85 \%(12 / 14)$ of the ROC group had reached hemostasis. From In the 5 minute the result remained and from minutes $10,100 \%$ $(13 / 13)$ achieved haemostasis in the AC group and 93\% (13/15) in the ROC group. There were two rebleedings in the ROC group. Elghteen hemostatic dressings were used in the control group and 34 in the ROC group. There were no damages/adverse effects. Conclusions: There was no evidence of a difference in hemostatic efficacy between groups. Further studies with larger samples are suggested.

Keywords: Hemostatics. Breast Neoplasms. Randomized Controlled Trial. Wounds and Injuries. Oncology Nursing. Hospice and Palliative Care Nursing. 


\section{LISTA DE ILUSTRAÇÕES}

Figura 1 Massa tumoral vegetante em mama esquerda com sua imagem axial do planejamento radioterapico.

Figura 2 Formação de vasos sanguíneos nas FNM, a partir de células progenitoras:neovasculogênese 27

Figura 3 Processo de angiogênese no microambiente tumoral.........................28

Figura 4 Fotografia de uma FNM decorrente de câncer de mama.....................28

Figura 5 Fotografias ilustrativas de sangramento leve $(A)$ e de tecido friável (B) de uma Ferida Neoplásica Maligna mamária. 30

Figura 6 llustração do curativo de alginato de cálcio utilizado no estudo .46

Figura 7 llustração do hemostático tópico cirúrgico utilizado no estudo. 47

Figura 8 Fluxograma do ECR. 49

Figura 9 Fluxograma de pacientes no estudo 69

Figura 10 Hemostasia das FNM ao longo do tempo 82 


\section{LISTA DE TABELAS}

Tabela 1 Mulheres com FNM sangrantes decorrentes de câncer de mama, de acordo com o hospital e a unidade de origem

Tabela 2 Características demográficas e clínicas das mulheres com FNM sangrantes decorrentes de câncer de mama

Tabela 3 Características histopatológicas e estadiamento do tumor 73

Tabela 4 Distribuição das mulheres, conforme o tratamento oncológico recebido

Tabela 5 Características das FNM sangrantes decorrentes de câncer de mama

Tabela 6 Características do sangramento das FNM decorrentes de câncer de mama 76

Tabela 7 Resultados dos marcadores sanguíneos das mulheres com FNM sangrantes decorrentes de câncer de mama

Tabela 8 Valores correspondentes aos sinais vitais de mulheres com FNM sangrantes decorrentes de câncer de mama

Tabela 9 TTH de FNM sangrantes decorrentes de câncer de mama

Tabela 10 Análise multivariada das variáveis independentes exploratórias (Modelo de Cox) para hemostasia em FNM sangrantes em mulheres acometidas pelo câncer de mama

Tabela 11 Probabilidade de alcance de hemostasia de FNM sangrantes em mulheres acometidas pelo câncer de mama

Tabela 12 Distribuição das mulheres que alcançaram hemostasia de FNM mamárias conforme tipo de tratamento hemostático, tempo de hemostasia e porcentagem 


\section{LISTA DE QUADROS}

Quadro 1 Hierarquia de níveis de evidência científica e grau de recomendação

Quadro 2 Tipos de intervenção tópica e classificação das evidências científicas dos estudos que investigaram o controle de sangramento em FNM decorrentes de câncer de mama

Quadro 3 Alocação prevista de pacientes no estudo, conforme estratos e grupos.

Quadro 4 Tempos de hemostasia alcançados pela COR informados nos estudos de hemostasia cirurgica e proporção de pacientes que os alcançaram 


\section{LISTA DE SIGLAS}

$\mathrm{AC}$

$A D$

ANVISA

bFGF

CDI

CEBM

CEP

CMLA

$\mathrm{CO}_{2}$

COBBANA Control of bleeding after bypass anastomoses

CONEP Comissão Nacional de Ética em Pesquisa

CONSORT Consolidated Standards of Reporting Trials

COR

CVC-TI

DM

DP

ECR

EEUSP

ER

EUA

FC

FNM

FR

$\mathrm{g} / \mathrm{dL}$

G1

G3

$\mathrm{HC}$ III

Alginato de cálcio

Assistência domiciliar

Agência Nacional de Vigilância Sanitária

Fator de crescimento fibroblástico básico

Câncer ductal infiltrante ou invasivo

Center for Evidence-Based Medicine

Comitê de Ética em Pesquisa

Câncer de mama localmente avançado

Dióxido de carbono

Celulose oxidada regenerada

Cateter venoso central totalmente implantado

Diabetes mellitus

Desvio-padrão

Ensaío clínico randomizado

Escola de Enfermagem da Universidade de São Paulo

Erro-padrão

Estados Unidos da América

Frequência cardíaca

Ferida neoplásica maligna

Frequência respiratória

Gramas/decilitros

Grau 1

Grau 3

Hospital de Câncer 3 


$\begin{array}{ll}\text { HC IV } & \text { Hospital de Câncer } 4 \\ \text { HCP } & \text { Hospital de Câncer de Pernambuco } \\ \text { HM } & \text { Hemáceas } \\ \text { HT } & \text { Hematócrito } \\ \text { IC } & \text { Intervalo de confiança } \\ \text { ID } & \text { Número de identificação } \\ \text { INCA } & \text { Instituto Nacional de Câncer } \\ \text { INR } & \text { Razão normalizada internacional } \\ \text { JWC } & \text { Journal Wound Care } \\ \text { K/UL } & \text { Kilolitro por metro cúbico } \\ \text { LI } & \text { Limite inferior do intervalo de confiança de 95\% } \\ \text { LS } & \text { Limite superior do intervalo de confiança de 95\% } \\ \text { NO } & \text { Óxido nítrico } \\ \text { PAD } & \text { Pressão arterial diastólica } \\ \text { PAS } & \text { Pressão arterial sistêmica } \\ \text { PASS } & \text { Power analysis and sample sie system } \\ \text { PRSP } & \text { Streptococcus pneumoniae } \\ \text { PTTa } & \text { Tempo de tromboplastina parcial ativada } \\ \text { ReBec } & \text { Rede Brasileira de Ensaios Clínicos } \\ \text { SPA } & \text { Serviço de Pronto-Atendimento } \\ \text { T } & \text { Temperatura } \\ \text { TAP } & \text { Tempo de protrombina ativada } \\ \text { TCLE } & \text { Termo de Consentimento Livre e Esclarecido } \\ \text { TTH } & \text { Tempo total de hemostasia } \\ \text { VEGF } & \text { Fator de crescimento endotelial vascular } \\ & \end{array}$




\section{SUMÁRIO}

1 INTRODUÇÃO

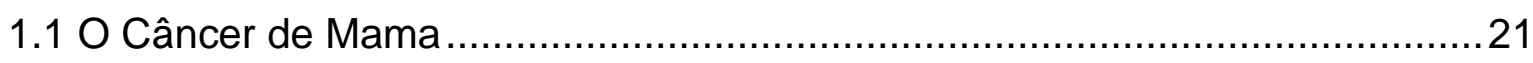

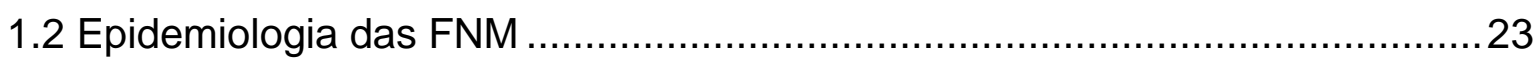

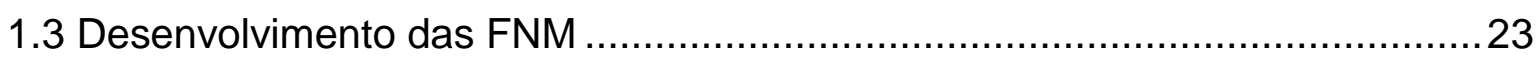

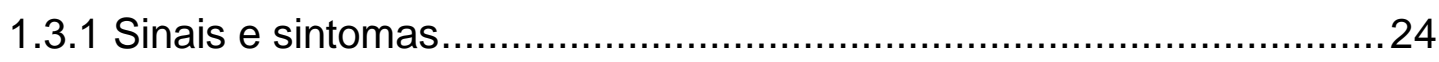

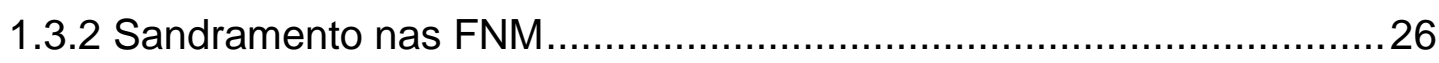

1.4 Hemostasia tópica nas FNM mamárias: Revisão de literatura..........................31

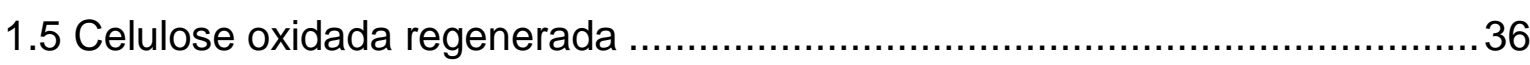

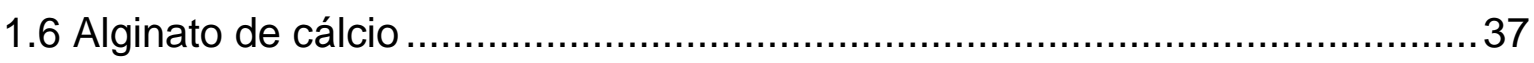

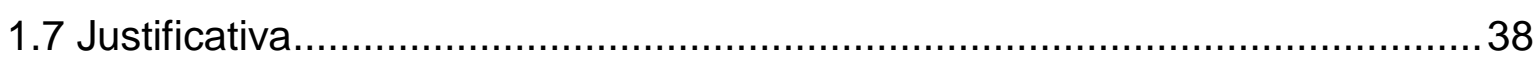

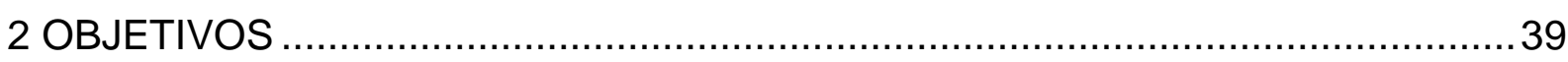

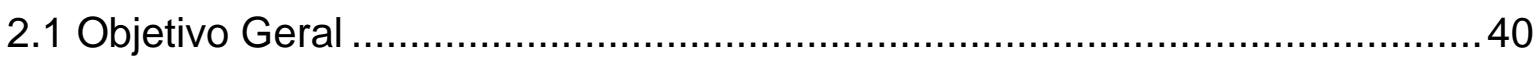

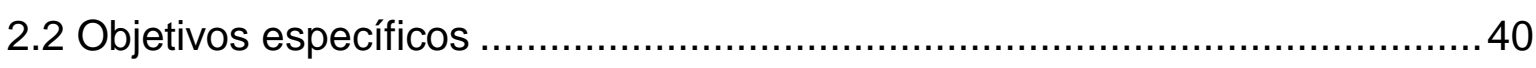

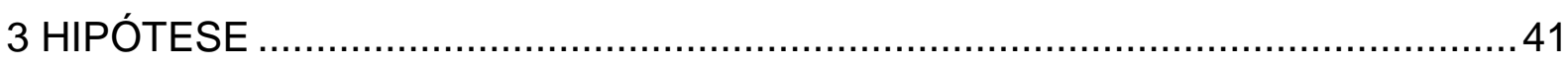

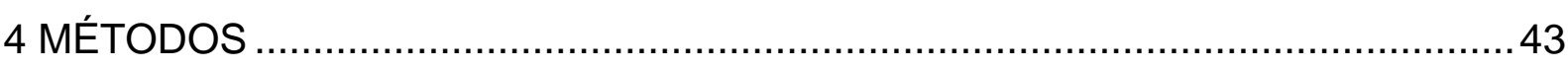

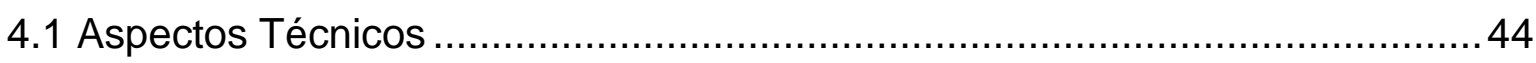

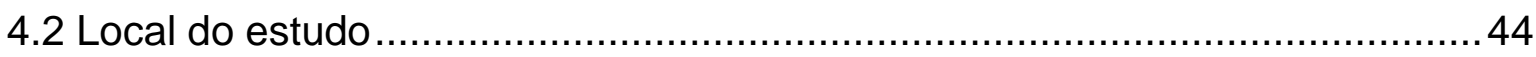

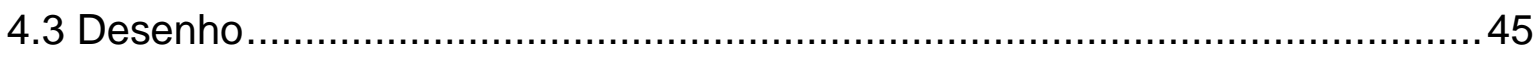

4.3.1 Produtos a serem testados nas intervenções do estudo …………....... 46

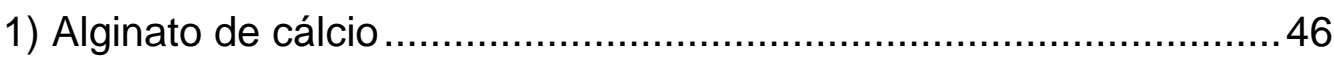

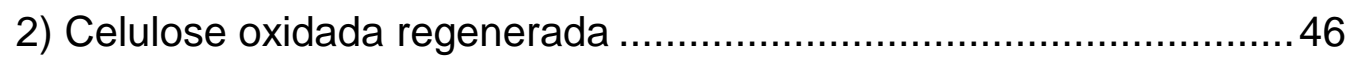

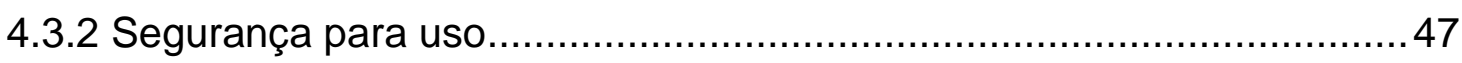

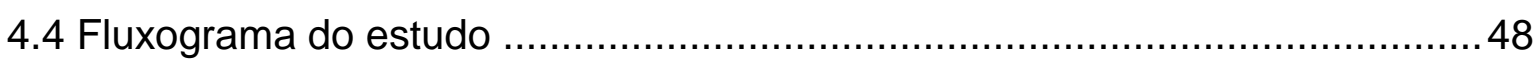

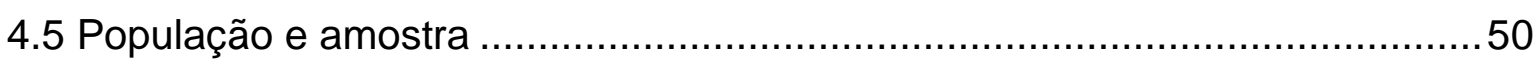

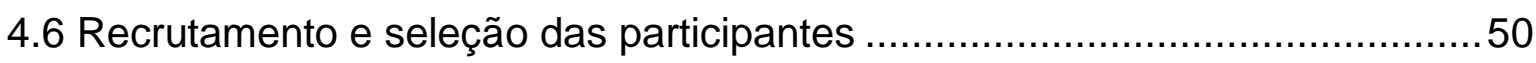

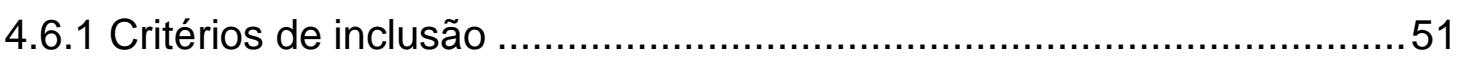

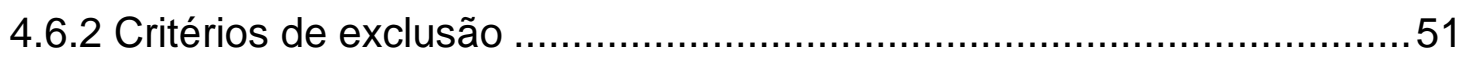

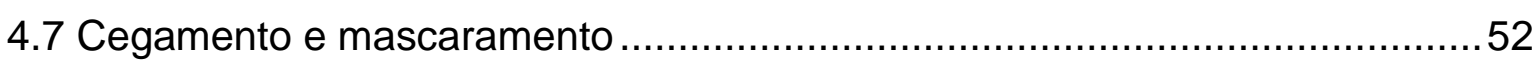

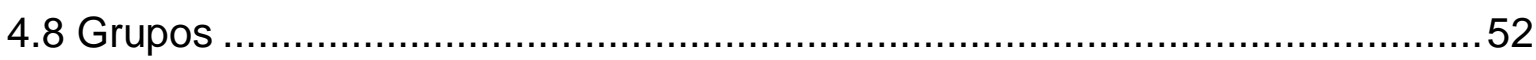

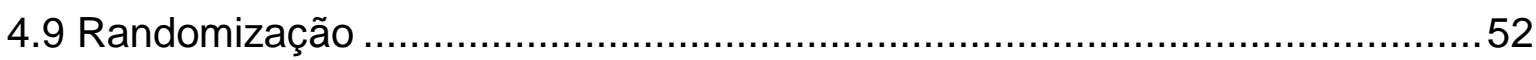

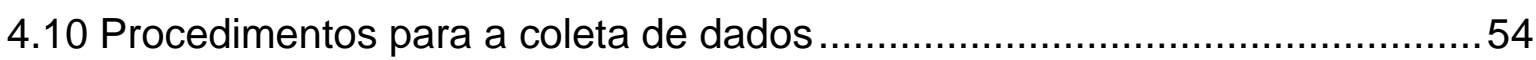


4.10.1 Capacitação dos profissionais para a coleta de dados .......................54

4.10.2 Instrumentos utilizados na coleta de dados .....................................54

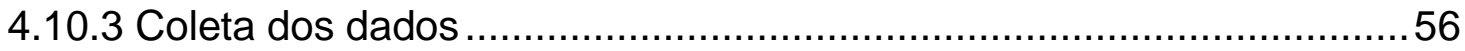

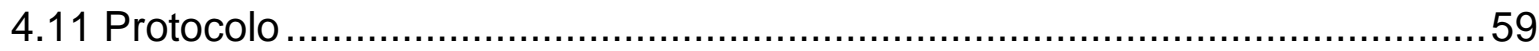

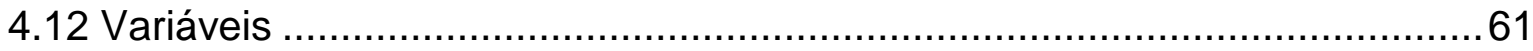

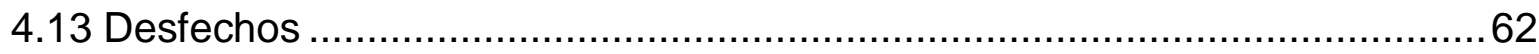

4.13.1 Definições operacionais para avaliação dos desfechos......................62

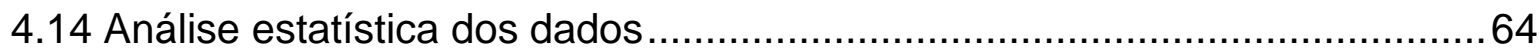

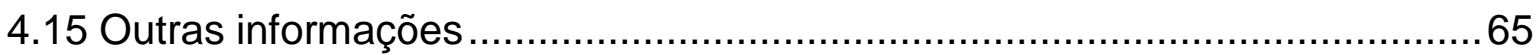

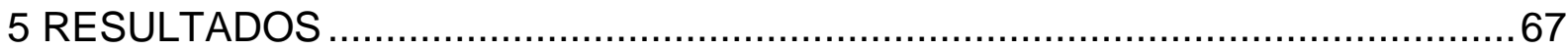

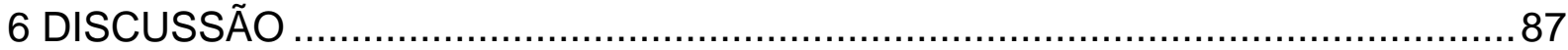

7 CONTRIBUIÇÕES, LIMITAÇÕES E RECOMENDAÇÕES …….........................94

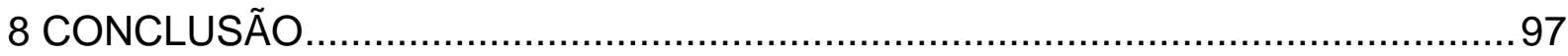

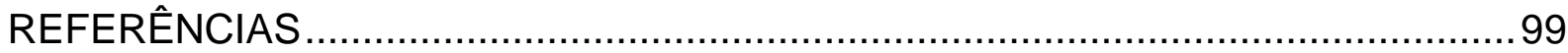

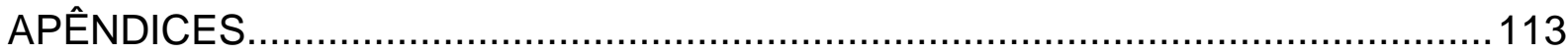

Apêndice A - Quadro de Distribuição do número de artigos pelas bases de dados consultadas na busca de artigos referentes à hemostasia clínica de feridas neoplásicas malignas. São Paulo, 2018 …………………………......114

Apêndice B - Termo de Consentimento Livre e Esclarecido (TCLE)...................116

Apêndice C - Ficha de Coleta de Dados .........................................................120

Apêndice D - Escala de Intensidade de Sangramento ........................................125

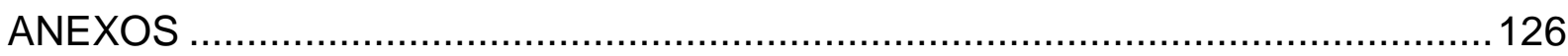

Anexo A - Aprovação do Comitê de Ética em Pesquisa do Instituto Nacional

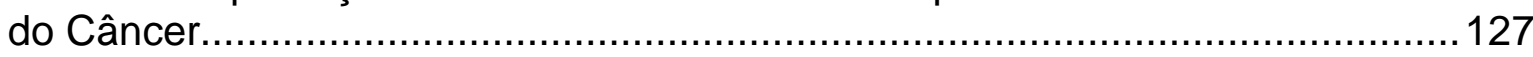

Anexo B - Parecer Consubstanciado do CEP Escola de Enfermagem USP .......128

Anexo C - Parecer Consubstanciado do CEP Instituto Nacional de Câncer

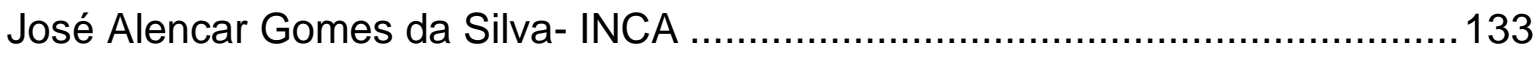

Anexo D - Estadiamento classificatório das feridas neoplásicas .........................141

Anexo E - View Letter - Journal of Wound Care................................................142 
1 INTRODUÇÃO 


\section{INTRODUÇÃO}

As feridas neoplásicas malignas (FNM) são formadas em decorrência do rompimento da pele pela proliferação descontrolada de células malignas que se infiltram no epitélio tegumentar ${ }^{1}$. A infiltração pode ocorrer a partir de tumores primários ou metastáticos ${ }^{1-2}$. No câncer de mama, é comum a FNM suceder pela progressão local do tumor, embora possa se verificar também pela progressão de metástase cutânea nas regiões torácica, dorsal e abdominal ${ }^{1,3-5}$.

Consistem em feridas complexas, disformes, exsudativas, fétidas e muito dolorosas, com alta carga bacteriana, fragilidade de bordas e leito friável. Seus sintomas característicos são a dor, o sangramento, o exsudato e o odor. Por estarem associadas ao desenvolvimento de câncer, são consideradas feridas crônicas, com chances de cicatrização dependente do controle ou cura da doença subjacente. Assim sendo, cursam com piora da degemeração tecidual no decorrer da fase final da vida ${ }^{1,6}$. Desta forma, as FNM impactam dramaticamente na qualidade de vida e bem-estar social dos pacientes e seus familiares por aumentar a sobrecarga de sofrimento físico e psicossocial, levando o paciente ao isolamento de sua vida social mais ativa e imputando ao familiar cuidar de um ente querido desfigurado e com presença de sintomas tão importantes, como o odor e o sagramento ${ }^{7-9}$.

Apesar disso, são feridas pouco investigadas em toda a literatura mundial e não há formas devidamente padronizadas de controle de seus sinais e sintomas ${ }^{6,10-}$ 11. Pesquisas qualitativas demonstram que pacientes e familiares aprendem a lidar com os sinais e sintomas dessas feridas por tentativa e erro e sentem-se sozinhos nessa terrível experiência ${ }^{7-8,12}$. Outras pesquisas apontam que enfermeiros demonstram déficits importantes em relação às principais medidas assistenciais, como escolha de curativo e controle de sinais e sintomas das FNM, buscando adaptar seus conhecimentos a partir de outros acumulados na experiência de cuidar de pacientes com feridas de outras etiologias, mais frequentes na prática clínica, como as lesões por pressão ${ }^{13-14}$. Trata-se, assim, de uma área carente de abordagens investigativas, tanto na área da prática como no ensino e pesquisa. 
As FNM mamárias são, particularmente, associadas a câncer de mama localmente avançado (CMLA), que é o câncer de mama nos estadiamentos II (quando com tamanho acima de 4 centímetros), III e IV com ou sem metástases, ainda que nem todos estes tipos de câncer tenham necessariamente FNM2,15-16.

O CMLA corresponde a cerca de $10 \%$ e $30 \%$ dos novos casos de câncer diagnosticados no mundo ${ }^{3}$. Nos países desenvolvidos, tais casos compreendem entre $10 \%$ e $20 \%{ }^{17}$. Estudo desenvolvido em hospital brasileiro, em São Paulo, identificou incidência de $15,75 \%$ de $\mathrm{CMLA}^{18}$. No entanto, o estudo não informou presença ou ausência de FNM.

Esse tipo de tumor vem se tornando mais frequente em decorrência do aumento da prevalência de câncer de mama, sobretudo nos países em desenvolvimento, nos quais, por precariedade de recursos na Saúde, os pacientes têm acesso tardio ao tratamento ${ }^{19-20}$. Literatura internacional estima que cerca de $50 \%$ de cânceres de mama em países em desenvolvimento já apresentam FNM, quando do diagnóstico da doença ${ }^{16}$.

\subsection{O CÂNCER DE MAMA}

O câncer de mama é o tipo mais frequente na população feminina em todo o mundo, excluindo-se o de pele ${ }^{22}$. Para 2018, o Globocan (Global Cancer Observatory - base de dados mundial de câncer) estimou a ocorrência de 18,1 milhões de casos novos de câncer no mundo e 9,6 milhões de mortes dele decorrentes. Dentre os casos novos, 8,7 milhões acometerão mulheres, dos quais 2,1 milhões serão cânceres de mama (11,6\% do total), com incidência de $24,2 \%$ e mortalidade de $15 \%$. Será o mais incidente e o de maior taxa de mortalidade na população feminina global ${ }^{23-24}$.

No Brasil, para o biênio 2018/2019, o Instituto Nacional de Câncer (INCA) estimou a ocorrência de 59.700 casos novos/ano, com risco estimado de 56,33 casos a cada 100 mil mulheres ${ }^{22}$.

Sobrevida superior a 5 anos vem aumentando paulatinamente nas mulheres ao redor do mundo. Mas, nos países em desenvolvimento, esta taxa ainda se encontra abaixo de 40\%, e nos desenvolvidos, está acima dos $80 \%{ }^{25-26}$. Para a America Latina, estima-se taxa entre 50\% e 70\% ${ }^{27}$. Estudo desenvolvido em Goiânia identificou que a sobrevida de 10 anos para mulheres acometidas pelo câncer de 
mama foi $56,3 \%{ }^{28}$. Outro estudo desenvolvido na região norte de Minas Gerais, identificou estimativa de $76,3 \%$ para a sobrevida de 5 anos.

O desenvolvimento de câncer decorre de instabilidades genômicas e alterações no ciclo celular que conferem às células a capacidade de se multiplicar de forma anormal, descontrolada e, consequentemente, invadir e destruir tecidos vivos $^{30}$.

A definição mais atual considera que o câncer seja:

um termo genérico que agrupa um conjunto de mais de 200 doenças que guardam características comuns e ao mesmo tempo extremamente diferentes em termos de origem genética e histopatológica, progressão, agressividade, prognóstico e resposta ao tratamento ${ }^{31: 5}$.

Acredita-se que o câncer de mama tenha origem na resposta das células do tecido mamário ao estrogênio ${ }^{32}$. Mas, outras descobertas postulam a influência de expressões irregulares de moléculas, como as supressoras de tumores, reguladoras do ciclo celular e de formação de tecidos, que se encontram silenciadas na ocorrência de alguns subtipos de câncer de mama e aumentadas em outros ${ }^{33}$.

As características histopatógicas desse tipo de câncer vem se tornando relevantes no entendimento do desenvolvimento de tumores malignos, conforme a definição mais atual da doença. Carcinoma Ductal Infiltrante (CDI), ou invasivo, é o tipo mais comum. A avaliação histopatológica considera também as alterações celulares e a contagem de mitoses das células malignas, sendo a variância entre os

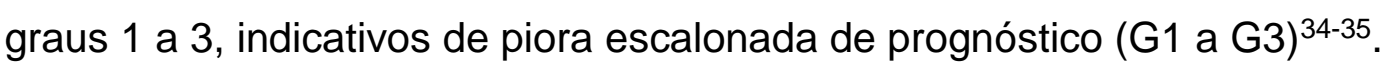

A capacidade da célula maligna expressar ou não receptores para estrogênio e progesterona ${ }^{36-37}$, bem como de expressarem receptores de fator de crescimento epidérmico humano, conhecido como gene c-er-2 ou HER $2^{38-40}$ e expressão do marcador celular Ki67 também são indicadores de prognóstico ${ }^{41}$. Em especial, o Ki 67, proteína preditora de invasão celular linfovascular, sua expressão (medida em percentagem) está associada ao poder de invasão de câncer nos tecidos, proliferação metastática, piora de prognóstico e diminuição de sobrevida ${ }^{41-42}$.

Desse modo, um paciente com negatividade para os receptores citados e com elevado percentual de Ki 67 terá pior prognóstico terapêutico, quando comparado às demais condições histopatológicas possíveis, o que pode vir a ter influência nas taxas de sobrevida e ocorrência de FNM, dado o perfil de evolução local agressiva 
que o tumor pode apresentar em função dos receptores e proteínas expressados ${ }^{37-}$ 38,42 .

Embora seja comum entre os clínicos o conceito de que a ferida (FNM) é o reflexo da progressão da doença, fato também reconhecido na literatura internacional ${ }^{1,43-44}$ poucos, porém, sucessivos estudos vêm mostrando que a FNM não está associada à diminuição de sobrevida ${ }^{2,45-48}$. No entanto, os estudos não são homogêneos em suas formas de seleção e avaliação clínica de pacientes e histologia dos tumores.

\subsection{EPIDEMIOLOGIA DAS FNM}

A literatura reporta a estimativa de que entre $5 \%$ e $10 \%$ dos pacientes com câncer avançado podem apresentá-las, sendo as mamas (47\% a 62\%) seguidas de cabeça e pescoço (33\% a 24\%), genitália (3\%), região dorsal (3\%) e outras (8\%), as partes do corpo mais afetadas ${ }^{6,11,49-50}$. Estes dados consolidaram-se na literatura, como um modelo de ocorrência topográfica das FNM ${ }^{51-52}$. No entanto, tratam-se de dados de países desenvolvidos, podendo haver diferença entre os de países em desenvolvimento.

Estudo de perfil epidemiológico, conduzido pelo INCA em sua unidade de cuidados paliativos, informou atendimento de 13.256 pacientes entre janeiro de 2007 e 2009, com incidência de 49\% de FNM, variando entre $10 \%$ e 17\% em acometidos por câncer de mama 53 .

Outro estudo brasileiro semelhante, que visou a identificar e a discutir o perfil sóciodemográfico e de saúde de pacientes que apresentavam FNM atendidos no Hospital de Câncer de Pernambuco (HCP), no período entre junho e agosto de 2013, identificou 51 pacientes, dos quais 12 (23,4\%) tinham FNM decorrentes de câncer de mama ${ }^{54}$.

\subsection{DESENVOLVIMENTO DAS FNM}

O desenvolvimento das FNM está relacionado ao processo de crescimento e desenvolvimento do próprio tumor no curso da doença maligna ${ }^{1-2}$. 
Ao longo de seu processo evolutivo, a FNM não tem aspecto uniforme. Enquanto partes do tumor encontram-se na fase proliferativa, outras seguem em processo de degeneração, pela falência orgânica da arquitetura vascular débil que o tumor promove para sua nutrição local ${ }^{55}$.

De acordo com a forma visual que o tumor apresenta em decorrência do processo oncogênico, diversos nomes vêm sendo empregados na prática clínica, como ferida vegetante, ulcerativa, cavitária, exofítica, em aspecto de couve-flor, dentre outros. A terminologia "ferida tumoral" é uma das mais comuns ${ }^{52,57}$. Na literatura internacional, emprega-se o termo "fungating" como referência às feridas que exibem massa tumoral mais proeminente, o que corresponderia ao termo "vegetante" ou em aspecto de couve-flor ${ }^{56-58 .}$

Os dados da figura a seguir ilustram FNM decorrente de câncer de mama em estadiamento IV.

Figuras 1 - Massa tumoral vegetante em mama esquerda com sua imagem axial do planejamento radioterápico
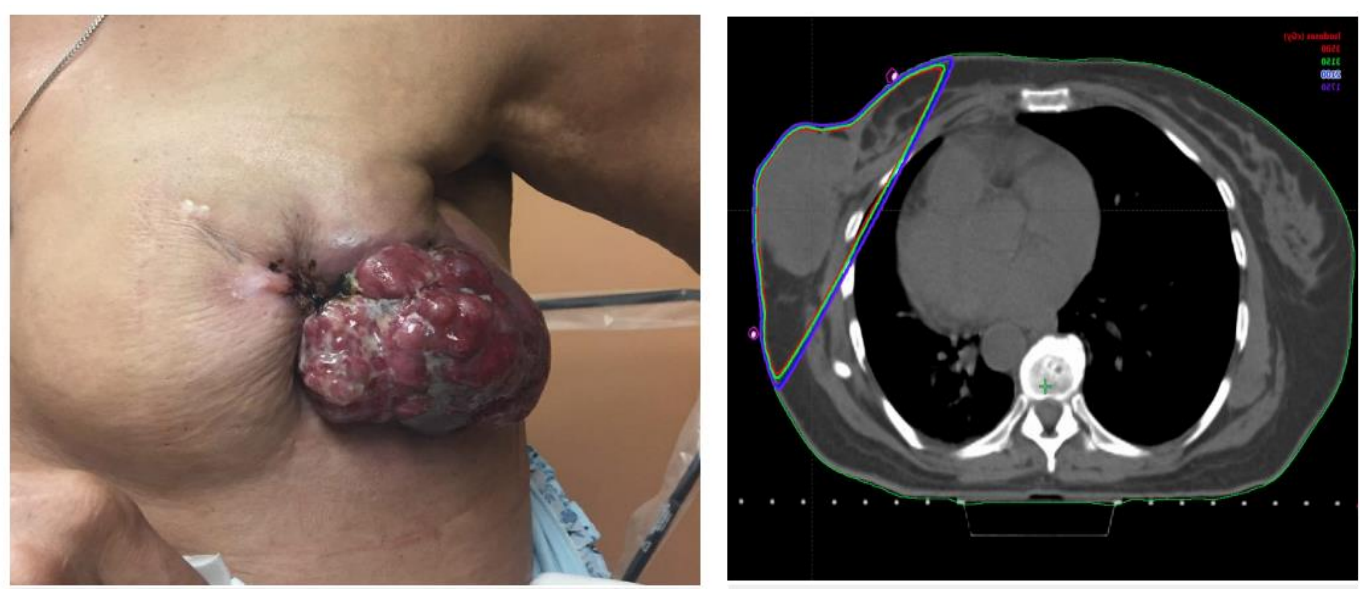

Fonte: Quackenbusch K, Amini A, Fischer CM, Rabinovitch R, $2016^{58}$.

Figura 1B

Figura $1 \mathrm{~A}$

Os dados da Figura 1A mostram massa tumoral exofítica e os da Figura 1B que a massa está comprometendo a parede torácica em decorrência da progressão local da doença.

\subsubsection{Sinais e sintomas}

A literatura aponta o sangramento como sinal e sintoma de menor frequência e pouco estudado na literatura corrente ${ }^{1,59}$. 
Estudo epidemiológico canadense ${ }^{11}$, envolvendo 67 pacientes com FNM de diferentes etiologias (16/34 com câncer de mama), identificou a dor como o sintoma mais prevalente $(31,3 \%)$, seguido de efeito massa, ou seja, imobilidade em decorrência do tamanho da massa tumoral $(23,9 \%)$, distresse $(19,4 \%)$, exsudato $(17,9 \%)$, odor $(11,9 \%)$, prurido $(6 \%)$, sangramento $(6 \%)$ e crostas $(1,5 \%)$.

O estudo desenvolvido na unidade de cuidados paliativos do INCA ${ }^{53}$, anteriormente citado, encontrou frequência de 33\% de sangramentos decorrentes de FNM em pacientes do setor de internação hospitalar da respectiva unidade.

Estudo brasileiro ${ }^{54}$ desenvolvido para caracterizar pacientes apresentando FNM por diversos tipos de câncer, em Pernambuco, também identificou a dor como principal sintoma das FNM, com prevalência de $89,1 \%$, seguido de exsudato $(84,3 \%)$, e odor (70,3\%). O sangramento foi quantificado como exsudato sanguinolento. Em outro estudo brasileiro60, desenvolvido para caracterizar o perfil de FNM decorrentes especificamente de câncer de mama, por meio de revisão de prontuários $(\mathrm{N}=62)$, detectou o sangramento em 22 pacientes $(35,4 \%)$, seguindo-se de dor (20/32,2\%), necrose (13/20,9\%), prurido (7/ 11,3\%), infecção (7/ 11,3\%), odor $(5 / 8,1 \%)$ e descamação (1/ 1,6\%).

A dor nas FNM pode ser justificada por lesão química, compressão por edema e destruição de fibras nervosas pelo crescimento do tumor ${ }^{1,6}$.

Estudo prospectivo, conduzido no Japão61 para investigar a relação de dor com FNM mamárias (22 mulheres), sugeriu que a dor também é decorrente do tecido de granulação tumoral que se entremeia ao tecido normal da ferida, incluindo suas bordas $^{1,61}$. Outros fenômenos como processo de inflamação subjacente ao local onde o tumor se estabelece, infecções secundárias e formação de biofilme no leito da ferida intensificam o estado inflamatório das feridas crônicas e, consequentemente, a dor ${ }^{62-64}$.

O exsudato ocorre pelo processo de lise das membranas celulares e apoptose, alteração da homeostase da linfa, processo inflamatório tecidual, hiperpermeabilidade de microvascularização do tumor ao fribrinogênio e coloides do plasma e secreção de fator de permeabilidade celular, sendo resultante do processo adicional de infecção e degeneração tecidual, por meio de liberação bacteriana de proteases que decompõem o tecido necrosado44,65-66. Proliferação celular ativa também estimula a produção de exsudato que, por sua vez, aumenta o processo inflamatório, fazendo com que a FNM fique circunscrita aos eventos de inflamação e 
destruição tissular, assim como qualquer outra lesão do tipo crônica64. Como complicação da drenagem exsudativa, a pele ao redor fica vulnerável à dermatite associada à umidade, o que pode ocasionar dor, aumento da infecção e da área deteriorada ${ }^{1,6,69-66}$.

O odor presente nas FNM decorre do processo gradual de colonização bacteriana que se inicia com a falência gradual da rede de nutrição sanguínea do tecido tumoral, condição em que a rede de vasos neoformados não consegue prover nível de oxigenação tecidual adequado ${ }^{1,55}$. A massa tumoral passa a sofrer hipoxia, colonização bacteriana, desvitalização e, por fim, a necrose tecidual se estabelece, dando origem a um intenso e rápido processo de degeneração tissular onde a FNM ocorreu $^{1,67}$. A microbiota bacteriana é mista, com presença de bactérias aeróbicas (como Pseudomonas Aeruginosa e Staphyloccus Aureus - MARSA), bem como anaeróbicas (como os bacteroides), responsáveis pela liberação de gases como putrescina e cadaverina, gases responsáveis pelo odor fétido nauseante e intolerável, que caracteriza as $\mathrm{FNM}^{1,6,68}$.

Na prática clínica observa-se que a presença de muito exsudato e odor forte podem conduzir à manipulação frequente da FNM, resultando em dor e sangramento local.

\subsubsection{Sangramento nas FNM}

O sangramento tumoral de qualquer órgão é observado em decorrência dos fenômenos de angiogênese e vasculogênese, intrínsecos aos eventos de formação do estroma da massa tumoral maligna ${ }^{1,69-70}$. As células malignas têm capacidade para induzir a formação de novos vasos sanguíneos a partir de células progenitoras presentes no microambiente tumoral, bem como guiar a formação de novos vasos sanguíneos a partir de vasos preexistentes. Quando se utiliza de células progenitoras, o processo denomina-se vasculogênese ou neovasculogênese; e quando se usa vasos preeexistentes, o processo denomina-se angiogênese ${ }^{71}$.

Qualquer um destes processos inicia-se quando as células tumorais entram em hipoxia, com elevação de dióxido de carbono (CO2) ou óxido nítrico (NO). Elas emitem sinal extracelular de produção de fator de crescimento endotelial vascular (VEGF) e fator de crescimento fibroblástico básico (bFGF), dentre outros, para iniciar a formação da vasculatura tumoral que irá sustentar o processo de crescimento maligno ${ }^{71-73}$. 
Destaca-se que o câncer de mama é um dos tipos de tumor maligno que mais apresentam produção de $\mathrm{VEGF}^{74}$, o que pode ser um dos fatores responsáveis pela friabilidade tão característica de suas FNM.

Os dados da Figura 2 ilustram o processo de neovasculogênese nas FNM. 
Figura 2 - Formação de vasos sanguíneos nas FNM, a partir de células progenitoras:neovasculogenese

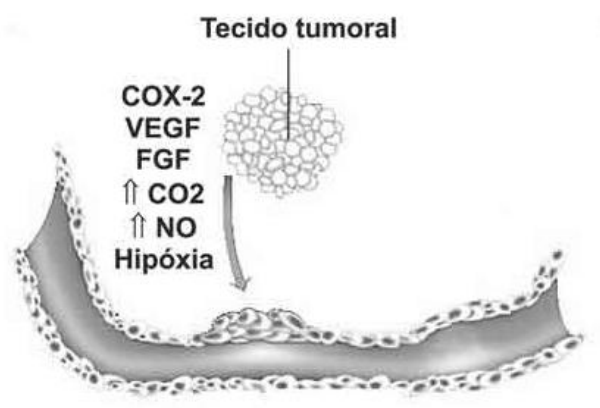

a

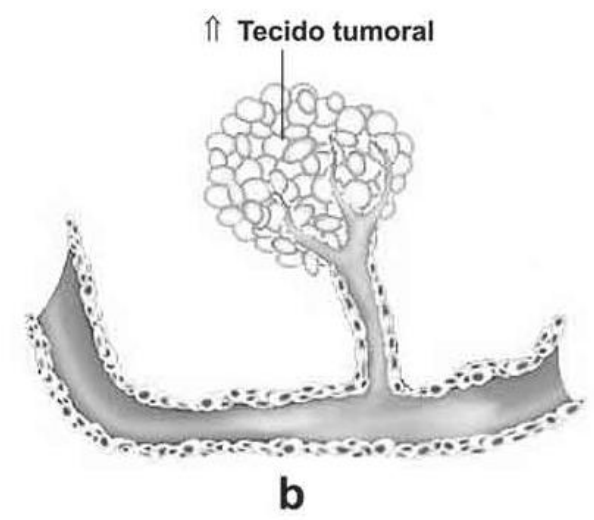

Fonte: Pinho MSL( 2005) ${ }^{72}$.

Assim, o tumor é nutrido por uma rede vascular neoformada e o leito tumoral fica abundandemente vascularizado ${ }^{73}$, o que caracteriza a friabilidade das FNM.

Os dados da Figura 3 ilustram o processo de angiogênese no microambiente tumoral, destacando a migração e formação de vasos sanguíneos para nutrir o tumor, a partir de um vaso sanguíneo preexistente. 
Figura 3 - Processo de angiogênese no microambiente tumoral

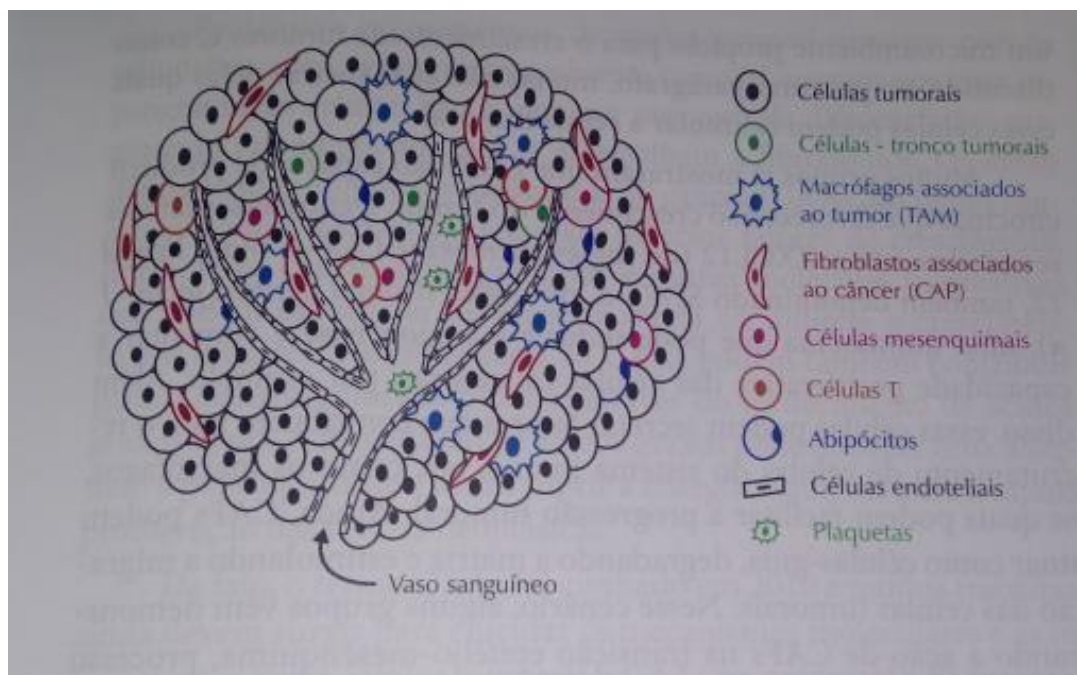

Fonte: Neto M AA, Cardim SGB, Mothê CMA, Andrade LNS( 2015 p. 191) ${ }^{73}$.

Os vasos neoformados, quer por angiogênese ou vasculogênese, são frágeis e ingurgitados e entremeiam-se ao tecido saudável adjacente, que facilmente se rompe ${ }^{69,75}$, ocasionando o sangramento.

Os dados da figura 4 mostram uma FNM mamária com tecido friável, sangramento e inicio de necrose ao centro do tumor exposto sobre a pele.

Figura 4 - Fotografia de uma FNM decorrente de câncer de mama

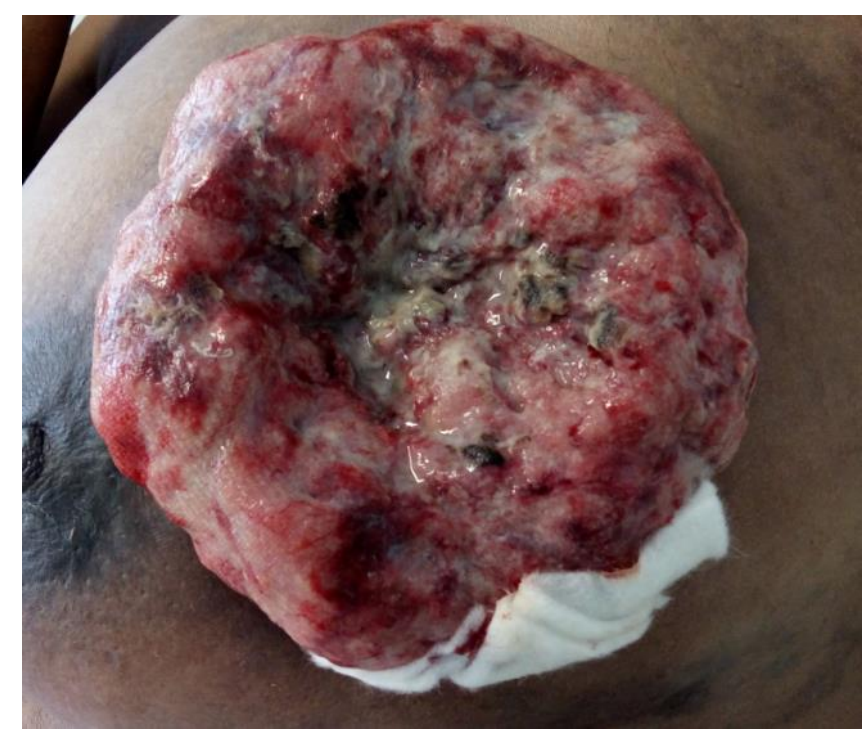

Fonte: Arquivo pessoal da autora. Pesquisa pregressa. Autorização Comitê de Ética em Pesquisa (CEP) INCA número: 132/2009 (Vide anexo A). 
Uma vez que o tumor tende a se expandir, ele pode causar o rompimento de vasos intrínsecos à massa tumoral e/ou vasos adjacentes, sejam eles capilares, arteríolas, vênulas, veias ou artérias. Acredita-se que nestes vasos as plaquetas circulantes tornam-se funcionalmente deficientes, com potencial hemostático diminuído, em razão do processo neoplásico maligno que segue em desenvolvimento nos vasos sanguíneos tumorais ${ }^{1,63}$.

$\mathrm{Na}$ avalição global, o sangramento tumoral geralmente é mensurado por graduação quantitativa nos níveis leve a intenso, tal graduação é feita de forma subjetiva. Adicionalmente o sangramento também pode ser classificado de acordo com sua causa, sendo do tipo espontâneo, quando ocorre sem aparente causa, ou do tipo induzido, quando a FNM é intencionalmente mobilizada ${ }^{43}$. Ainda, ele pode ser caracterizado pela forma como escoa dos vasos sanguíneos: em forma de vasamento, em fluxo contínuo em em jato ${ }^{76}$. A prática clínica evidencia ainda uma possível classificação; que se faz considerando o local em que o sangramento ocorre na ferida: delimitado: quando o sangramento está bem definido em apenas uma parte da extensão da FNM; difuso: quando se encontra espalhado, ainda que centrado em apenas uma parte da ferida; ou de fundo: quando se inicia em forma de brotamento, da parte mais funda do leito da ferida.

Muitas vezes, mesmo os sangramentos leves são persistentes, como o sangramento demonstrado nas fotografias $2 \mathrm{~A}$ e $2 \mathrm{~B}$. 
Figura 5 - Fotografias ilustrativas de sangramento leve $(A)$ e de tecido friável $(B)$ de uma Ferida Neoplásica Maligna mamária
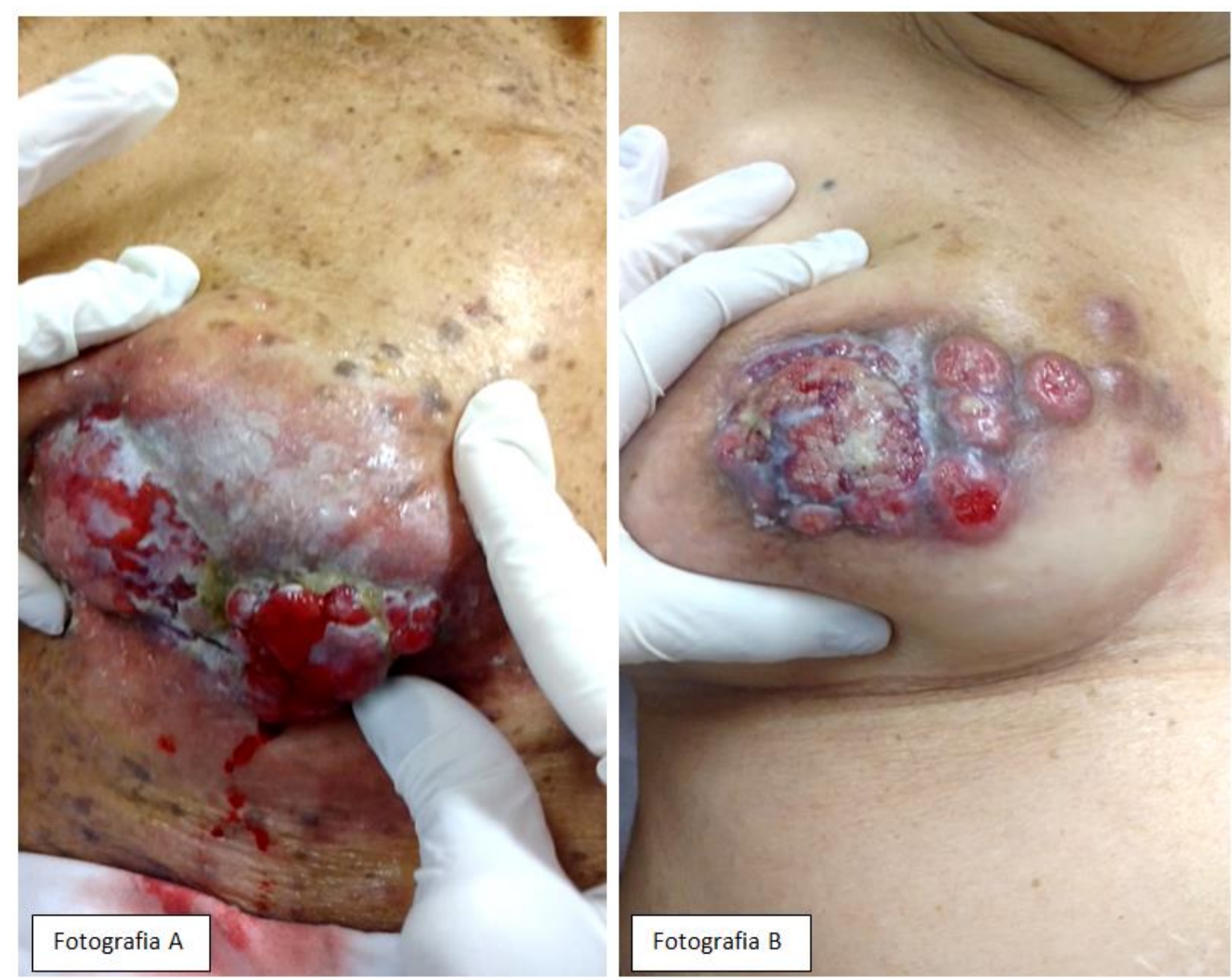

Fonte: Arquivo pessoal da autora. Pesquisa pregressa. Autorização CEP/INCA número: 132/2009.

A fotografia A ilustra um sangramento que teve inicio ao ser realizado o exame de palpação, para avaliar a mobilidade do tumor com vistas à cirurgia de mastectomia higiênica. A fotografia B ilustra uma FNM com um ponto de tecido friável, com risco de sangramento à manipulação para realização do curativo. 


\subsection{HEMOSTASIA TÓPICA NAS FNM MAMÁRIAS: REVISÃO DE LITERATURA}

Poucos estudos vêm explorando a hemostasia clínica em FNM, de modo que faltam informações para o desenvolvimento de diretrizes baseadas em fortes evidências ${ }^{10}$.

Especificamente em FNM mamárias, revisão sistemática de literatura, conduzida no desenvolvimento deste estudo e submetida à avaliação para publicação, identificou apenas seis estudos (6\%), dentre 83 recuperados em sete base de dados indexadas (vide Apêndice A) no período de 25 a 27 de fevereiro de 2019.

Os dados foram extraídos por meio do uso de formulário específico elaborado pelos pesquisadores após reunião de consenso. Foram consideradas as seguintes variáveis: autoria, país e ano de publicação, desenho, tamanho da amostra, intervenções hemostáticas, cointervenções, critérios utilizados, desfecho, recomendação dos autores, tipo e grau de recomendação da evidência científica, conforme a hierarquia de Oxford associada ao grau de recomendação ${ }^{77-78}$.

Quadro 1 - Hierarquia de níveis de evidência científica e grau de recomendação

\begin{tabular}{|c|l|c|}
\hline $\begin{array}{c}\text { Nível de } \\
\text { evidência }\end{array}$ & \multicolumn{1}{|c|}{ Critério de graduação } & $\begin{array}{c}\text { Grau de } \\
\text { recomendação }\end{array}$ \\
\hline 1 & Revisão sistemática de ensaios clínicos randomizados & Alta \\
\hline 2 & $\begin{array}{l}\text { Ensaio clínico randomizado ou estudo observacional com efeito } \\
\text { dramático }\end{array}$ & Alta \\
\hline 3 & Estudo de coorte com acompanhamento & Moderada/baixa \\
\hline 4 & Estudos de séries de caso, caso controle, estudos controlados & Muito baixa \\
\hline 5 & Opinião de especialistas/ baseado na razão & Muito baixa \\
\hline
\end{tabular}

Fonte: Tradução livre e adaptada de "Oxford Centre for Evidence-Based Medicine 2011 Levels of Evidence". CEBM. Center for Evidence-Based Medicine. University Oxford [Internet]. UK;2016[2018;2018 nov 17]. Disponível em: https://www.cebm.net/wp-content/uploads/2014/06/CEBM-Levels-of-Evidence-2.1.pdf. ${ }^{77}$

Ao todo, 52 pacientes participantes dos estudos primários alcançados por esta revisão foram submetidos a 10 diferentes intervenções tópicas hemostáticas em três distintas modalidades de estudos, desenvolvidos no período entre 2000 e 2014 .

As intervenções tópicas estão descritas nos dados apresentados no Quadro 2. 
Quadro 2 - Tipos de intervenção tópica e classificação das evidências científicas dos estudos que investigaram o controle de sangramento em FNM decorrente de câncer de mama. São Paulo, 2018

\begin{tabular}{|c|c|c|c|c|c|c|}
\hline ID & Desenho/Amostra & Objetivos & Intervenção & Desfecho & Limitações & Recomendações \\
\hline 1 & $\begin{array}{l}\text { Coorte prospective } \\
\text { descritiva; } 32 \\
\text { pacientes } \\
\text { acompanhados por } \\
42 \text { dias com } \\
\text { avaliação nos dias } \\
0,24 \text { e } 42^{43} \text {. }\end{array}$ & $\begin{array}{l}\text { Avaliar o efeito do } \\
\text { uso de vários } \\
\text { produtos tópicos e } \\
\text { características das } \\
\text { feridas. }\end{array}$ & $\begin{array}{l}\text { Aplicação de } \\
\text { alginato de cálcio, } \\
\text { hemostáticos (não } \\
\text { especificados), } \\
\text { adrenalina, para } \\
\text { sangramentos } \\
\text { espontâneos e } \\
\text { curativos não } \\
\text { aderentes, como os } \\
\text { de interface } \\
\text { composto de 100\% } \\
\text { de poliester ou } \\
\text { curativos } \\
\text { impregnados com } \\
\text { silicone. }\end{array}$ & $\begin{array}{l}\text { Em D0 18\%, (6) pacientes) tinham } \\
\text { sangramento espontâneo e } 28 \% \text { (9) tinham } \\
\text { sangramento induzido. No sangramento } \\
\text { espontâneo, } 64 \% \text { estavam controlados e } \\
18 \% \text { parcialmente ou não controlados. Em } \\
\text { D21, aumentou a frequência de } \\
\text { sangramento espontâneo para } 28 \% \text {, mas o } \\
\text { número de controle subiu para } 84 \% \text {. O } \\
\text { sangramento induzido aumentou para } 7 \% \\
\text { (25) pacientes, predominando a intensidade } \\
\text { leve. Em D42, 95\% (30) pacientes não } \\
\text { tinham nenhum sangramento espontâneo e } \\
\text { os que tinham estavam sob controle. Houve } \\
\text { aumento do sangramento induzido para } \\
80 \% \text { (26) pacientes com intensidade leve a } \\
\text { moderada, destes } 92 \% \text { controlados e } 8 \% \\
\text { com controle parcial. }\end{array}$ & $\begin{array}{l}\text { Não informou o } \\
\text { efeito de } \\
\text { intervenção } \\
\text { especificada pelos } \\
\text { produtos tópicos } \\
\text { empregados. }\end{array}$ & $\begin{array}{l}\text { Empregar o uso } \\
\text { de curativos } \\
\text { designados para } \\
\text { absorção do } \\
\text { exsudato, porque } \\
\text { a capacidade } \\
\text { deles de } \\
\text { hemostasia, não } \\
\text { aderência à } \\
\text { ferida, absorção e } \\
\text { habilidade em } \\
\text { proporcionar meio } \\
\text { úmidosão úteis } \\
\text { para as FNM }\end{array}$ \\
\hline \multicolumn{7}{|c|}{ Nível de evidência 3/Força de recomendação: Baixa } \\
\hline 2 & Relato de caso ${ }^{79}$ & $\begin{array}{l}\text { Compartilhar } \\
\text { experiência clínica. }\end{array}$ & $\begin{array}{l}\text { Aplicação } \\
\text { sequencial de } \\
\text { nitrato de prata, gel } \\
\text { foam, celulose } \\
\text { oxidada } \\
\text { regenerada, } \\
\text { trombina ativada } \\
\text { com gluconato de } \\
\text { cálcio. }\end{array}$ & $\begin{array}{l}\text { Controle efetivo obtido com trombina } \\
\text { ativada com gluconato de cálcio. }\end{array}$ & $\begin{array}{l}\text { Não descreveu a } \\
\text { forma de } \\
\text { avaliação do } \\
\text { sangramento e do } \\
\text { hemostático } \\
\text { empregado. }\end{array}$ & $\begin{array}{l}\text { Checar plaquetas } \\
\text { e disturbios de } \\
\text { coagulação. } \\
\text { Considerar } \\
\text { hemostaticos } \\
\text { tópicos à base de } \\
\text { trombina ativada. }\end{array}$ \\
\hline
\end{tabular}


Quadro 2 - Tipos de intervenção tópica e classificação das evidências científicas dos estudos que investigaram o controle de sangramento em FNM decorrente de câncer de mama. São Paulo, 2018

continuação

\begin{tabular}{|c|c|c|c|c|c|c|}
\hline ID & Desenho/Amostra & Objetivos & Intervenção & Desfecho & Limitações & Recomendações \\
\hline 3 & Relato de caso ${ }^{80}$ & $\begin{array}{l}\text { Avaliar o efeito do } \\
\text { curativo hidrocelular } \\
\text { trilaminado, com } \\
\text { adesivo gel suave. } \\
\text { Seguimento por } 6 \\
\text { meses e visitas } \\
\text { domiciliares } 2 \text { a } 3 \\
\text { vezes por semana. }\end{array}$ & $\begin{array}{l}\text { Aplicação de } \\
\text { curativo } \\
\text { hidrocelular } \\
\text { trilaminado com } \\
\text { prata. }\end{array}$ & $\begin{array}{l}\text { Nas primeiras visitas observou-se: maior } \\
\text { conforto, correção da estética, controle do } \\
\text { exsudato, odor, dor e do sangramento pela } \\
\text { retirada atraumática. Melhora visível da } \\
\text { aparência da lesão em } 10 \text { dias. Ao longo do } \\
\text { tratamento, passou a espassar os tempos } \\
\text { de trocas do curativo para } 48 \text { h e } 72 \mathrm{~h} \text { (nos } \\
\text { últimos } 6 \text { meses de vida). }\end{array}$ & $\begin{array}{l}\text { Não descreveu a } \\
\text { forma de } \\
\text { avaliação da } \\
\text { hemostasia }\end{array}$ & $\begin{array}{l}\text { Utilizar curativos } \\
\text { hidrocelulares } \\
\text { com adesivo de } \\
\text { gel suave ou } \\
\text { silicone. }\end{array}$ \\
\hline \multicolumn{7}{|c|}{ Nível de evidência 4/Força de recomendação: Muito baixa } \\
\hline 4 & $\begin{array}{l}\text { Relato de dois } \\
\text { casos }^{81}\end{array}$ & $\begin{array}{l}\text { Relatar efeitos do uso } \\
\text { da Pasta de Mohs } \\
\text { modificada em } \\
\text { combinação com a } \\
\text { terapia sistêmica e a } \\
\text { mastectomia } \\
\text { subsequente para } \\
\text { controle de } \\
\text { sangramento e } \\
\text { exsudato. }\end{array}$ & $\begin{array}{l}\text { Aplicação de pasta } \\
\text { de Mohs } \\
\text { modificada com } \\
\text { uso preliminar de } \\
\text { vaselina na pele ao } \\
\text { redor para proteção } \\
\text { contra o contato da } \\
\text { pasta com a pele } \\
\text { saudável. }\end{array}$ & $\begin{array}{l}\text { Após três ciclos (de } 2 \text { a } 3 \text { dias cada ciclo) } \\
\text { de aplicação, o tumor tornou-se "achatado". } \\
\text { Passou a ser utilizado curativo não adesivo, } \\
\text { de gel e espuma poliuretano com troca uma } \\
\text { vez por semana. Após } 28 \text { dias a contar do } \\
\text { primeiro dia do uso da pasta, a paciente foi } \\
\text { operada. }\end{array}$ & $\begin{array}{l}\text { Não descreveu a } \\
\text { forma de } \\
\text { avaliação da } \\
\text { hemostasia. }\end{array}$ & $\begin{array}{l}\text { Para câncer de } \\
\text { mama localmente } \\
\text { avançado, utilizar } \\
\text { a pasta de Mohs } \\
\text { associada ao } \\
\text { tratamento } \\
\text { multidisciplinar. }\end{array}$ \\
\hline \multicolumn{7}{|c|}{ Nível de evidência 4/Força de recomendação: Muito baixa } \\
\hline
\end{tabular}


Quadro 2 - Tipos de intervenção tópica e classificação das evidências científicas dos estudos que investigaram o controle de sangramento em FNM decorrente de câncer de mama. São Paulo, 2018

continuação

\begin{tabular}{|c|c|c|c|c|c|c|}
\hline ID & Desenho/Amostra & Objetivos & Intervenção & Desfecho & Limitações & Recomendações \\
\hline 5 & $\begin{array}{l}\text { Série de cinco } \\
\text { casos }^{82}\end{array}$ & $\begin{array}{l}\text { Descrever o uso da } \\
\text { pasta de Mohs } \\
\text { modificada para } \\
\text { controlar } \\
\text { sangramento. }\end{array}$ & $\begin{array}{l}\text { Aplicação da pasta } \\
\text { de Mohs } \\
\text { modificada com } \\
\text { aplicação } \\
\text { preliminar de } \\
\text { lidocaína geleia e } \\
\text { gazes na pele ao } \\
\text { redor por } 5 \text { a } 10 \\
\text { minutos. }\end{array}$ & $\begin{array}{l}\text { Sangramento ativo de artéria foi controlado } \\
\text { em até } 10 \text { minutos após a aplicação. } \\
\text { Controle do sangramento global foi mantido } \\
\text { por 3semanas a } 3 \text { meses. Odor e exsudato } \\
\text { também foram controlados. Relato de } \\
\text { melhora na qualidade de vida. }\end{array}$ & $\begin{array}{l}\text { Não descreveu a } \\
\text { forma de } \\
\text { avaliação da } \\
\text { hemostasia. }\end{array}$ & $\begin{array}{l}\text { Intervenção pode } \\
\text { ser adotada por } \\
\text { médicoscirurgioes } \\
\text {, oncologistas e } \\
\text { enfermeiras de } \\
\text { cuidados } \\
\text { paliativos. }\end{array}$ \\
\hline \multicolumn{7}{|c|}{ Nível de evidência 4/Força de recomendação: Muito baixa } \\
\hline 6 & Série de 15 casos $^{83}$ & $\begin{array}{l}\text { Investigar o efeito da } \\
\text { formalina tópica } 10 .\end{array}$ & $\begin{array}{l}\text { Aplicação de gazes } \\
\text { embebidas com o } \\
\text { produto até } 10 \mathrm{ml} .\end{array}$ & $\begin{array}{l}\text { Sensação suportável de ardência na ferida, } \\
\text { controle satisfatório do sangramento em até } \\
\text { seis a oito reaplicações. }\end{array}$ & $\begin{array}{l}\text { Não descreveu a } \\
\text { forma de } \\
\text { avaliação da } \\
\text { hemostasia. }\end{array}$ & $\begin{array}{l}\text { O uso da } \\
\text { formalina a } 10 \% \text { é } \\
\text { útil em tumores } \\
\text { ulcerados. }\end{array}$ \\
\hline
\end{tabular}


Observa-se que os estudos identificados empregaram intervenções hemostáticas tópicas do tipo coberturas hemostáticas, coberturas não aderentes e uso off label de droga vasoativa e substâncias cauterizantes. Todos são estudos de evidência científica de fraca força e de baixa a muito baixa recomendação. Dentre eles, estudo descritivo, de coorte, ID 1, produziu a evidência de maior robustez (nível de evidência 3/recomendação modero-baixa) para o uso de alginato de cálcio, hemostático (não identificado), adrenalina e curativo não aderente ${ }^{43}$. Destaca-se que o estudo ID 2 empregou dentre suas intervenções, a aplicação da COR, porém sem resultado eficaz, e a hemostasia de fato foi obtida pela aplicação de trombina ativada; um hemostático de terceira geração ${ }^{79}$.

Da revisão sistemática, conclui-se que as evidências científicas para o manejo tópico do sangramento nas FNM mamárias são fracas, oriundas de estudos observacionais, série e relatos de casos, com recomendação baixa ou muito baixa.

Diante destes achados, recomenda-se o desenvolvimento de ensaios clínicos randomizados (ECR), testando as intervenções identificadas a fim de gerar recomendações com evidências mais robustas.

No ECR desenvolvido nesta tese, foi escolhido testar a eficácia da celulose oxidada regenerada (COR). Atualmente, a COR vem sendo indicada para FNM sangrantes em consenso de especialistas e estudos de revisão de literatura e de atualização ${ }^{1,10,84-85}$, porém não há estudos de ECR testando sua eficácia nas FNM.

Naturalmente, o grupo controle foi exposto ao alginato de cálcio; produto, atualmente, estabelecido como cobertura hemostática-padrão em FNM, mas sua indicação primária é para o o controle do exsudato e promoção de cicatrização em feridas crônicas e agudas ${ }^{86-87}$.

Destaca-se que não há no mercado de produtos de feridas insumos desenvolvidos, especificamente, para FNM; situação que vem motivando pesquisadores a desenvolverem estudos que venham gerar informações para desenvolvimento de produtos que melhor atendam às demandas específicas das $\mathrm{FNM}^{43,88}$. 


\subsection{CELULOSE OXIDADA REGENERADA}

Dentre os hemostáticos tópicos cirúrgicos absorvíveis, a celulose oxidada regenerada (COR) é o mais simples e mais comum ${ }^{89-90}$.

A celulose oxidada regenerada (COR) é um hemostático tópico em forma de gaze biodegradável, biocompátivel e reabsorvível, de coloração amarela pálida que, quando em contato com o sangue, se torna uma gaze escura ${ }^{91}$. É composta de 50\% de celulose derivada da polpa de madeira oxidada e regenerada quimicamente por mecanismos de decomposição e recomposição ${ }^{92}$.

Quando em contato com o sangue, absorve a água e agrega hemoglobina, plaquetas e outras células, formando um pseudocoágulo. Acredita-se que tenha interação com o fator XII da cascata de coagulação ${ }^{93-97}$. Por isso, é classificada como hemostático passivo, mecânico ou físico, ou seja, que atua criando uma base barreira ou uma matriz para adesão e agregação plaquetária91,96; e a barreira física por ela proporcionada serve como um depósito para o trombo. Esse efeito mecânico constitui ação inicial do produto ${ }^{98}$.

Ação subsequente consiste na diminuição local do pH (de 3,5 a cerca de 4). Este baixo $\mathrm{pH}$ decorre da ação do grupo de ácido carboxílico que age em contato com o sangue, entumesce e forma um gel que atua, como uma solução cáustica desnaturando proteínas orgânicas, como as hemácias, a globulina, a albumina e as plaquetas, dando origem a um coágulo acastanhado em decorrência da interação da celulose oxidada com hematina: molécula carreadora de ferro contida na hemoglobina ${ }^{99-100 .}$.

Em meio ácido, a hematina, provavelmente, exerça o efeito hemostático do produto $^{100}$. $\mathrm{O}$ baixo $\mathrm{pH}$ ainda confere à celulose propriedades bactericidas contra algumas bactérias importantes, como Staphylococcus aureus (MRSA); Staphylococcus epidermidis (MRSE), Streptococcus pneumoniae (PRSP) dentre outras $^{92,101-102}$.

Tem rápida ação hemostática (com tempo médio de até 8 minutos) e pode absorver até sete vezes o seu peso. Sua degeneração inicia-se após 18 horas do implante ${ }^{100-102}$. No processo de degeneração, o ácido pilurônico é despolimerizado por enzimas glicosidases, e o componente fibroso do produto é fagocitado e hidrolisado pelos macrófagos locais ${ }^{101}$. 
Em relato de caso publicado em 2002, os autores descreveram o uso da COR para controlar sangramento superficial persistente, proveniente da superfície de uma FNM cavitária decorrente de câncer de pulmão. Consideraram que o hemostático teve impacto na prática da enfermagem, pela redução na carga de trabalho na troca de curativos e drenos e recomendaram sua incorporação na prática clínica ${ }^{103}$. No entanto, não há evidências fortes sobre a eficácia desta prática na hemostasia das $\mathrm{FNM}^{10}$.

\subsection{ALGINATO DE CÁLCIO}

Trata-se de uma cobertura em forma de malha não tecido, biodegradável, derivada de algas marinhas ${ }^{104-105}$. Quando em contato com o exsudato da ferida, ocorre troca iônica entre o sódio nele presente e o cálcio contido na cobertura, havendo liberação de cálcio no leito do tecido. Nessa troca iônica, o sódio absorvido no alginato muda sua estrutura de consistência fibrosa para gel, deixando a ferida com menos exsudato e, ao mesmo tempo, mantendo o meio úmido e promovendo ambiente melhorado para o processo de cicatrização e regeneração epidérmica ${ }^{94,106}$. $\mathrm{O}$ alginato absorve cerca de 15 a 20 vezes seu peso em exsudato ${ }^{107-108}$. A adição de carboximetilcelulose na composição da cobertura visou a aumentar o poder de absorção do exsudato nas feridas (absorção vertical) ${ }^{109}$.

Acredita-se que o efeito hemostático do alginato de cálcio deve-se ao fato de que o cálcio liberado no leito sangrante das feridas interage com a cascata de coagulação, de forma ainda não esclarecida, considerando-se que esse íon é um fator mediador do processo de coagulação sanguínea para a ativação de plaquetas e a formação de coágulos, conhecido como fator $\mathrm{VI}^{106,110}$. Estudos in vitro e em animais sugerem que duas moléculas de alginato combinan-se com o íon de cálcio e formam o $\mathrm{Ca}^{2+}$, cujo efeito seria o de desencadear a coagulação sanguínea por meio da ativação de trombócitos, fatores VII, IX e X da cascata de coagulação. Ao mesmo tempo em que o íon $\mathrm{Ca}^{2+}$ ativa a cascata, o íon sódio seria o responsável por manter uma matriz firme que dá sustentação aos coágulos formados ${ }^{106,110-111 .}$

Em estudos experimentais primários conduzidos em animais, reconheceu-se que as propriedades de formação e sustentação de coágulos sanguíneos quando 
em contato com sangue e fluídos de plasma tornavam o alginato de cálcio atrativo ao uso cirúrgico ${ }^{111}$.

Este histórico fundamenta a lógica do raciocínio clínico utilizado para o uso do alginato de cálcio nas FNM, como diretriz terapêutica integrante de protocolos institucionais de maneira global ${ }^{1,10,55,57,112-113}$. No entanto, não há fortes evidências científicas sobre sua eficácia no manejo do sangramento nesse tipo de ferida ${ }^{10}$.

\subsection{JUSTIFICATIVA}

Estudos de sobrevida vêm demonstrando que, ao longo do tempo, o câncer de mama vem se tornando uma doença de progressão mais lenta como resultado dos avanços diagnósticos e terapêuticos na eficiência global dos sistemas de saúde para seu controle $28-29$. Isto significa que as mulheres podem estar convivendo mais tempo com suas FNM e, portanto, necessitando de cuidados clínicos mais assertivos fundamentados em pesquisas científicas de eficácia para a proposição de práticas seguras, validadas por estudos de forte evidência ${ }^{13,114}$.

Destaca-se, assim, a importância de se desenvolver pesquisas, tendo como metodologia de desenvolvimento o Ensaio Clínico Randomizado - ECR, especialmente, em países menos desenvolvidos, onde supostamente as FNM ocorrem com mais frequência, dentro da lógica de que a prevalência e incidência de câncer de mama avançado são superiores em países com poucos recursos e falta de estruturação na assistência à saúde, como no Brasil27,29,115.

Nesse contexto, o desenvolvimento de ECR sobre a eficácia de intervenções para um fenômeno tão pouco investigado, faz-se necessário e útil para a expansão do conhecimento clínico baseado em evidências.

Os resultados poderão contribuir com a construção de novas formas de cuidado e geração de subsídios de sustentação científica para práticas empiricamente padronizadas. A discussão dos achados à luz da literatura poderá revelar padrões e características do sangramento, incorrendo na proposição de novos estudos de importância clínica. 
2 OBJETIVOS 


\section{OBJETIVOS}

\subsection{OBJETIVO GERAL}

Avaliar a eficácia da COR no controle do sangramento de FNM decorrente de câncer de mama versus o alginato de cálcio (AC).

\subsection{OBJETIVOS ESPECÍFICOS}

1. Avaliar e comparar a proporção de pacientes que alcançaram a hemostasia no limite de tempo de 20 minutos em ambos os grupos;

2. Comparar o tempo necessário para a obtenção de hemostasia em ambos os grupos. 
3 HIPÓTESE 


\section{HIPÓTESE}

- $\mathbf{H}_{0}$ : Não há diferença média significante no tempo de hemostasia quando se utiliza hemostático tópico à base de celulose oxidada regenerada, comparativamente, ao uso de curativo padrão para controle do sangramento de FNM, decorrente de câncer de mama.

- $\mathbf{H}_{1}$ : Há diferença média significante de 5 minutos no tempo de hemostasia, quando se utiliza hemostático tópico à base de celulose oxidada regenerada, comparativamente, ao uso de curativo de alginato de cálcio para controle do sangramento de FNM decorrente de câncer de mama. 
4 MÉTODOS 


\section{MÉTODOS}

\subsection{ASPECTOS ÉTICOS}

O presente projeto de pesquisa foi desenvolvido de acordo com a Resolução 466/2012 do Conselho Nacional de Saúde - Comissão Nacional de Ética em Pesquisa (CONEP) ${ }^{117}$ e encaminhado ao Comitê de Ética em Pesquisa da Escola de Enfermagem (CEP-EEUSP), por meio da Plataforma Brasil, junto ao qual obteve aprovação (Parecer Número 2.157.193 - Anexo B). O projeto foi encaminhado também ao Comitê de Ética em Pesquisa do Instituto Nacional de Câncer José Alencar Gomes da Silva - INCA, obtendo aprovação conforme o Parecer Número 2.288.858 (Anexo C). Após a aprovação do projeto de pesquisa em ambos os comitês, iniciou-se a coleta de dados; e todas as mulheres foram informadas sobre os objetivos e procedimentos da pesquisa e a confidencialidade dos dados e, estando de acordo, assinaram o Termo de Consentimento Livre e Esclarecido (TCLE) em duas vias, ficando uma via com a paciente e a outra com a pesquisadora principal (Apêndice B).

A inclusão das pacientes no estudo e a coleta de dados somente foram realizadas mediante a assinatura do TCLE, obedecendo aos preceitos éticos e legais exigidos pela Resolução do CONEP, citada anteriormente.

\subsection{LOCAL DO ESTUDO}

Os dados foram coletados em dois dos cinco hospitais que compõem o Instituto Nacional de Câncer José Alencar Gomes da Silva - INCA, a saber: Hospital de Câncer especializado no tratamento e controle do câncer de mama - HC III e Hospital de Câncer especializado em Cuidados Paliativos - HC IV.

O HC III possui 50 leitos de internação hospitalar e oferece tratamento oncológico de todas as modalidades: cirúrgico, quimioterápico, radioterápico, hormonioterápico. Possui serviços de atendimento ambulatorial, de pronto-socorro e de internação. Quando os pacientes se encontram em estágio de doença avançada, 
sem perspectivas de controle pela terapia de combate à doença, são transferidos para o Hospital HC IV onde terão acompanhamentos até o óbito. O HC IV oferece atendimento nas modalidades ambulatorial, pronto-socorro, internação hospitalar, com 56 leitos e, adicionalmente, serviço de assistência domiciliar (AD).

Destaca-se que o HC III é o único hospital que oferece tratamento e controle exclusivo de câncer de mama no Brasil.

Em ambos os hospitais, os profissionais de saúde utilizam-se de protocolo de condutas terapêuticas emergenciais e controle de hemorragia tumoral do INCA, o qual é aplicado às $\mathrm{FNM}^{118}$. O referido protocolo foi sintetizado e divulgado pelo $\mathrm{HC}$ IV, entre 2001 e 2002, e mantém-se vigente nas rotinas assistenciais das duas unidades hospitalares do INCA ${ }^{119}$.

O protocolo preconiza uso de medicação antifibrinolítica via sistêmica, preferencialmente a via endovenosa com seguimento pela via oral, se necessário. A medicação padronizada é o ácido aminocaproico (Ipsylon) por via endovenosa ou oral. Topicamente, são empregadas as seguintes medidas na dependência do julgamento clínico do profissional de saúde: compressão local quando possível, alginato de cálcio, hemostáticos tópicos cirúrgicos à base de celulose oxidada regenerada ou de colágeno suíno ou, ainda, uso de adrenalina e cobertura secundária absorvente, finalizando o curativo da FNM após qualquer uma das opções citadas ${ }^{118-119}$.

\subsection{DESENHO}

Trata-se de um ensaio controlado randomizado (ECR) de eficácia, estratificado, com alocação exploratória 1:1, aberto, paralelo, unicêntrico ${ }^{120-122}$.

A randomização estratificada foi adotada para melhor assegurar a homogeneidade da alocação, considerando os diferentes níveis de intensidade de sangramento: leve, moderado e intenso ${ }^{120}$.

Uma vez que a revisão bibliográfica não localizou ECR de hemostasia clínica em FNM, o desenho elaborado teve por embasamento estudos controlados randomizados desenvolvidos para testar a eficácia de hemostáticos tópicos cirúrgicos em cirurgia de humanos ${ }^{123-128}$. 


\subsubsection{Produtos a serem testados nas intervenções do estudo}

\section{1) Alginato de cálcio}

O grupo controle recebeu tratamento pelo uso de alginato de cálcio com carboximetilcelulose (Biatain ${ }^{\circledR}$ Alginate) em forma de fita, conforme demonstrado nos dados da Figura 6.

Figura 6 - Ilustração do curativo de alginato de cálcio utilizado no estudo

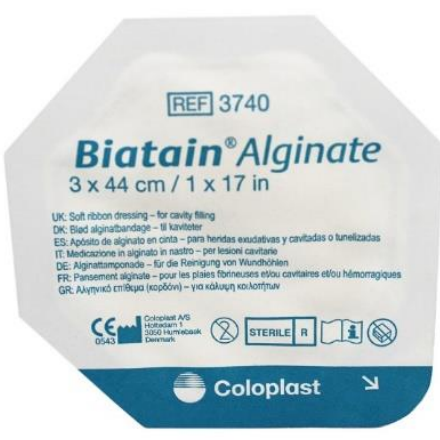

Fonte: Coloplast do Brasil - São Paulo/SP. 2018 229.

O alginato de cálcio Biatain $^{\circledR}$ Alginate é produzido pela empresa dinamarquesa Coloplast ${ }^{129}$. O produto está registrado na Agência Nacional de Vigilância Sanitária (ANVISA), como material de saúde correlato, sob o número de registro 104303310091 , com o nome técnico de Curativo e Classificação de Risco III (alto risco) $)^{130}$.

\section{2) Celulose oxidada regenerada}

O grupo intervenção recebeu o tratamento pelo uso de hemostático tópico cirúrgico à base de celulose oxidada regenerada (Surgicel ${ }^{\circledR}$ ) na forma de gaze, conforme demonstrado nos dados da Figura 7. 
Figura 7 - llustração do hemostático tópico cirúrgico utilizado no estudo

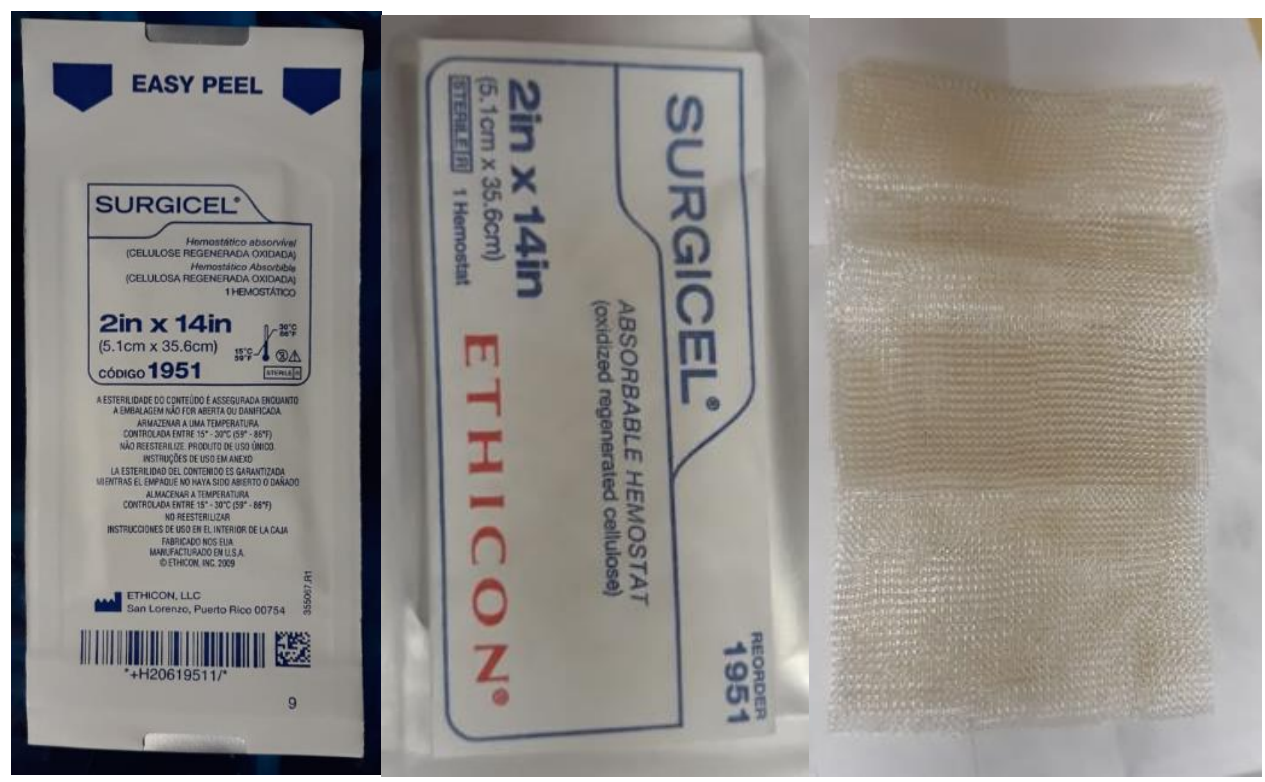

Fonte: Johnson \& Johnson do Brasil ${ }^{131}$

O hemostático cirúrgico tópico absorvível, à base de celulose oxidada regenerada Surgice ${ }^{\circledR}$ é produto integrante da linha ETHICON, produzido em Porto Rico e importado pela empresa Johnson \& Johnson do Brasil ${ }^{131}$. Está registrado na ANVISA como material de saúde correlato, sob o número de registro 10132590056, com o nome técnico de Hemostático Cirúrgico e em Classificação de Risco IV (risco máximo) ${ }^{132}$.

\subsubsection{Segurança para uso}

Estudos primários sobre $\mathrm{o}$ alginato de cálcio e de celulose oxidada regenerada demonstraram que estes são seguros para o uso em humanos, sem relatos de toxicidade ou danos teciduais inaceitáveis nos estudos conduzidos $95,97,111,133$. Outros estudos dizem respeito à presença de inflamação, como reação de corpo estranho no tecido e mimetização de tumores pela demora na degradação e absorção para ambos os produtos ${ }^{95,133}$.

Relato de caso sobre o uso de alginato de cálcio (Kaltostat®) em hemostasia pós-operatória de retirada de tumor maligno de glândula salivar submandibular informa degradação biológica incompleta 12 semanas após sua implantação, fazendo com que o produto mimetizasse recidiva do tumor, o que depois se 
confirmou, como reação inflamatória local ${ }^{134}$. Espera-se degradação em até 7 dias para o alginato de cálcio e sugere-se que seja mantido na ferida por até 4 dias ${ }^{134-135}$.

Há também relatos da presença de celulose oxidada regenerada, mimetizando tumores ${ }^{92,136-137}$ e ocasionando granulomas, quando do uso em mucosa gástrica na hemostasia de retirada de tumores em animais ${ }^{91}$. Mais recentemente, publicou-se relato de caso em que uma paciente submetida à cirurgia cardíaca passou a apresentar alterações nos marcadores sanguíneos para inflamação. Após o 13ำ dia de pós-operatório, uma tomografia revelou massa hipodensa circundando a aorta, levando à cirurgia imediata, na qual se detectou hematoma retendo a $\operatorname{COR}^{138}$.

Embora o fabricante recomende sua retirada após a hemostasia, geralmente, ela é deixada no tecido em razão de sua bioabsorção ${ }^{92,133}$. Cerca de $40 \%$ das reações de corpo estranho relacionadas ao uso da COR são diagnosticadas no primeiro ano subsequencial à cirurgia, e cerca de $50 \%$ são descobertas após 5 ou mais anos de cirurgia ${ }^{133}$. Sugere-se utilizar o hemostático com o menor tamanho possível, para a obtenção de hemostasia eficaz e mínimo implante de material, uma vez que sua biodegrabilidade mostrou não ser rápida ${ }^{136-137}$.

Em seu uso corrente na hemostasia das FNM, a COR é retirada pela aplicação de solução fisiológica ou mesmo liberada do leito da ferida por meio de exsudato aí presente. Neste cenário, a degradação biológica é pouco considerada.

\subsection{FLUXOGRAMA DO ESTUDO}

O desenho do estudo e o fluxo dos pacientes são ilustrados nos dados da Figura 8. 
Figura 8 - Fluxograma do ECR

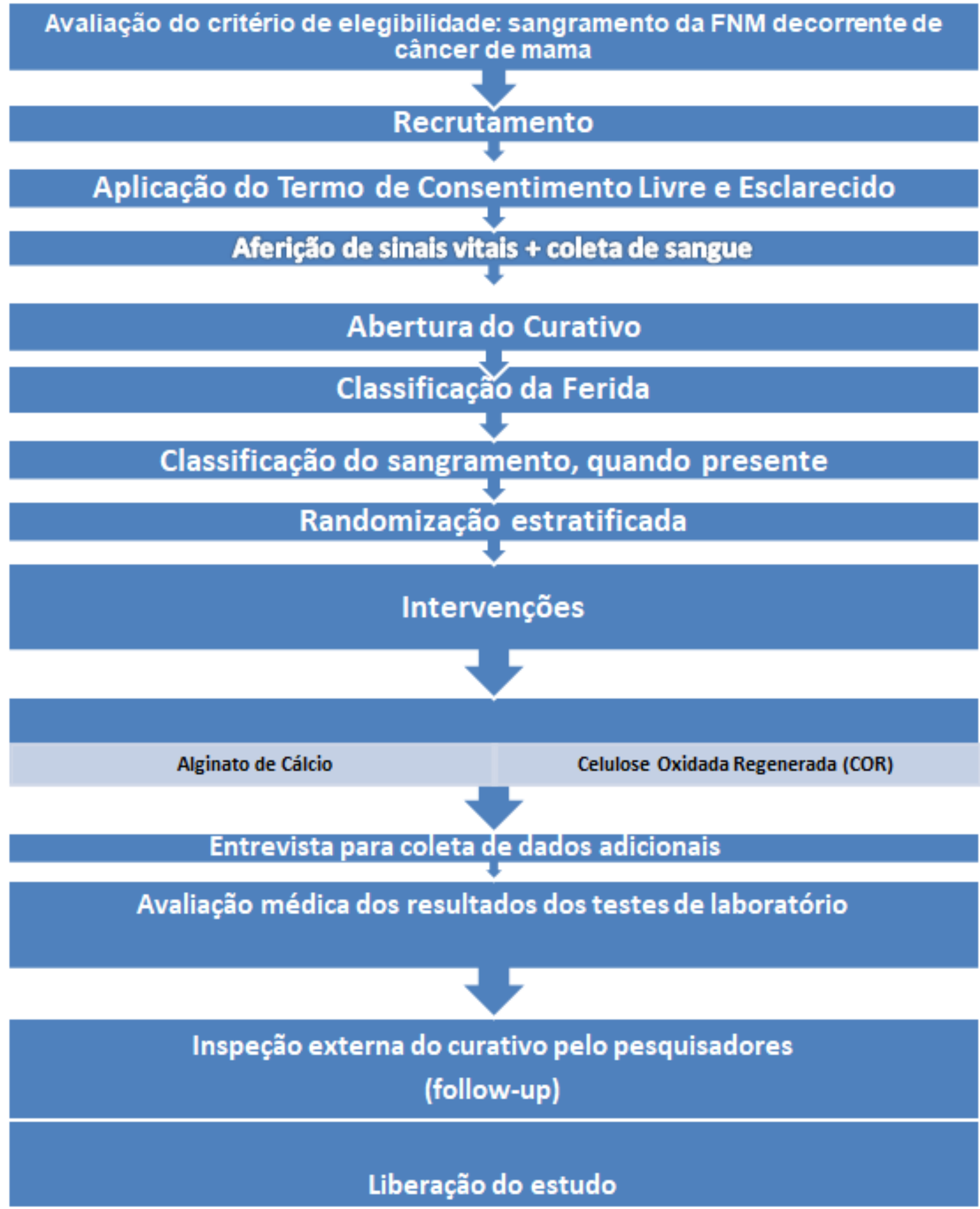

Fonte: CONSORT (2010) ${ }^{138-139}$ 


\subsection{POPULAÇÃO E AMOSTRA}

A população do estudo compreendeu mulheres acometidas por FNM, decorrentes de câncer de mama.

Em razão de não haver estudos com informações necessárias para o cálculo amostral em hemostasia clínica de FNM, foram considerados os parâmetros citados no estudo COntrol of Bleeding after Bypass Anastomoses - COBBANA ${ }^{123}$, desenhado para investigar a eficácia de hemostático microfibilar de colágeno comparativamente à COR em amostra de 28 pacientes. O COBBANA identificou diferença significante $(p<0,001)$ entre as médias do tempo de hemostasia para 0 curativo à base de colágeno (2,1 $\pm 1,1$ minutos) e a COR $(6,9 \pm 3,8$ minutos)

O estudo de Sintler et al (2005) ${ }^{127}$ investigou o tempo necessário para obtenção de hemostasia na linha de sutura de endarterectomias de carótidas, utilizando hemostático selante à base de fibrina (Quixil®) em comparação ao alginato de cálcio (Kaltostat®), também apontou diferença significante $(p<0,001)$ nos tempos de hemostasia do curativo à base de fibrina (mediana = 2,5 minutos; mínimo = 1 minuto; máximo = 4 minutos) e alginato (mediana $=17$ minutos; mínimo $=7$ minutos; máximo = 59 minutos). Considerando-se estes parâmetros e empregandose 0 teste $t$ de Student para amostras independentes, estimou-se amostra de 12 pacientes no grupo intervenção e 12 no grupo controle para se detectar a diferença de 5 minutos na média de tempo de hemostasia entre os dois grupos, ao nível de significância de 5\%, com um poder de $86,5 \%$. Para tanto, admitiu-se um desviopadrão de 4 minutos.

Para esses cálculos, utilizou-se o software estatístico PASS 2008 (Power Analysis and Sample Sie System) - NCSS Statistical Software.

\subsection{RECRUTAMENTO E SELEÇÃO DAS PARTICIPANTES}

O recrutamento das pacientes ocorreu nos ambulatórios, setor de emergência e enfermarias das instituições participantes do estudo. Todas as pacientes que tinham curativo em FNM na mama foram consideradas potenciais participantes do estudo. 
Médicos e enfermeiros foram previamente informados sobre os objetivos da pesquisa, critérios de elegibilidade e como comunicar a existência de pacientes elegíveis. Quando uma paciente era identificada como potencialmente elegível, a informação era passada à pesquisadora principal do estudo por telefone, e-mail ou mensagens por aplicativos.

O período de recrutamento de pacientes foi entre 28 de setembro de 2017 e 31 de agosto de 2018, com a coleta de dados somente no período diurno e em horário comercial, para assegurar que um mesmo pesquisador aplicasse a compressão manual em todos os experimentos, bem como a disponibilidade dos profissionais de saúde que pudessem atestar a hemostasia. Quando as pacientes apresentavam sangramento da FNM no período noturno, enfermeiros assistenciais ou técnicos de enfermagem repassavam a informação à pesquisadora principal, que comparecia diariamente às enfermarias para captar pacientes, nos períodos da manhã e tarde.

\subsubsection{Critérios de inclusão}

Para serem incluídas no estudo, as pacientes com FNM decorrentes de câncer de mama deveriam apresentar:

- Idade igual ou superior a 18 anos;

- Sangramento ativo da ferida

- Aceitação de punção venosa para coleta de sangue.

\subsubsection{Critérios de exclusão}

Os critérios de exclusão no estudo foram:

- Pacientes com sangramento na FNM com suspeita de causa arterial (sangramento pulsátil);

- Pacientes com sangramento na FNM sem visualização que permitisse identificar seu local de origem, prejudicando o processo de aplicação de qualquer uma das intervenções do estudo;

- Pacientes com sangramento tumoral em área com qualquer hemostático tópico aderido;

- Pacientes com sangramento tumoral de grande porte e risco iminente de morte; 
- Pacientes torporosas, inconscientes ou com qualquer outra condição que determinasse inabilidade de comunicação com os pesquisadores, sem familiares presentes;

- Pacientes com conhecida alergia aos produtos tópicos hemostáticos utilizados no estudo;

- Pacientes com doenças hematológicas associadas; e

- Pacientes que já participaram do estudo em momento/episódio de sangramento anterior.

\subsection{CEGAMENTO E MASCARAMENTO}

Em razão da natureza do material tópico empregado nas intervenções, o estudo foi impossibilitado de ser cegado.

Para diminuir vieses, a pesquisadora principal executou a hemostasia em todos os experimentos e a validou por meio de resposta dicotômica (sim ou não) dos profissionais da equipe de assistência que acompanhavam o experimento.

\subsection{GRUPOS}

As pacientes do estudo foram randomizadas em dois grupos, sendo:

Grupo 1 - grupo controle, exposto à aplicação do curativo de alginato de cálcio Biatain $^{\circledR}$ Alginate na apresentação em fita, medindo $3 \times 44 \mathrm{~cm}$. $O$ grupo foi designado pela abreviação AC.

Grupo 2 - grupo intervenção, exposto ao hemostático de celulose oxidada regenerada Surgicel $\AA^{\circledR}$ original, medindo $5,1 \times 35,6 \mathrm{~cm}$. $O$ grupo foi designado pela abreviação COR.

\subsection{RANDOMIZAÇÃO}

A randomização foi estratificada, considerando-se três estratos possíveis para alocação das pacientes do estudo, de acordo com a intensidade de sangramento apresentado: 
1‥ Estrato: Sangramento Leve

20. Estrato: Sangramento Moderado

3‥ Estrato: Sangramento Intenso

A estratificação da amostra pela intensidade de sangramento também foi utilizada por Fischer et al, (2013) ${ }^{140}$ em estudo que investigou a eficácia e a segurança de hemostático composto de fibrinogênio e trombina humana (EVARREST®) no controle de sangramento de pacientes submetidos a cirurgias torácicas, abdominais, retroperitoniais e pélvicas.

Um estatístico independente elaborou uma lista de instruções para o preparo dos envelopes opacos, o que foi feito por um pesquisador independente que seguiu a orientação: cada envelope deveria conter o título de um dos estratos, identificado por fora, e contendo por dentro a indicação COR ou AC, iniciando-se pelo estrato leve no grupo controle, leve no grupo intervenção, seguindo-se o sorteio sucessivamente. Ao final, a randomização gerou 24 envelopes para a seguinte alocação, conforme mostrada nos dados do Quadro 3:

Quadro 3 - Alocação prevista de pacientes no estudo conforme estratos e grupos

\begin{tabular}{|c|c|c|}
\hline \multicolumn{3}{|c|}{ Randomização por envelopes opacos } \\
\hline Estratos & \multicolumn{2}{|c|}{ Grupos no estudo } \\
\hline & Grupo controle (AC) & Grupo intervenção (COR) \\
\hline Leve & 4 & 4 \\
\hline Moderado & 4 & 4 \\
\hline
\end{tabular}

Fonte: dados da pesquisa.

Os envelopes continham etiquetas identificando-os por nível de sangramento e sequência numérica e foram acondicionados em três pastas distintas, de acordo com os respectivos estratos. Estes envelopes ficaram em poder da pesquisadora principal do estudo e foram abertos por sorteio somente no momento exato da intervenção experimental. Dessa forma, até o momento de se aplicar os produtos hemostáticos (alginato de cálcio ou COR), a pesquisadora principal e as enfermeiras 
envolvidas na realização do curativo nas FNM não sabiam qual seria o produto a ser utilizado.

Após a pesquisadora principal avaliar e classificar o sangramento, o envelope era sorteado, de acordo com o respectivo estrato, e aberto pela enfermeira assistencial que conduzia a troca do curativo.

\subsection{PROCEDIMENTOS PARA A COLETA DE DADOS}

\subsubsection{Capacitação dos profissionais para a coleta de dados}

Enfermeiros assistenciais foram capacitados para participar e/ou colaborar com o desenvolvimento do estudo pela pesquisadora principal, por meio de aulas exploratórias individuais realizadas no horário de serviço, em cada cenário onde ocorreu a coleta de dados. O conteúdo era informativo, tendo por foco explanar a necessidade da realização do estudo, o protocolo de pesquisa, o diagrama do estudo, intervenções, conceitos de hemostasia clínica, classificação da ferida e da intensidade do sangramento. Embora esta capacitação fosse necessária para informar sobre o fluxo do recrutamento e uniformizar conceitos, ambas as instituições tinham rotina assistencial estabelecida para o atendimento às pacientes com sangramento decorrente de FNM, em todos os setores de coleta de dados, e os profissionais de saúde eram experientes em relação a esse procedimento.

Assim, a pesquisa envolveu 33 profissionais de saúde colaboradores que receberam capacitação específica, entre médicos, enfermeiros, técnicos de enfermagem e funcionários administrativos nas duas instituições onde os dados foram coletados, além de um estatístico independente atuando nas análises estatísticas do projeto, no processo de randomização e na análise dos dados coletados.

\subsubsection{Instrumentos utilizados na coleta de dados}

Três instrumentos foram usados para coleta dos dados:

- Ficha de registros dos dados;

- Instrumento de avaliação das FNM; e

- Instrumento de avaliação do sangramento das FNM 
A Ficha de Registro de Dados foi elaborada para a coleta e registro dos dados sóciodemográficos e clínicos: identificação anonimizada, de modo a constar somente o código da pesquisa; dados demográficos (idade, sexo) e dados clínicos referentes: ao tumor, à ferida, ao sangramento, à intervenção e aos exames laboratoriais; data de coleta dos dados e assinatura da pesquisadora principal do estudo (Apêndice C). Este instrumento foi elaborado pela pesquisadora principal e testado em três pacientes, antes do início da coleta dos dados. A realização desses testes apontou a necessidade de ajustes nos itens relacionados à identificação do paciente (anomização), inclusão de dados relativos à histopatologia tumoral (condição do receptor HER2 e da proteína Ki 67) e de avaliação do sangramento (inclusão da modalidade "sangramento de fundo").

O instrumento de classificação de FNM utilizado é descritivo e encontra-se disponível visualmente em alguns setores onde ocorreu a coleta de dados, sendo utilizado regularmente na prática institucional. O instrumento classifica as FNM nos estadiamentos $1,1 \mathrm{~N}, 2,3$, e 4, de acordo com o padrão de acometimento e destruição das estruturas da pele pelo tumor e sinais e sintomas presentes na ferida (Anexo D). A classificação é derivada de um estudo piloto americano conduzido no Johns Hopkins Hospital, em Baltimore, e publicado no final da década de $1990^{62}$. Embora o instrumento seja utilizado há mais de uma década nos hospitais onde a coleta de dados foi realizada, ele não é adaptado culturalmente e validado para o Brasil. Seu uso foi adotado por tradução livre nos âmbitos do HC IV e foi disseminado para uso no $\mathrm{HC} I I{ }^{57}$.

O instrumento utilizado para a avaliação do sangramento das FNM foi a Escala de Mensuração de Intensidade do Sangramento: instrumento desenvolvido por médicos americanos para uso em estudos de eficácia de hemostáticos tópicos em cirurgias ${ }^{76}$ (Apêndice D). A escala contém quatro critérios em relação ao sangramento, considerando: 1) apresentação visual, 2) local anatômico de origem, 3) descrição qualitativa do nível de intensidade e 4) estimativa por $\mathrm{ml} /$ minuto de perda sanguínea. A pontuação é feita por escores de zero (sem sangramento, com perda sanguínea menor de 1,0 ml por minuto) a quatro (sangramento ameaçador da vida, com perda sanguínea maior que 50,0 ml por minuto).

Tal como o instrumento de avaliação de FNM, a escala de avaliação do sangramento não tem adaptação cultural e validação para o idioma português do Brasil. Ela foi desenvolvida e validada por médicos americanos (EUA). No entanto, 
para o presente estudo, a escala foi traduzida de modo livre pela pesquisadora principal e testada em três pacientes, nas mesmas ocasiões em que foi testada a ficha de coleta de dados, conforme informado anteriormente.

\subsubsection{Coleta dos dados}

Para o desenvolvimento do estudo, a pesquisadora principal estava presente diariamente nas enfermarias, serviço de emergência e ambulatórios das instituições realizando o recrutamento e a coleta de dados, por meio de busca ativa.

A pesquisadora principal tinha como referência a enfermeira assistencial responsável pelo plantão diurno, em cada setor de coleta de dados. Uma vez que as enfermeiras identificassem pacientes potencialmente elegíveis, a pesquisadora principal era informada e fazia a abordagem à paciente para certificar-se de sua elegibilidade e convidá-la a participar do estudo.

Havendo adesão da paciente à pesquisa, a assinatura do Termo de Consentimento Livre e Esclarecido (TCLE) era solicitada e a paciente seguia o fluxo da pesquisa, conforme ilustrado nos dados da Figua 8.

Iniciava-se, então, o preenchimento da ficha de coleta de dados, por meio de entrevista, exame físico, aferição de sinais vitais e coleta de amostra de sangue para os exames laboratoriais.

A pesquisadora principal criou uma lista de códigos designando os pacientes pela letra $\mathrm{P}$ seguida de números arábicos. Isto foi necessário para minimizar o risco de identificação e preservar o anonimato das participantes na pesquisa. Os códigos foram inscritos nas fichas de coleta das respectivas pacientes e a lista de códigos permaneceu em poder somente da pesquisadora principal.

Em todos os locais de coleta de dados, a pesquisadora principal acordava com a enfermeira assistencial a respeito do horário para realização do curativo, sempre que a troca não podia ser realizada na sequência do preenchimento da ficha de coleta de dados e as demais intervenções necessárias (aferição de sinais vitais e coleta de amostra de sangue).

Para a realização do experimento, desenvolveu-se um protocolo de execução, elaborado conforme a conduta clínica de rotina, já estabelecida nas instituições participantes do estudo. Este protocolo foi amplamente divulgado em ambas as instituições onde se deu a coleta de dados e encontra-se detalhado, a seguir: 
- Enfermeira pesquisadora aborda a paciente, discorre sobre a realização e a contribuição da pesquisa para a prática de controle de sangramento da FNM e solicita a assinatura do Termo de Consentimento Livre e Esclarecido TCLE;

- Mediante aceite da paciente, a pesquisadora principal afere os sinais vitais e coleta amostras de sangue para exames laboratoriais (hemograma, bioquímica e coagulograma);

- A pesquisadora principal determina o profissional de saúde médico ou enfermeiro para acompanhar o procedimento, e a enfermeira assistencial que conduzirá a troca do curativo (terceiro profissional envolvido no estudo);

- A enfermeira assistencial inicia a retirada do curativo/cobertura anterior da FNM;

- A enfermeira assistencial realiza a limpeza com solução salina e identifica o foco de sangramento na FNM;

- A pesquisadora principal classifica a ferida, utilizando o Estadiamento Classificatório de Feridas Tumorais e avalia o sangramento por meio da Escala de Intensidade de Sangramento;

- A enfermeira assistencial abre o envelope, de acordo com a classificação de intensidade do sangramento;

- A pesquisadora principal seleciona o material a ser aplicado na intervenção experimental, de acordo com a indicação contida no envelope;

- A enfermeira assistencial posiciona o cronômetro digital específico para contagem do tempo, sem que a pesquisadora principal o visualize;

- A pesquisadora principal dispõe o produto hemostático definido sobre a ferida e solicita o início da contagem do tempo, no mesmo momento em que inicia a compressão manual;

- A pesquisadora principal avalia periodicamente a obtenção de hemostasia, fazendo alternações entre compressão e avaliação;

- A enfermeira assistencial contabiliza o tempo total para alcance da hemostasia, utilizando o cronômetro digital;

- A pesquisadora principal interroga o profissional de saúde (médico ou outra enfermeira e não a enfermeira assistencial) quanto à obtenção ou não da hemostasia; 
- A pesquisadora principal confirma a hemostasia junto ao respondente e solicita o encerramento da contagem de tempo;

- Havendo divergência entre ambos, a pesquisadora principal interroga a enfermeira assistencial presente. Detectada a hemostasia, espera-se o tempo de 5 minutos para avaliar ressangramento;

- Não detectado o ressangramento, a enfermeira assistencial escreve o tempo computado no envelope que foi aberto e retoma a continuidade do curativo;

- A pesquisadora principal identifica o envelope com o número do código de pesquisa da paciente e acompanha a realização total do curativo; e

- A pesquisadora principal solicita emissão do pedido de sangue ao médico presente no setor ou ao médico plantonista do serviço de pronto atendimento (SPA);

\section{Mediante ressangramento:}

- A pesquisadora principal continua fazendo a aposição do hemostático, previamente utilizado, e reavalia a hemostasia;

- A pesquisadora principal continua com a compressão digital, fazendo aposição de mais hemostáticos, considerando o limite de tempo de até 20 minutos; e

- Se não houver hemostasia ao final de 20 minutos, a pesquisadora principal encerra o experimento e a paciente segue para intervenções terapêuticas definidas pelos profissionais da equipe de saúde (de acordo com as rotinas do serviço.

Após:

- A pesquisadora principal encaminha as amostras de sangue já coletadas ao laboratório.

Decorrido o tempo necessário para a realização dos exames de sangue pelo serviço de laboratório, segue-se o protocolo do seguinte modo:

- A pesquisadora principal captura resultados dos exames de sangue por sistema eletrônico;

- A pesquisadora principal solicita avaliação dos resultados do exame de sangue pelo médico participante da pesquisa; $\mathrm{e}$ 
- A pesquisadora principal retorna ao paciente para inspeção da ocorrência de ressangramento, manifestada pela presença de mancha de sangue no curativo externo.

Se Sim: A pesquisadora principal assinala a ocorrência na ficha de coleta de dados e a nova conduta fica a cargo da enfermeria assistencial responsável pelo paciente.

Se Não: A pesquisadora principal assinala a não ocorrência na ficha de coleta de dados e libera a paciente da pesquisa.

\subsection{PROTOCOLO}

Os procedimentos de aplicação dos produtos ocorreram de modo igual para ambos os grupos e incluiu quatro procedimentos que precederam o experimento do estudo, que são descritos a seguir:

1) Verificação dos sinais vitais: realizada pela pesquisadora principal. antes da paciente ser submetida à intervenção principal do estudo.

A aferição da pressão arterial foi realizada por esfignomanômetro e estetoscópio no membro superior contralateral à FNM mamária.

A aferição da frequência cardíaca $(\mathrm{FC})$ foi realizada por compressão digital em região da artéria radial para percepção da pulsação e contagem do número de pulsações cronometradas, durante 1 minuto e mensuradas por meio de cronômetro digital.

A aferição da frequência dos movimentos respiratórios (FR) foi realizada por meio de observação direta dos movimentos de expansão e contração da caixa torácica e contagem do número de movimentos cronometrados durante 1 minuto e mensurados pelo cronômetro digital.

A aferição da temperatura corporal foi realizada, usando-se termômetro digital posicionado na região axilar contralateral à FNM mamária.

2) Coleta de sangue: foi realizada por meio de punção simples de veia periférica, usando garrote e seringas; ou em cateter venoso central totalmente implantado (CVC-TI), por meio de punção do dispositivo, utilizando agulha específica para o procedimento. Foram coletados cerca de $10 \mathrm{ml}$ para distribuição em três frascos (hemograma, bioquímica e coagulograma). 
3) Avaliação da FNM: foi realizada após a abertura do curativo e limpeza do local da FNM. A pesquisadora principal inspecionava o leito, limites, profundidade e bordas da FNM e classificava seu estadiamento, de acordo com o Estadiamento classificatório das feridas neoplásicas.

4) Avaliação do sangramento: foi realizada após a limpeza do local da FNM. A pesquisadora principal inspecionava o sangramento presente atentando quanto à forma de extravasamento e intensidade. Quanto à forma de extravasamento, foi classificada como sangramento delimitado, quando ocorreu em uma parte bem definida da ferida; difuso, quando foi de forma espalhada pela ferida, sem delimitação e de fundo. Este último compreendeu o sangramento que ocorreu em feridas com formação de cavidades, em forma de brotamento ou pontos com sangramento concomitante, em todo o leito fundo, porém, visível da FNM. Quanto à intensidade, o sangramento foi classificado de acordo com a Escala de Intensidade de Sangramento.

A seguir, realizava-se a intervenção considerada como a principal do estudo:

5) Aplicação do produto hemostático: após a irrigação da ferida com solução salina, sua avaliação, bem como o sangramento presente, aplicava-se 0 produto hemostático, conforme o grupo, ou seja, o Alginato de Cálcio (Grupo Controle) ou a COR (Grupo Intervenção), diretamente sobre a área sangrante da ferida.

Para a aplicação de qualquer um dos produtos, utilizava-se luva cirúrgica, sem qualquer tipo de gaze entre a mão enluvada da pesquisadora e o produto hemostático era colocado na ferida. A compressão manual ocorreu diretamente sobre o produto. Não houve corte de qualquer um dos produtos empregados, até ser alcançada a hemostasia. Após alcançada a hemostasia, o produto de tratamento era mantido sobre a ferida, independentemente da quantidade utilizada e o curativo era finalizado. Havendo excesso do produto seco sobre a ferida, este excedente era recortado por meio de tesoura cirúrgica e descartado.

A aplicação descrita está de acordo com as instruções dos respectivos fabricantes ${ }^{129,131}$. 


\subsection{VARIÁVEIS}

Para a análise dos resultados, foram consideradas as seguintes variáveis:

\section{Variáveis dependentes}

- Obtenção de hemostasia - categórica nominal, binária ou dicotômica, obtida assinalando as alternativas sim ou não;

- Tempo total de hemostasia - numérica contínua, obtida pela contagem do tempo, em minutos e segundos;

- Presença de ressangramento - categórica nominal, binária ou dicotômica, obtida assinalando as alternativas sim ou não; e

- Quantidade total de hemostáticos necessária para obtenção da hemostasia: numérica discreta, obtida pela contagem das unidades de hemostáticos utilizadas.

\section{Variáveis independentes}

- Idade - quantitativa discreta considerada em anos;

- Sexo - categórica nominal, binária ou dicotômica, obtida assinalando a alternativa feminino ou masculino;

- Histologia tumoral - categórica nominal multinominal (ex: carcinoma ductal infiltrante; carcinoma lobular; carcinoma in situ, etc.);

- Estadiamento tumoral - categórica ordinal (ex: T2N1M1; T1bN2M1, etc.); e

- Estadiamento da ferida tumoral - categórica ordinal (ex: estadiamento 1, $1 \mathrm{~N}, 2,3$, e 4).

\section{Variáveis de confusão}

- TAP (Tempo de Protrombina Ativada) - numérica contínua;

- INR (Razão Normalizada Internacional) - numérica contínua;

- PTTa (Tempo de Tromboplastina Parcial ativada) - numérica contínua;

- Número de plaquetas - numérica contínua;

- Valor da hemoglobina - numérica contínua;

- Valor do hematócrito - numérica contínua; 
- Medicações anticoagulantes - categórica nominal multinominal, (ex: ácido acetilsalicílico, heparina);

- Medicação antifibrinolítica - categórica nominal multinominal, (ex; ácido aminocaproico);

- Tratamento oncológico pregresso - categórica nominal multinominal (ex: cirurgia, radioterapia, quimioterapia, hormonioterapia); e

- Tratamento oncológico atual - categórica nominal multinominal (idem as do tratamento oncológico pregresso).

\subsection{DESFECHOS}

Os seguintes desfechos foram listados:

\section{Desfecho Primário:}

- Tempo total de hemostasia (TTH).

\section{> Desfechos Secundários:}

- Proporção de pacientes que alcançaram a hemostasia na FNM dentro do tempo limite de 20 minutos;

- Recorrência de sangramento (ressangramento) nos primeiros 5 minutos, após a aplicação da intervenção e inspeção direta da superfície do produto aplicado;

- Recorrência de sangramento (ressangramentos 1 e 2), visualizada pela mancha de sangue no curativo, até o término da coleta de dados (vide item 4.13.1 - Definições operacionais para avaliação dos desfechos); e

- Número de unidades de produtos utilizados.

\subsubsection{Definições operacionais para avaliação dos desfechos}

Hemostasia: a avaliação de hemostasia considerou a absorção do sangue pela cobertura hemostática aplicada por meio de compressão digital no ponto sangrante da ferida, sem traspassamento de sangue adicional por meio do produto e sem vestígios na luva da pesquisadora; ou ainda, sem transposição sobre o hemostático ou sem escorrimento por suas lateriais. 
Proporção de pacientes que alcançaram hemostasia: avaliação por porcentagem.

Número de unidades de produto hemostático utilizado: produto hemostático adicional foi utilizado sempre que aquele já alocado na ferida mostrou sinais de saturação, evidenciado quando o produto tornava-se encharcado com sangue e traspassava para a luva do profissional, bem como pela continuidade do escoamento de sangue no leito da ferida. Esta forma de avaliação de hemostasia é similar àquela realizada no estudo de Gupta et al. (2015 $\left.{ }^{128}\right)$.

Ressangramento 1: Foi considerado primeiro ressangramento aquele que ocorreu dentro do período de 5 minutos, após a hemostasia ter sido declarada alcançada no estudo.

Ressangramento 2: Foi considerado segundo ressangramento, aquele que ocorreu quando a pesquisadora principal retornou ao paciente para informar sobre a avaliação do exame de sangue realizada pelo médico (follow up). Nesta oportunidade, conforme o protocolo do estudo, a pesquisadora principal inspecionava externamente o curativo para detecção de mancha de sangue sobre a cobertura final ou extravasamento de sangue pelas laterais do curativo.

Valores de referência para avaliação dos resultados dos exames de sangue no estudo':

Hemáceas (HM): $3.90-5.60$

Hemoglobina (HT): 11.5 a $16.4 \mathrm{~g} / \mathrm{dL}$.

Hematócrito (HT): 36-47\%.

Plaquetas: 150 a $400 \mathrm{k} / \mathrm{ul}$.

Cálcio: 8,4 a 10,2 mg/dL.

Tempo de Atividade de Protrombina (TAP): 11 a 13,0 segundos.

Razão Normalizada Internacional (INR): 0.8 - 1.2

Tempo de Trompoblastina Parcial Ativada (PTTA): 21 a 31 segundos

1 Valores de referência considerados no Laboratório do Hospital de Câncer- HC III do Instituto Nacional de Câncer - INCA. Técnico responsável: Jorge da Silva Issa - CRBM - 1515. 


\section{Valores de referência para avaliação dos sinais vitais apresentados pelos pacientes no estudo:}

Pressão Arterial Sistêmica (PAS) ${ }^{3}: \leq 120 \mathrm{mmHg}$

Pressão Arterial Diastólica (PAD) $3: \leq 80 \mathrm{mmHg}$

Frequência Cardíaca (FC): $60-100$ batimentos por minuto

Temperatura Axilar (To.): 36 a 36.8

Frequência Respiratória (FR): 12 a 20 movimentos por minutos.

\subsection{ANÁLISE ESTATÍSTICA DOS DADOS}

Primeiramente, os dados dos instrumentos de coleta foram transferidos para a planilha Excel por dupla digitação, sendo realizada uma digitação pela pesquisadora principal do estudo e outra por um pesquisador auxiliar. A seguir, os dois pesquisadores realizaram a conferência das tabelas elaboradas. Este processo deu origem a uma tabela final preeenchida, a qual foi considerada o banco de dados da pesquisa e, então, enviada a um estatístico independente para análise.

Os dados da análise descritiva são apresentados em números, porcentagens, médias e desvio-padrão, variação mínima e máxima e Intervalo de Confiança de 95\%. E os dados da análise inferencial na forma de tabelas de frequência, de contingência por grupos e em gráficos de curva de sobrevivência para as variáveis referentes ao tempo de hemostasia.

A estimativa das curvas de sobrevivência dos tempos de hemostasia para ambos os grupos foi feita com o estimador de Kaplan-Meir e a comparação com o test log-rank. O modelo de riscos proporcionais de Cox foi ajustado para as mesmas comparações anteriores, controlando as variáveis de confusão apontadas. As demais comparações entre os grupos foram feitas com test $t$ de Student ou teste de Wilcoxon-Mann-Whitney para as variáveis numéricas e teste Qui-quadrado ou Exato de Fisher para as categóricas.

\footnotetext{
2 Potter PA, Perry AG, Stockert PA, Hall AM. Procedimentos e Intervenções de Enfermagem. 8ª . Ed. Rio de Janeiro:Elsevier; 2013.

3 Sociedade Brasileira de Cardiologia. 7a. Diretriz Brasileira de Hipertensão Arterial (7DBHA). Arq Bras Cardiol 2016;107(3 Supl.3):1-83.
} 
Em razão da dificuldade de captação dos dados pela pouca frequência do evento sangramento, adicionaram-se apenas quatro pacientes para corrigir as perdas eventuais do estudo.

As análises estatísticas foram realizadas utilizando o software R 3.5.1 (R Core Team, 2018, Viena, Áustria), disponibilizado pela R Foundation for Statistical Computing de Vienna, Austria, disponível na URL https://www.R-project.org/ e considerou um nível de significância de $5 \%(p<0,05)$.

\subsection{OUTRAS INFORMAÇÕES}

O estudo foi cadastrado na Rede Brasileira de Ensaios Clínicos (ReBec) sob o número RBR - 9mqzvz com o nome: Eficácia da Celulose Oxidada Regenerada versus Alginato de Cálcio no Controle do Sangramento de Feridas Malignas decorrentes de Câncer de Mama: Ensaio Clínico Randomizado.

O protocolo do estudo pode ser acessado em: http://www.ensaiosclinicos.gov.br/rg/RBR-9mqzvz/.

O protocolo do estudo foi submetido à avaliação para publicação na revista Journal Wound Care (JWC) e recebeu parecer favorável para publicação no ano corrente de 2019, conforme Anexo E.

As fontes de financiamento do estudo foram:

- Instituto Nacional de Câncer José Alencar Gomes da Silva, que forneceu o material para o experimento, verificação da pressão arterial e temperatura corporal (estetoscópio, esfignomanômetro e termômetro digital exclusivos para a pesquisa), papel A4 para impressão do Termo de Consentimento Livre e Esclarecido (TCLE), tubos de coleta de amostra de sangue e realização de todos os exames de sangue necessários (hemograma, bioquímica e coagulograma); e

- Escola de Enfermagem da Universidade de São Paulo (USP), onde as análises estatísticas do estudo foram realizadas, e auxílio financeiro advindo do Programa de Pós-Graduação em Enfermagem na Saúde do Adulto (PROESA) - Programa de Excelência Acadêmica da Coordenação de Aperfeiçoamento de Pessoal de Nível Superior (PROEX-CAPES), para custeio parcial de participação em congresso e visita técnica internacionais e 
despesas totais com a tradução do artigo de revisão sistemática sobre sangramento em FNM para o idioma inglês. 


\section{Resultados}

Dentre 61 mulheres com FNM decorrente de câncer de mama recrutadas para o estudo, 28 (45,9\%) apresentaram sangramento, prosseguindo, assim, para alocação, seguimento e análise do estudo, conforme demonstrado no fluxograma (Figura 9). 
Figura 9 - Fluxograma de pacientes no estudo

\section{FLUXOGRAMA}

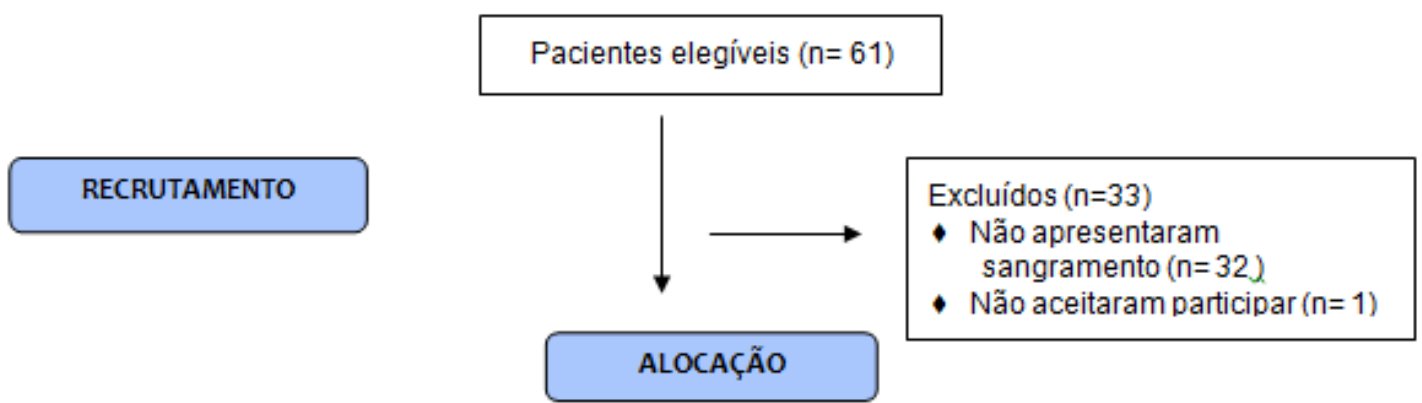

Randomizações ( $n=28$ )

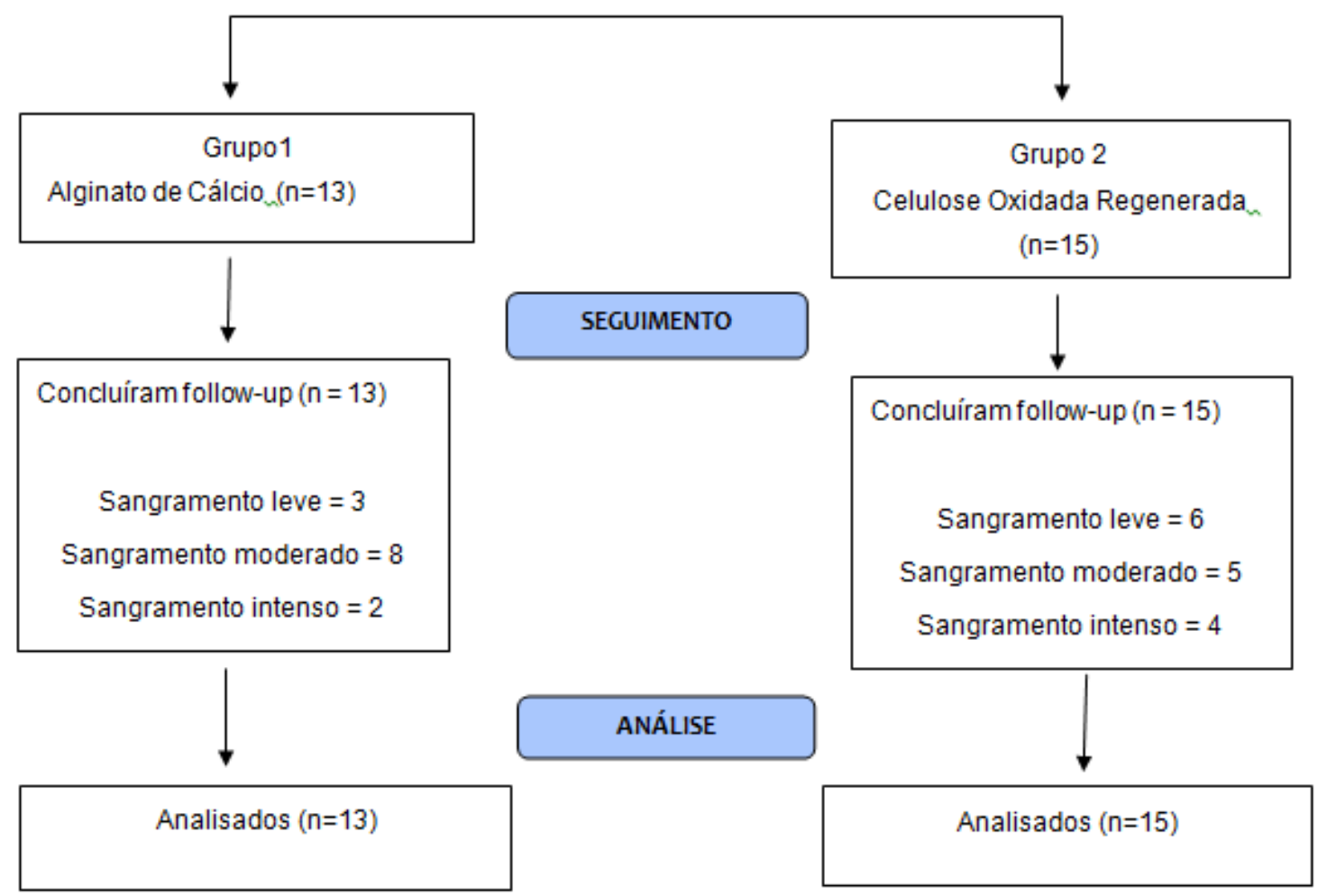

Fonte: (CONSORT, 2010138-139). 
Dentre as 28 mulheres participantes, 20 (71,43\%) foram captadas no HC III, especialmente, nas enfermarias, e oito (28,57\%) no HC IV (Tabela XX).

Os dados da Tabela 1 apresentam a distribuição das mulheres pelo setor de coleta e unidade hospitalar.

Tabela 1 - Mulheres com FNM sangrante decorrente de câncer de mama, conforme o hospital e a unidade de origem. Rio de Janeiro, 2017-2018

\begin{tabular}{lcccccc}
\hline \multirow{2}{*}{ Setor } & \multicolumn{2}{c}{ HC III } & \multicolumn{2}{c}{ HC IV } & \multicolumn{2}{c}{ Total } \\
& $\mathbf{n}$ & $\%$ & $\mathbf{n}$ & $\%$ & $\mathbf{n}$ & $\%$ \\
\hline Enfermaria & 14 & 50,00 & 7 & 25,00 & 21 & 75,00 \\
Pronto-atendimento & 4 & 14,28 & 1 & 3,57 & 5 & 17,85 \\
Ambulatório & 2 & 7,15 & - & - & 2 & 7,15 \\
Total & 20 & 71,43 & 08 & 28,57 & 28 & 100,00 \\
\hline
\end{tabular}

A seguir, as tabelas apresentam a caracterização das pacientes, dos tumores, dos tratamentos do câncer, das FNM e do sangramento na comparação entre os grupos AC e COR.

Conforme os dados da Figura 9, a randomização determinou 13 (46,43\%) participantes no grupo AC e $15(53,57)$ no grupo COR. A caracterização da amostra, de acordo com o grupo, é apresentada nos dados da Tabela 2. 
Tabela 2 - Características demográficas e clínicas das mulheres com FNM sangrante decorrente de câncer de mama, conforme o grupo de alocação. Rio de Janeiro, 2017- 2018

\begin{tabular}{|c|c|c|c|c|}
\hline & Total $(\mathrm{N}=28)$ & Alginato de cálcio $(\mathrm{N}=13)$ & $\operatorname{COR}(\mathrm{N}=15)$ & p valor \\
\hline Idade $\left(\right.$ anos) ${ }^{*}$ & & & & 0,589 \\
\hline Média (IC95\%) & $57,68(51,80-63,56)$ & $59,39(49,45-69,32)$ & $56,20(48,24-64,16)$ & \\
\hline DP & 15,16 & 16,44 & 14,37 & \\
\hline Mediana & 55,00 & 55,00 & 54,00 & \\
\hline Fumante, $\mathbf{N}(\%)^{* *}$ & & & & 0,821 \\
\hline Não & $20(71,43)$ & $10(76,92)$ & $10(66,67)$ & \\
\hline $\mathrm{Sim}$ & $2(7,15)$ & $1(7,69)$ & $1(6,67)$ & \\
\hline Ex-fumante & $6(21,42)$ & $2(15,39)$ & $4(26,67)$ & \\
\hline Comorbidades*** & & & & 0,025 \\
\hline Não & $9(32,14)$ & $7(53,85)$ & $2(13,33)$ & \\
\hline Sim & $19(67,86)$ & $6(46,15)$ & $13(86,67)$ & \\
\hline HAS $(1)^{\text {the }}$ & & & & 0,554 \\
\hline Não & $15(55,55)$ & $8(61,54)$ & $7(50,00)$ & \\
\hline $\operatorname{Sim}$ & $12(44,45)$ & $5(38,46)$ & $7(50,00)$ & \\
\hline Diabetes Mellitus $(1)^{(+*+*}$ & & & & 0,028 \\
\hline Não & $17(62,96)$ & $11(84,62)$ & $6(42,86)$ & \\
\hline Sim & $10(37,04)$ & $2(15,38)$ & $8(57,14)$ & \\
\hline Trombose venosa profunda ${ }^{* * *}$ & & & & 0,199 \\
\hline Não & $23(82,14)$ & $12(92,31)$ & $11(73,33)$ & \\
\hline Sim & $5(17,86)$ & $1(7,69)$ & $4(26,67)$ & \\
\hline Trombo-embolia pulmonar* & & & & 1,000 \\
\hline Não & $27(96,43)$ & $13(100,00)$ & $14(93,33)$ & \\
\hline Sim & $1(3,57)$ & $0(0,00)$ & $1(6,67)$ & \\
\hline Outras comorbidades ${ }^{* \star * *}$ & & & & 0,879 \\
\hline Não & $24(85,71)$ & $11(84,62)$ & $13(86,67)$ & \\
\hline Sim & $4(14,29)$ & $2(15,38)$ & $2(13,33)$ & \\
\hline Uso de enoxaparina*** & & & & 0,814 \\
\hline Não & $20(71,43)$ & $9(30,77)$ & $11(26,67)$ & \\
\hline Sim & $8(28,57)$ & $4(69,23)$ & $4(73,33)$ & \\
\hline Uso de ácido acetilsalić́lico (AAS)* & & & & 1,000 \\
\hline Não & $27(96,43)$ & $13(100,00)$ & $14(73,33)$ & \\
\hline Sim & $1(3,57)$ & $0(0,00)$ & $1(6,67)$ & \\
\hline Uso de ácido aminocapróico*** & & & & 0,143 \\
\hline Não & $15(53,57)$ & $5(38,46)$ & $10(66,67)$ & \\
\hline $\mathrm{Sim}$ & $13(46,43)$ & $8(61,54)$ & $5(33,33)$ & \\
\hline Metástases $(2)^{+* *+*}$ & & & & 0,619 \\
\hline Não & $6(23,08)$ & $2(18,18)$ & $4(26,67)$ & \\
\hline Sim & $20(76,92)$ & $9(81,82)$ & $11(73,33)$ & \\
\hline Performance status (PS) ${ }^{(3)^{+*+*}}$ & & & & 0,500 \\
\hline 1 & $4(14,81)$ & $2(16,67)$ & $2(13,33)$ & \\
\hline 2 & $6(22,22)$ & $1(8,33)$ & $5(33,33)$ & \\
\hline 3 & $6(22,22)$ & $3(25,00)$ & $3(20,00)$ & \\
\hline 4 & $11(40,75)$ & $6(50,00)$ & $5(33,33)$ & \\
\hline
\end{tabular}

(1) 1 caso sem informação no grupo COR

(2) 2 casos sem informação no grupo Alginato de cálcio

(3) 1 caso sem informação no grupo Alginato de cálcio

IC95\% - Intervalo de Confiança de 95\% para a média*Teste t

** Teste Exato de Fischer

*** Teste Qui-quadrado 
De modo geral, a média de idade das mulheres foi 57,68 anos (DP=15,16), com variação entre 27 e 91 anos. Verificou-se predominância de não fumantes $(71,4 \%)$, com comorbidades $(67,9 \%)$, em uso de medicação coagulante, metástases e com baixa performance clínica (PS). Dentre as pacientes com comorbidades $(\mathrm{N}=19)$, quatro $(21,0 \%)$ tinham mais de um tipo de doença e a Hipertensão Arterial Sistêmica foi a mais frequente, seguida de Diabetes Mellitus tipo 2.

Verificaram-se diferenças estatisticamente significantes entre os grupos apenas para a presença de comorbidades $(p=0,025)$ e, especificamente, de Diabetes Mellitus $(p=0,028)$, predominantes no grupo COR.

Os dados da Tabela 3 apresentam as características de estadiamento, histologia e imuno-histoquímica dos tumores das mulheres envolvidas no estudo. 
Tabela 3 - Características histopatológicas e de estadiamento do tumor de mulheres com FNM sangrante decorrente de câncer de mama, conforme o grupo. Rio de Janeiro, 2017- 2018

\begin{tabular}{|c|c|c|c|}
\hline & Alginato de cálcio $(\mathrm{N}=13)$ & $\operatorname{COR}(\mathrm{N}=15)$ & p valor \\
\hline Tipo histológico, $\mathbf{N}(\%)^{\star *}$ & & & 0,087 \\
\hline Apócrino & $1(7,69)$ & $0(0,00)$ & \\
\hline Ductal infiltrante & $10(76,92)$ & $15(100,00)$ & \\
\hline Mucinoso & $1(7,69)$ & $0(0,00)$ & \\
\hline Papilífero & $1(7,69)$ & $0(0,00)$ & \\
\hline Grau histológico** & & & 0,115 \\
\hline 1 & $1(7,69)$ & $0(0,00)$ & \\
\hline 2 & $4(30,77)$ & $9(69,23)$ & \\
\hline 3 & $8(61,54)$ & $4(30,77)$ & \\
\hline Estadiamento tumoral ${ }^{\star \star \star}$ & & & 0,619 \\
\hline III & $2(18,18)$ & $4(26,67)$ & \\
\hline IV & $9(81,82)$ & $11(73,33)$ & \\
\hline \multicolumn{4}{|l|}{ Imuno-histoquimica } \\
\hline HER $^{\star \star \star}$ & & & 0,440 \\
\hline Negativo & $6(46,15)$ & $8(61,54)$ & \\
\hline Positivo & $7(53,85)$ & $5(38,46)$ & \\
\hline $\operatorname{RE}(\%)^{\star \star \star \star}$ & & & 0,499 \\
\hline Média (IC95\%) & $26,00(5,50-85,00)$ & $38,46(50,00-100,00)$ & \\
\hline DP & 36,64 & 48,32 & \\
\hline Mediana (min - max) & $1,00(0,00-90,00)$ & $5,00(0,00-100,00)$ & \\
\hline $\mathbf{R P}(\%)^{\star \star \star \star \star}$ & & & 0,220 \\
\hline Média (IC95\%) & $18,54(66,00-95,00)$ & $26,00(5,50-95,00)$ & \\
\hline DP & 35,72 & 37,42 & \\
\hline Mediana (min - max) & $0,00(0,00-95,00)$ & $1,00(0,00-100,00)$ & \\
\hline Ki67 (\%)* & & & 0,124 \\
\hline Média (IC95\%) & $39,83(21,92-57,75)$ & $60,45(38,00-82,91)$ & \\
\hline DP & 28,19 & 33,43 & \\
\hline Mediana (min - max) & $30,00(3,00-90,00)$ & $75,00(5,00-90,00)$ & \\
\hline
\end{tabular}

Imuno-histoquímica: $\mathrm{N}=13$ para alginato de cálcio, exceto Ki67 (N=12). N=13 para COR, exceto Ki67 (N=11).

*Test $\mathrm{t}$

** Teste Exato de Fischer

*** Teste Qui-quadrado

$* * * *$ Wilcoxon-Mann-Whitney

$* * * \star *$ Brunner-Munzel 
De modo geral, os dados demonstram que os tumores das mulheres participantes do estudo eram predominantemente do tipo CDI e em estadiamento IV, o que as caracteriza como acometidas por câncer em estadiamento avançado. Não houve diferenças estatisticamente significantes entre os grupos quanto a estas características.

Os dados da Tabela 4 apresentam os tipos de tratamento oncológico recebidos pelas mulheres da amostra.

Tabela 4 - Distribuição das mulheres com FNM sangrante decorrente de câncer de mama, conforme o tratamento oncológico recebido e o grupo. Rio de Janeiro, 2017- 2018

\begin{tabular}{lccccccc}
\hline Tratamento oncológico & \multicolumn{2}{c}{ Total } & Alginato de cálcio & \multicolumn{2}{c}{ COR } & $\begin{array}{c}\text { p } \\
\text { valor }\end{array}$ \\
\hline Pregresso & $\mathrm{n}$ & $\%$ & & & & & \\
$\quad$ Nenhum & 14 & 50,00 & 7 & 53,85 & 7 & 46,67 & 0,710 \\
$\quad$ Quimioterapia intravenosa & 14 & 50,00 & 6 & 46,15 & 8 & 43,33 & \\
Atual & & & & & & & \\
$\quad$ Nenhum & 16 & 57,14 & 7 & 53,85 & 9 & 60,00 & \\
$\quad$ Hormonioterapia & 5 & 17,86 & 3 & 23,08 & 2 & 13,33 & 0,892 \\
$\quad$ Quimioterapia intravenosa & 4 & 14,28 & 2 & 15,39 & 2 & 13,33 & \\
$\quad$ Quimioterapia oral & 3 & 10,72 & 1 & 7,69 & 2 & 13,33 & \\
\hline
\end{tabular}

Teste qui-quadrado 
Metade das mulheres incluídas no estudo não recebeu qualquer tratamento pregresso, e a outra metade, a quimioterapia endovenosa. Dentre as que estavam em tratamento atual (16), a hormonioterapia foi a modalidade mais frequente $(17,86 \%)$.

Os dados da Tabela 5 caracterizam a amostra, conforme as variáveis relacionadas às FNM.

Tabela 5 - Características das FNM sangrantes decorrentes de câncer de mama, conforme o grupo. Rio de Janeiro, 2017- 2018

\begin{tabular}{|c|c|c|c|c|c|c|c|}
\hline \multirow{2}{*}{$\begin{array}{l}\text { Características da ferida } \\
\text { neoplásica maligna }\end{array}$} & \multicolumn{2}{|c|}{ Total } & \multicolumn{2}{|c|}{$\begin{array}{l}\text { Alginato de cálcio } \\
\qquad(n=13)\end{array}$} & \multicolumn{2}{|c|}{$\begin{array}{c}\text { COR } \\
(n=15)\end{array}$} & \multirow{2}{*}{$\begin{array}{c}p \\
\text { valor }\end{array}$} \\
\hline & $\mathrm{n}$ & $\%$ & $\mathrm{n}$ & $\%$ & $\mathrm{n}$ & $\%$ & \\
\hline \multicolumn{8}{|l|}{ Estadiamento $^{\star \star \star}$} \\
\hline 2 & 7 & 25,00 & 2 & 15,38 & 5 & 33,33 & \multirow{3}{*}{0,522} \\
\hline 3 & 16 & 57,14 & 8 & 61,54 & 8 & 53,33 & \\
\hline 4 & 5 & 17,86 & 3 & 23,08 & 2 & 13,33 & \\
\hline \multicolumn{8}{|l|}{ Sinais e sintomas ${ }^{\star \star \star}$} \\
\hline Dor referida ${ }^{(1)}$ & & & & & & & \multirow{3}{*}{0,932} \\
\hline Não & 21 & 84,00 & 11 & 84,62 & 10 & 83,33 & \\
\hline $\operatorname{Sim}$ & 4 & 16,00 & 2 & 15,38 & 2 & 16,67 & \\
\hline \multicolumn{8}{|l|}{ Exsudato } \\
\hline Não & 19 & 67,86 & 8 & 61,54 & 11 & 73,33 & \multirow[t]{2}{*}{0,513} \\
\hline Sim & 9 & 32,14 & 5 & 38,46 & 04 & 26,67 & \\
\hline \multicolumn{8}{|l|}{ Odor ${ }^{(2)}$} \\
\hline Não & 16 & 64,00 & 8 & 64,54 & 8 & 53,33 & \multirow[t]{2}{*}{0,667} \\
\hline Sim & 9 & 36,00 & 5 & 38,46 & 4 & 26,67 & \\
\hline \multicolumn{8}{|l|}{ Cobertura $^{(3)^{* \star}}$} \\
\hline Alginato de cálcio & 3 & 11,11 & 1 & 08,33 & 2 & 13,33 & \multirow{8}{*}{0,677} \\
\hline Celulose oxidada regenerada & 2 & 07,41 & 1 & 08,33 & 1 & 6,67 & \\
\hline Colágeno & 1 & 03,70 & 1 & 08,33 & 0 & 0,00 & \\
\hline Gazes secas & 11 & 40,75 & 3 & 25,00 & 8 & 53,33 & \\
\hline Metronidazol gel $0.8 \%$ & 5 & 18,52 & 3 & 25,00 & 2 & 13,33 & \\
\hline Óleo mineral & 1 & 03,70 & 0 & 00,00 & 1 & 6,67 & \\
\hline Gaze Petrolato & 3 & 11,11 & 2 & 16,67 & 1 & 6,67 & \\
\hline Vaselina & 1 & 03,70 & 1 & 08,33 & 0 & 0,00 & \\
\hline
\end{tabular}

(1) 3 casos sem informação no grupo COR

(2) 3 casos sem informação no grupo COR

(3) 1 caso sem informação no grupo Alginato de Cálcio

*Test t

** Teste Exato de Fischer

*** Teste Qui-quadrado

$* * * *$ Wilcoxon-Mann-Whitney

$* * * * *$ Brunner-Munzel 
Observa-se que o estadiamento grau 3 das FNM foi o mais frequente (16/ $57,14 \%$ ). Excluindo-se o sangramento, presente em $100 \%$ das FNM, o odor e o exsudato foram os sinais e sintomas secundários mais frequentes (36\% e 32,14\% respectivamente). Houve maior frequência do uso de gazes secas seguido de metronidazol gel, óleo mineral, gaze petrolato e vaselina como coberturas. Alginato de cálcio e hemostáticos tópicos também foram tipos de coberturas utilizadas previamente.

As características de sangramento das FNM são apresentadas nos dados da Tabela 6.

Tabela 6 - Características de sangramento nas FNM, decorrentes de câncer de mama, conforme o grupo. Rio de Janeiro, 2018

\begin{tabular}{|c|c|c|c|c|c|c|c|}
\hline \multirow{2}{*}{$\begin{array}{l}\text { Características do perfil de } \\
\text { sangramento }\end{array}$} & \multicolumn{2}{|c|}{ Total } & \multicolumn{2}{|c|}{$\begin{array}{l}\text { Alginato de cálcio } \\
\qquad(n=13)\end{array}$} & \multicolumn{2}{|c|}{$\begin{array}{c}\text { COR } \\
(n=15)\end{array}$} & \multirow[t]{2}{*}{ p valor } \\
\hline & $\mathbf{n}$ & $\%$ & $\mathbf{n}$ & $\%$ & $\mathbf{n}$ & $\%$ & \\
\hline \multicolumn{8}{|l|}{ Intensidade ${ }^{\star \star \star}$} \\
\hline Leve & 9 & 32,14 & 3 & 23,08 & 6 & 40,00 & \multirow{3}{*}{0,342} \\
\hline Moderado & 13 & 46,43 & 8 & 61,54 & 5 & 33,33 & \\
\hline Intenso & 6 & 21,43 & 2 & 15,38 & 4 & 26,67 & \\
\hline \multicolumn{8}{|l|}{ Tipo*** } \\
\hline Espontâneo & 14 & 50,00 & 7 & 53,85 & 7 & 46,67 & \multirow{2}{*}{0,710} \\
\hline Induzido & 14 & 50,00 & 6 & 46,15 & 8 & 53,33 & \\
\hline \multicolumn{8}{|l|}{ Localização(1) $)^{* \star}$} \\
\hline De fundo & 2 & 07,41 & 1 & 07,69 & 1 & 07,14 & \multirow{3}{*}{1,000} \\
\hline Delimitado & 14 & 62,96 & 8 & 61,54 & 9 & 64,29 & \\
\hline Difuso & 8 & 29,63 & 4 & 30,77 & 4 & 28,57 & \\
\hline \multicolumn{8}{|l|}{ Tratamento*** } \\
\hline Nenhum & 15 & 53,57 & 5 & 38,46 & 10 & 66,67 & \multirow[b]{2}{*}{0,143} \\
\hline $\begin{array}{l}\text { Ácido aminocapróico } \\
\text { sistêmico }\end{array}$ & 13 & 46,43 & 8 & 61,54 & 5 & 33,33 & \\
\hline
\end{tabular}

(1) 1 caso sem informação no grupo COR

** Teste Exato de Fischer

*** Teste Qui-quadrado 
Descritivamente, o sangramento moderado foi o mais frequente $(13 / 46,43 \%)$, no grupo controle (8/ 61,54\%). O grupo intervenção concentrou a maior porcentagem de sangramento intenso (4/ 26,67\%). Quanto ao tipo de sangramento, ocorreu igualmente de forma espontânea e manipulação para realização do curativo. Quanto à localização, o sangramento delimitado e localizado em área qualquer do leito da FNM foi predominante na amostra (14/62,96\%), sem sangramento oriundo de bordas ou margens das FNM.

Pouco menos da metade das pacientes (13/46,4\%) encontrava-se em uso do ácido aminocaproico, ou seja, era tratada sistemicamente com medicação antifibrinolítica quando recebeu a intervenção experimental. Houve concentração dessas pacientes previamente tratadas sistemicamente no grupo controle (8/ $61,54 \%)$.

Os dados da Tabela 7 apresentam os resultados das variáveis relacionadas aos exames de sangue (hemograma, bioquímica e hemograma). 
Tabela 7 - Resultados dos marcadores sanguíneos das mulheres com FNM sangrantes decorrentes de câncer de mama, conforme o grupo. Rio de Janeiro, 2017-2018

\begin{tabular}{|c|c|c|c|c|c|c|c|c|c|c|c|c|c|}
\hline \multirow{2}{*}{$\begin{array}{l}\text { Marcadores } \\
\text { sanguíneos }\end{array}$} & \multirow[b]{2}{*}{ Média } & \multicolumn{5}{|c|}{ Alginato de cálcio } & \multicolumn{6}{|c|}{ COR } & \multirow{2}{*}{$\begin{array}{c}\text { p- } \\
\text { valor }\end{array}$} \\
\hline & & DP & Mediana & $\begin{array}{l}\text { Mín - } \\
\text { Máx }\end{array}$ & LI95\% & LS95\% & Média & DP & Mediana & $\begin{array}{l}\text { Mín - } \\
\text { Máx }\end{array}$ & LI95\% & LS95\% & \\
\hline Hemácias* & 3,06 & 0,82 & 2,96 & $1,41-4,34$ & 2,562 & 3,556 & 3,17 & 0,99 & 3,21 & $1,3-4,97$ & 2,625 & 3,717 & 0,749 \\
\hline Hemoglobina* & 8,35 & 2,30 & 7,9 & $3,8-12,2$ & 6,966 & 9,742 & 8,74 & 2,66 & 8,2 & $4,0-14,4$ & 7,269 & 10,211 & 0,687 \\
\hline Hematócrito* & 25,77 & 6,68 & 24,9 & $11,8-36,0$ & 21,731 & 29,807 & 27,19 & 8,62 & 25,5 & $11,9-46,1$ & 22,418 & 31,969 & 0,633 \\
\hline Plaquetas* & 343,77 & 107,99 & 289,00 & $201-493$ & 278,511 & 409,027 & 231,80 & 150,45 & 276.00 & $21-483$ & 148,484 & 315,116 & 0,035 \\
\hline Cálcio**** & 8,20 & 0,65 & 8,3 & $7,1-9,0$ & 7,8 & 8,7 & 9,12 & 2,15 & 8,8 & $6,4-15,2$ & 8,0 & 10,1 & 0,213 \\
\hline $\mathrm{TAP}^{* \star * *}$ & 12,66 & 1,35 & 12,3 & $10,3-16,0$ & 12,0 & 13,4 & 13,49 & 2,60 & 12,5 & $10,4-19,5$ & 11,55 & 15,0 & 0,751 \\
\hline $\mathrm{INR}^{* \star \star *}$ & 1,14 & 0,11 & 1,1 & $1-1,43$ & 1,075 & 1,2 & 1,17 & 0,17 & 1,095 & $0,99-1,59$ & 1,055 & 1,265 & 0,941 \\
\hline PTTa* & 27,09 & 3,52 & 27,7 & $22,4-34,3$ & 24,968 & 29,216 & 25,50 & 4,71 & 26,65 & $17,8-35,3$ & 22,783 & 28,217 & 0,331 \\
\hline
\end{tabular}

TAP: Tempo de Protrombina em segundos

INR: Razão Normalizada Internacional

PTTa: Tempo de Tromboplastina Ativa

LI $95 \%$ e LS95\% - Respectivamente, limites inferior e superior do intervalo de confiança de 95\% para a média

${ }^{*}$ Test $\mathrm{t}$

** Teste Exato de Fischer

*** Teste Qui-quadrado

**** Wilcoxon-Mann-Whitney

$* * * * *$ Brunner-Munzel 
Nos dados da Tabela 7, observa-se que houve diferença estatisticamente significante somente para as plaquetas $(p=0,035)$. Ao observar a variação das medianas, constata-se que o grupo COR concentrou todas as pacientes plaquetopênicas do estudo.

Os níveis de hemoglobina encontraram-se globalmente abaixo dos valores de referência e o mesmo repetiu-se em relação aos valores de hematócrito.

Em relação aos marcadores de coagulograma (TAP, INR e PTTa), o TAP obteve valores ligeiramente elevados (alargados) em ambos os grupos, com elevação discretamente maior no grupo COR. O INR e o PTTA mantiveram-se dentro dos valores de referência.

Os dados da Tabela 8 apresentam os resultados derivados da mensuração dos sinais vitais das participantes do estudo. 
Tabela 8 - Valores correspondentes aos sinais vitais de mulheres com FNM sangrantes decorrentes de câncer de mama, conforme o grupo. Rio de Janeiro, 2017-2018

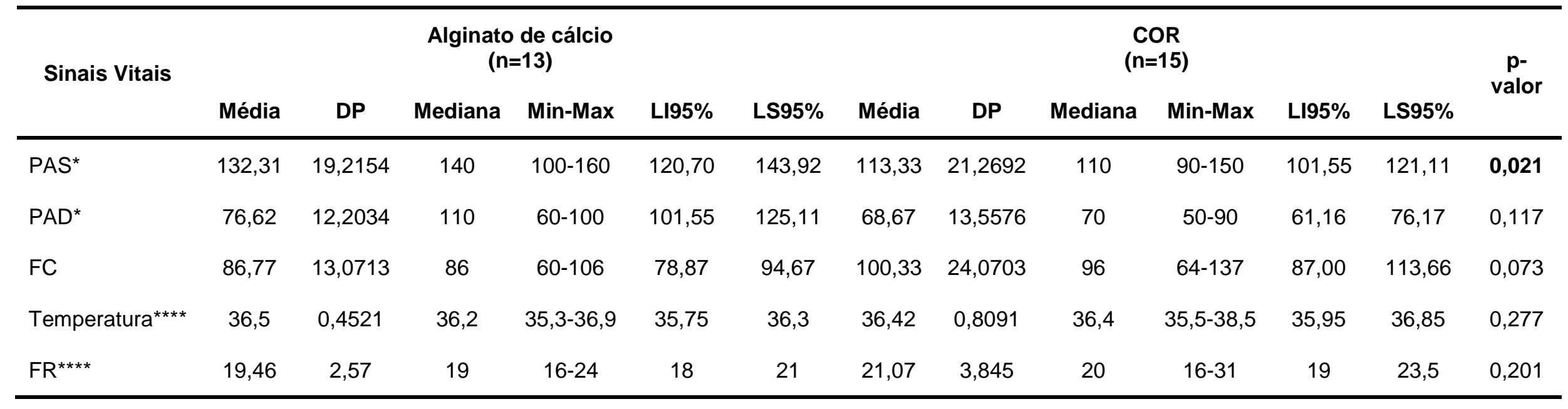

LI95\% e LS95\% - Respectivamente, limites inferior e superior do intervalo de confiança de 95\% para a média.

PAS: pressão arterial sistêmica. PAD: pressão arterial diastólica. FC: frequência cardíaca. FR: frequência respiratória.

*Test $t$ de Student

** Teste Exato de Fischer

*** Teste Qui-quadrado

**** Wilcoxon-Mann-Whitney

$* * * * *$ Brunner-Munzel 
Para os resultados de sinais vitais (Tabela 8), houve diferença estatisticamente significante apenas para a PAS ( $p$-valor=0,021), com mediana do grupo controle compatível com HAS.

A seguir, são apresentadas tabelas referentes aos resultados sobre os desfechos do estudo.

Os dados da Tabela 9 apresentam os resultados da análise descritiva do TTH, em cada grupo.

Tabela 9 - TTH de FNM sangrantes por câncer de mama, conforme o grupo. Rio de Janeiro, 2017-2018

\begin{tabular}{lcccc}
\hline Grupo & $\begin{array}{c}\text { Tempo } \\
\text { médio/segundos }\end{array}$ & Mediana & LI95\% & LS95\% \\
\hline Alginato de Cálcio & 67,0 & 30,4 & 27,1 & - \\
COR & 93,8 & 30,1 & 18,6 & 189 \\
\hline
\end{tabular}

- Sem precisão

LI95\% e LS95\% - Respectivamente limites inferior e superior do intervalo de confiança de $95 \%$ para tempo médio até a ocorrência de hemostasia.

Descritivamente, observa-se que o TTH foi menor no grupo AC, porém, com valores de medianas muito similares àqueles obtidos no grupo COR. Não foi possível identificar com precisão o IC 95\% superior no grupo controle. 
Os dados da Figura 10 ilustram como a hemostasia ocorreu ao longo do tempo, nos diferentes grupos (Curva de Kaplan-Meier).

Figura 10 - Hemostasia das FNM ao longo do tempo, conforme o grupo. Rio de Janeiro, 2017-2018

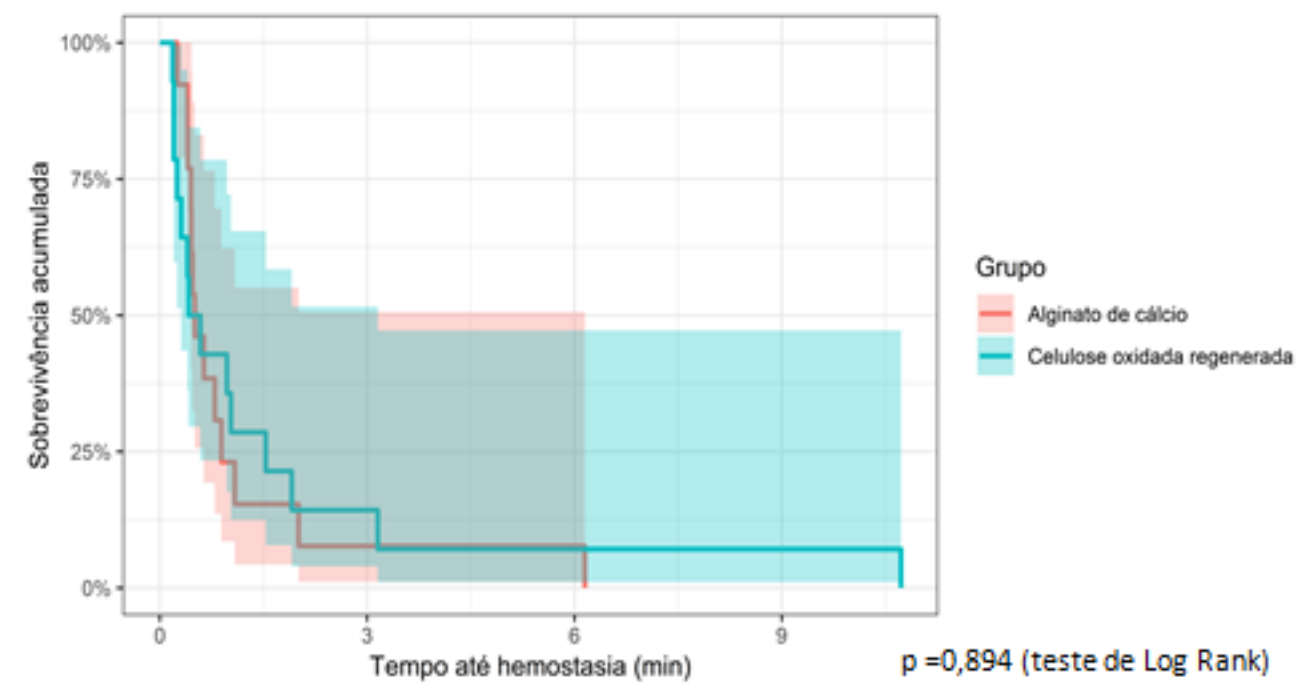

Verifica-se que todas as pacientes de ambos os grupos atingiram a hemostasia até o tempo aproximado de 11 minutos e não houve evidência de diferença de TTH entre os grupos ( $p=0,894)$. 
Os dados da Tabela 10 apresentam os resultados sobre os efeitos dos produtos hemostáticos sobre o TTH, controlando-se as variáveis DM, comorbidades, plaquetas e PAS que se apresentaram distintas por grupo (conforme mostrados nas Tabelas 2,7 e 8).

Tabela 10 - Análise multivariada das variáveis independentes exploratórias (Modelo de Cox) para hemostasia em FNM sangrantes em mulheres acometidas pelo câncer de mama. Rio de Janeiro, 2017-2018

\begin{tabular}{lccc}
\hline Variável & HR ajustado & IC 95\% & p valor \\
\hline Celulose Oxidada Regenerada & 1.342 & $0.432-4.174$ & 0.611 \\
DM & 1.614 & $0.549-4.743$ & 0.384 \\
Comorbidades & 0.633 & $0.288-1.761$ & 0.381 \\
Plaquetas & 1.000 & $0.997-1003$ & 0.998 \\
PAS & 1.015 & $0.991-1.040$ & 0.218 \\
\hline
\end{tabular}

$\mathrm{DM}=$ Diabetes melittus

PAS = Pressão Arterial Sistólica

Os resultados da Tabela 10 mostram que não há evidência de diferenças de TTH por tipo de produto hemostático $(\mathrm{p}=0.611)$, quando se controlam as variáveis DM, comorbidades, plaquetas e PAS, diferentes estatisticamente entre os grupos. 
Os dados da Tabela 11 apresentam a probabilidade de alcance de hemostasia (Curva de Sobrevivência), considerando-se os momentos chave (30 segundos, 1, 3 e 5 minutos), ao longo do tempo.

Tabela 11 - Probabilidade de alcance de hemostasia de FNM sangrantes em mulheres acometidas pelo câncer de mama. Rio de Janeiro, 2017-2018

\begin{tabular}{|c|c|c|c|c|}
\hline \multirow{3}{*}{ Grupos } & \multicolumn{4}{|c|}{ Tempo } \\
\hline & $\begin{array}{c}30 \\
\text { segundos }\end{array}$ & $\begin{array}{c}1 \\
\text { Minuto }\end{array}$ & $\begin{array}{c}3 \\
\text { Minutos }\end{array}$ & $\begin{array}{c}5 \\
\text { Minutos }\end{array}$ \\
\hline & $\%$ média & \% média & \% média & \% média \\
\hline Alginato de Cálcio & $53,85 \% \pm 13,83 \%$ & $23,89 \% \pm 11,69 \%$ & $7,69 \% \pm 7,39 \%$ & $7,69 \% \pm 7,39 \%$ \\
\hline COR & $50,00 \% \pm 13,36 \%$ & $35,71 \% \pm 12,81 \%$ & $14,29 \% \pm 9,35 \%$ & $7,14 \% \pm 6,88 \%$ \\
\hline
\end{tabular}

Teste de Log-Rank: $p=0,894$

Sobrevida acumulada \pm Erro-Padrão

Os dados da Tabela 11 mostram que, numericamente, a maior diferença de probabilidade para alcance de hemostasia está no primeiro minuto, incluindo-se os 30 segundos iniciais, para as mulheres de ambos os grupos. As pequenas diferenças numéricas encontradas entre os grupos não possuem significado estatístico $(p=0,894)$, conforme se verifica na Figura 10. Constata-se que a probabilidade de uma paciente não ter alcançado hemostasia aos 30 segundos é em torno de $50 \%$ e pouco mais de $7 \%$ no $5^{\circ}$. minuto para a COR.

Os dados da Tabela 12 apresentam descritivamente a proporção de mulheres que conseguiram hemostasia nos tempos 30 segundos, 3, 5 e 10 minutos.

Tabela 12 - Distribuição das mulheres que alcançaram hemostasia de FNM mamárias conforme tipo de tratamento hemostático, tempo de hemostasia e porcentagem. Rio de Janeiro, 2017-2018

\begin{tabular}{lcccc}
\hline Tipo de tratamento & $\begin{array}{c}\mathbf{3 0} \text { segundos } \\
\mathbf{n}(\%)\end{array}$ & $\begin{array}{c}\mathbf{3} \text { minutos } \\
\mathbf{n}(\%)\end{array}$ & $\begin{array}{c}\mathbf{5} \text { minutos } \\
\mathbf{n}(\%)\end{array}$ & $\begin{array}{c}\mathbf{1 0} \text { minutos } \\
\mathbf{n}(\%)\end{array}$ \\
\hline AC $(\mathrm{n}=13)$ & $6(46,1)$ & $12(92,2)$ & $12(92,2)$ & $13(100)$ \\
COR $(n=14)^{(1)}$ & $7(50)$ & $12(85,7)$ & $12(85,7)$ & $13(92,8)$ \\
\hline
\end{tabular}

(1) = 1 caso sem informação no grupo COR 
Observa-se que, até no período dos 5 até aos 10 minutos, todos as pacientes no grupo controle $A C$ alcançaram a hemostasia e uma no grupo da COR não alcançou. Assim, considerando o desfecho proporção de pacientes que alcançaram a hemostasia na FNM dentro do tempo limite de 20 minutos, observa-se que todas as pacientes em ambos os grupos alcançaram hemostasia.

Quanto ao desfecho ressangramento, detectado até 5 minutos de observação, depois de confirmada a hemostasia tópica, ocorreu em duas mulheres no grupo COR. Não houve ressangramento detectado entre o período de tempo correspondente ao término do curativo até à avaliação dos resultados dos exames laboratoriais (seguimento) e liberação das pacientes. Sete pacientes $(25,92 \%)$ necessitaram de mais de uma unidade de produto hemostático para controle do sangramento das FNM, sendo duas pacientes no grupo AC e cinco no grupo COR. Houve maior consumo de unidades no grupo $\mathrm{COR}$, no qual utilizaram quatro vezes mais hemostáticos (20 unidades) comparativamente ao AC (5 unidades). Considerando-se que as demais pacientes utilizaram somente uma unidade cada uma, obtiveram-se 36 unidades de COR (2,6 unidades/ paciente) e 16 unidades de alginato de cálcio ( 1,2 unidade/ paciente).

Não houve danos/efeitos adversos. 


\section{DISCUSSÃO}

O presente estudo avaliou a eficácia de hemostático tópico à base de celulose oxidada regenerada em comparação ao curativo de alginao de cálcio, no controle de sangramento de FNM em mulheres com câncer de mama, por meio da mensuração do TTH, da proporção de mulheres que alcançaram hemostasia, ocorrência de ressangramento e número de produtos hemostáticos tópicos utilizados.

É relevante considerar que as amostras de ambos os grupos não apresentaram diferenças estatisticamente significantes após análise multivariada independente exploratória (Modelo de Cox) quanto à idade, tabagismo, comorbidades, uso de medicações coagulativas e anticoagulantes, tipo histológico e estadiamento dos tumores, tratamentos oncológicos pregressos e atuais, estadiamento e presença de sinais e sintomas nas feridas, tipos de coberturas, marcadores sanguíneos de coagulação, níveis de hemoglobina, hematócrito e níveis séricos de cálcio. Ainda que o grupo COR tenha incluído mais pacientes com comorbidades, diabéticos e plaquetopênicos, e o grupo AC, mais pacientes com aumento de PAS, tais variáveis não apresentaram diferenças estatísticas quando ajustadas pelo modelo de regressão de Cox, considerando o tipo de curativo empregado.

Para o TTH, desfecho primário do estudo, elaborou-se a hipótese de diferença de tempo médio de 5 minutos que fundamentou, inclusive, o cálculo amostral. Não havendo informações para delineá-lo, além do desenho de ECR na hemostasia tópica de FNM, consideraram-se estudos de hemostasia cirúrgica em humanos. No entanto, o padrão de TTH obtido foi distinto do esperado, sendo sensivelmente menor quando comparado aos demais ECR de hemostasia cirúrgica. Neste estudo, na conversão matemática para minutos, o TTH do grupo AC resultou em arredondamento para 1 minuto, e no grupo COR, para 1,5 minutos (um minuto e meio), confirmando diferença descritiva de apenas meio minuto, ou seja, 30 segundos, sem diferença significativa entre os grupos $(p=0,894)$. As medianas foram muito parecidas.

Em ECR conduzido por Kakaei et al. (2013) ${ }^{141}$, no qual os autores compararam o efeito de diferentes hemostáticos em cirurgia de ressecção de fígado 
( $\mathrm{N}=45)$, o TTH médio da COR $(\mathrm{n}=15)$ foi 3,26 (DP = 1,48). Constata-se que este TTH foi 2,8 vezes maior que o apresentado com a aplicação da COR na hemostasia das FNM no estudo desenvolvido nesta tese.

Estudo de ECR multicêntrico, conduzido por Hanks et al. (2003) ${ }^{142}$, utilizou a COR no grupo controle $(n=34)$ para investigar a eficácia de hemostático tópico à base de fibrina, do tipo selante de tecido (Vivostat $\left.{ }^{\circledR}\right) \quad(n=35)$ em cirurgias cardiotorácicas, gerais e vasculares, encontrando valores parecidos ao estudo de Kakaei et al. $(2013)^{141}$. O TTH médio para a COR foi 3,3 minutos $(D P=1,7)$ e mediana 3,2, ou seja, 2,2 vezes maior quando comparado ao TTH da COR na hemostasia das FNM.

ECR mais recente, desenvolvido por Lakshman et al. (2018) ${ }^{143}$ para investigar a eficácia de outro tipo de hemostático tópico do tipo selante de tecido (FS Grifols) ( $n=116)$, utilizou a COR como grupo controle $(n=108)$. O estudo foi desenhado para atestar a não inferioridade do selante de tecido comparado à COR na hemostasia de cirurgias gerais, urológicas e ginecológicas. O TTH médio da COR foi 3,0 minutos, ou seja, duas vezes maior que o TTH das FNM.

Reportando-nos aos dados do estudo COBBANNA ${ }^{123}$, que embasaram o cálculo amostral para o presente estudo, o tempo médio gasto para que a COR realizasse hemostasia em anastomoses de safenas foi 6,9 ( $D P=3,8$ minutos) e, portanto, bastante superior ao TTH aqui encontrado para o mesmo hemostático tópico (cinco vezes).

TTH médio bastante superior para a COR foi também encontrado no estudo de Schenk et al. (2003) ${ }^{144}$, quando avaliaram a eficácia de hemostático do tipo selante de tecido à base de fibrina em pacientes $(\mathrm{N}=48)$ submetidos à cirurgia vascular periférica, com anticoagulação no período intraoperátorio, tal como no estudo COBBANNA. A COR apresentou TTH médio de 12 minutos, ou seja, oito vezes maior que o tempo médio da COR aplicada à hemostasia das FNM.

Assim, os estudos de hemostasia cirúrgica mostraram TTH médio da COR de duas a oito vezes maior ao TTH que a COR apresentou na hemostasia clínica das FNM mamárias do estudo desenvolvido nesta tese.

No ECR realizado por Sintler et al. $\left(2005^{127}\right)(\mathrm{N}=20$ pacientes submetidos à endarterectomia de carótidas), também considerado para o cálculo amostral desta pesquisa, o TTH médio para a hemostasia promovida pelo AC foi 17 minutos (com variância entre 7 e 59 minutos), ou seja, 17 vezes maior que o TTH médio 
apresentado pelo AC na hemostasia tópica das FNM mamárias, da mesma maneira como ocorreu para a COR nos estudos mencionados anteriormente. Este resultado permite inferir que o TTH médio utilizado nas considerações sobre hemostasia do $\mathrm{AC}$ no estudo aqui desenvolvido foi superestimado, tal como ocorreu a COR, ao se considerar os estudos de hemostasia cirúrgica em humanos.

Em estudos experimentais in vivo, os resultados são controversos. Velázquez-Aviña et al (2014) ${ }^{91}$ testaram a COR para hemostasia de ressecção de mucosa gástrica, por endoscopia, em ratos e porcos anticoagulados. O TTH médio final do estudo foi 40,5 (19-90) segundos, dado mais próximo aos resultados constatados no presente estudo. Contrariamente, no estudo experimental pioneiro de Blair et al. (1988) ${ }^{145}$, para investigar a eficácia hemostática de alginato de cálcio $\left(\right.$ Kaltostat $\left.^{\circledR}\right)$ gaze, COR (Surgicel ${ }^{\circledR}$ ) e colágeno suíno (Medistat $^{\circledR}$ ) na hemostasia de laceração de fígado de ratos $(\mathrm{N}=42)$, TTH inferior a 3 minutos foi verificado em todos os animais do grupo AC comparado com a média de 5,7 (DP=0,75) minutos para o colágeno, 12,09 $(\mathrm{DP}=0,9)$ minutos para a COR e mais de 15 minutos para a gaze. TTH médio elevado para a COR, portanto, foi similar àquele obtido no estudo in vivo de Schenk et al; (2003) ${ }^{144}$.

$\mathrm{Na}$ presente tese, apenas um paciente do grupo COR alcançou hemostasia aos 11 minutos, porém o fato explica-se pela variação amostral (outlier).

As diferenças encontradas em relação à hemostasia cirúrgica ficam mais evidentes ao se analisarem os TTH em proporções, conforme marcos cronológicos.

Os dados do Quadro 5 apresentam os tempos alcançados com o emprego da COR nos estudos de hemostasia cirúrgica, considerados no desenvolvimento do estudo desta tese. 
Quadro 4 - Tempos de hemostasia alcançados pela COR informados nos estudos de hemostasia cirúrgica e proporção de pacientes que os alcançaram

\begin{tabular}{|c|c|c|c|c|}
\hline ESTUDO & TIPO DE CIRURGIA & $\begin{array}{c}3 \text { MINUTOS } \\
n(\%)\end{array}$ & $\begin{array}{c}5 \text { MINUTOS } \\
n \text { (\%) }\end{array}$ & $\begin{array}{c}10 \text { MINUTOS } \\
\text { n (\%) }\end{array}$ \\
\hline Schenk et al. $\left(2003^{144}\right)$ & \multirow{2}{*}{$\begin{array}{l}\text { Anastomose de Shunt } \\
\text { arteriovenoso para } \\
\text { colocação de cateter } \\
\text { de diálise }\end{array}$} & & \multirow[t]{2}{*}{-} & \multirow[t]{2}{*}{$7(50,0)$} \\
\hline $\begin{array}{l}\text { Fibrina selante }(n=24) x \\
\text { COR }(n=14)\end{array}$ & & & & \\
\hline Hanks et al. $\left(2003^{142}\right)$ & \multirow{2}{*}{$\begin{array}{l}\text { Geral,cardiotorácica } \\
\text { obstétrica/ginecológica } \\
\text { e vascular }\end{array}$} & \multirow[t]{2}{*}{-} & \multirow[t]{2}{*}{$12(35,3)$} & \multirow[t]{2}{*}{-} \\
\hline $\begin{array}{l}\text { Fibrina selante }(n=35) x \\
\text { COR }(n=34)\end{array}$ & & & & \\
\hline Qerimi et al. $\left(2013^{123}\right)$ & \multirow{2}{*}{$\begin{array}{l}\text { Anastomoses de } \\
\text { safenas }\end{array}$} & \multirow[t]{2}{*}{$8(25,0)$} & \multirow[t]{2}{*}{$11(34,0)$} & \multirow[t]{2}{*}{$13(41,0)$} \\
\hline $\begin{array}{l}\text { Colageno microfibrilar } \\
(n=32) \times \operatorname{COR}(n=32)\end{array}$ & & & & \\
\hline Fischer et al. $\left(2013^{140}\right)$ & \multirow{2}{*}{$\begin{array}{l}\text { Abdome, } \\
\text { retroperitôneo, pelve e } \\
\text { torácica não cardiáca }\end{array}$} & \multirow[t]{2}{*}{-} & \multirow[t]{2}{*}{-} & \multirow[t]{2}{*}{$22(73,3)$} \\
\hline $\begin{array}{l}\text { Fibrina selante }(n=60) x \\
\text { COR }(n=30)\end{array}$ & & & & \\
\hline Genyk et al. $\left(2016^{124}\right)$ & \multirow[t]{2}{*}{ Ressecção de fígado } & \multirow[t]{2}{*}{$55(50,0)$} & \multirow[t]{2}{*}{$75(76,4)$} & \multirow[t]{2}{*}{$87(87,9)$} \\
\hline $\begin{array}{l}\text { Fibrina selante }(n=101) x \\
\text { COR }(n=99)\end{array}$ & & & & \\
\hline Lanksman et al. $\left(2018^{143}\right)$ & \multirow{2}{*}{$\begin{array}{l}\text { Geral, urológica e } \\
\text { ginecológica }\end{array}$} & \multirow[t]{2}{*}{$65(60,2)$} & \multirow[t]{2}{*}{$85(78,7)$} & \multirow[t]{2}{*}{$90(83,3)$} \\
\hline $\begin{array}{l}\text { Fibrina selante }(n=116) x \\
\text { COR }(n=108)\end{array}$ & & & & \\
\hline
\end{tabular}

- dado não informado no estudo

Observa-se que a eficácia hemostática da COR em prover hemostasia até o limite de tempo de 10 minutos variou entre $41,0 \%$ e $87,9 \%$ nos estudos de hemostasia cirúrgica, ou seja, em cerca de $12 \%$ dos casos de sangramento, a COR não foi eficaz.

Cabe destacar que, em estudos de hemostasia cirúrgica, quando o hemostático tópico não forneceu hemostasia até o tempo limite de 10 minutos foi considerado "falho"123-124,10,143-144. No presente estudo, o tempo limite adotado foi 20 minutos, de modo que não se pode falar em hemostático falho. Mas, se comparado aos estudos de hemostasia cirúrgica, a COR falhou em apenas um caso $(7,2 \%)$ e não houve esta ocorrência no grupo controle, até os 10 minutos, sem diferença 
estatisticamente significante entre os grupos. Estudos futuros com amostras maiores poderiam esclarecer estes achados, especificamente, nos casos de sangramentos intensos, pouco frequentes em nosso estudo.

Tendo em vista os TTH dos estudos cirúrgicos, experimentais e aqueles constatados no estudo desenvolvido nesta tese, pode-se recomendar a adoção de marcos cronológicos de 30 segundos, 3 minutos, 5 minutos e o tempo limite de 10 minutos em estudos futuros sobre hemostasia em FNM.

Quanto ao desfecho ressangramento, o mesmo ocorreu em apenas duas $(14,3 \%)$ das mulheres no grupo COR, após 5 minutos do estabelecimento de hemostasia. As FNM ressangrantes tinham sangramento do tipo intenso, predominante no grupo COR (Tabela 6).

Em relação ao desfecho de segundo tipo de ressangramento, o mesmo não foi apresentado por nenhuma mulher no estudo. A percepção de sangue no curativo externo é um marcador de eficácia hemostática frágil, porque o curativo não é reaberto para inspeção direta e constatação de novo sangramento. Adicionalmente, os curativos são volumosos para fornecer absorção maior às FNM que são, geralmente, exsudativas (vide Tabela 5). No entanto, a reabertura do curativo para inspeção direta de ressangramento poderia expor a paciente ao risco de sangramento tumoral adicional, em razão da característica de friabilidade das FNM, não tendo sido, portanto, realizada; tal como não é feita na prática clínica real.

Em relação ao número de produtos hemostáticos utilizados, último desfecho listado no ECR aqui desenvolvido, observa-se que, dentre a amostra, sete $(25,92 \%)$ pacientes necessitaram de mais de uma unidade de produto hemostático. Na comparação por grupos, cinco eram pacientes do Grupo COR e utilizaram quatro vezes mais hemostáticos, quando comparados às mulheres do grupo AC. No estudo COBBANA $^{123}, 21$ (66\%) dentre 32 pacientes que utilizaram a COR, em quaisquer uma de suas anastomoses, necessitaram de um segundo hemostático, totalizando 53 unidades gastas comparativamente a nenhuma no grupo intervenção, o que significa gasto de 1,6 unidades por paciente no grupo COR. No estudo aqui desenvolvido, o consumo foi 2,6 unidades de COR por paciente comparativamente a 1,2 unidades de $A C$ por paciente. Destaca-se, porém, que, três dentre cinco pacientes do grupo COR tinham FNM com sangramento intenso e dois pacientes com FNM de sangramento moderado; enquanto havia somente uma paciente com sangramento intenso e outra com sangramento moderado no grupo AC. 
Provavelmente, a concentração de pacientes com sangramento intenso no grupo COR influenciou o resultado deste desfecho.

Por outro lado, a diferença na quantidade de hemostáticos utilizados pode ser explicada pelo baixo poder de absorção da COR. Contrariamente, o AC tem destacado poder absorvente. Estudos que avaliaram sua capacidade hemostática mostram que o AC absorve até 20 vezes seu peso, e a COR, até sete vezes. Em estudo conduzido por Blair e Salmon (1990) ${ }^{145}$, para testar o uso de AC em cirurgias humanas, os pesquisadores identificaram que o alginato tem capacidade de absorção quatro vezes maior que a gaze; e a COR tem pequena capacidade absorvente, sendo considerada um hemostático fraco e caro ${ }^{145}$.

Estudo in vitro ${ }^{146}$, que utilizou sangue de pessoas saudáveis e pacientes em uso regular de medicações anticoagulantes orais, investigou o potencial hemostático e as propriedades físicas de diferentes tipos de coberturas utilizadas em lesões superficiais, incluindo dois tipos de AC e a COR. O AC com carboximetilcelulose, tal como o tipo utilizado no presente estudo, apresentou a maior capacidade de absorção comparativamente a qualquer outra cobertura, incluindo a COR, que mostrou a menor capacidade de absorção entre todos. Os autores afirmam que a capacidade absorvente dos alginatos lhes confere vantagens na coagulação sanguínea. Este estudo reforça a afirmação de Blair et al. (1990) ${ }^{145}$ em relação à baixa absorção da COR frente ao AC. Nesta tese, a maior capacidade absorvente de $A C$, certamente, influenciou no número de produtos utilizados, maior para a COR comparativamente ao AC. Há que se ressaltar ainda que a maior concentração de sangramento intenso em FNM no grupo COR tornou a avaliação de sua eficácia inconclusiva em relação a esse desfecho, quando comparada ao grupo controle. Provavelmente, amostra numericamente maior considerando subgrupos de sangramento leve, moderado e intenso, proporcionaria outra condição de distribuição que permitiria, então, melhor avaliação para este desfecho.

O estudo aqui conduzido teve por finalidade tecer análise sobre 0 sangramento global das FNM mamárias.

Até onde podemos saber, trata-se do primeiro estudo a analisar tempo de hemostasia neste tipo de ferida, o que o caracteriza como um estudo inovador e importante para um país em desenvolvimento. 


\section{CONTRIBUIÇÕES, LIMITAÇÕES E RECOMENDAÇÕES}




\section{CONTRIBUIÇÕES, LIMITAÇÕES E RECOMENDAÇÕES}

Os resultados do presente estudo contribuem para o melhor embasamento da opinião de especialistas que indicam ambos os produtos para a hemostasia das FNM, em geral, uma vez que ambos demonstraram capacidade hemostática nas FNM em mulheres com câncer de mama. Anteriormente a este estudo, o dado era inexistente. Assim, o estudo vem valorizar tal conduta dos especialistas. Outra contribuição de destaque diz respeito às informações estatísticas, de fluxo de pacientes e modos de intervenções que poderão auxiliar no melhor delineamento de novos estudos sobre o tema. A partir das perspectivas deste estudo, protoloclos de condutas poderão ser desenvolvidos e incorporados na prática clínica.

Contribuições secundárias relevantes relacionam-se à própria discussão sobre um tema tão pouco frequente na literatura atual, mas, de intenso impacto negativo na qualidade de vida de pacientes com câncer avançado. Um grupo distinto de pacientes que, paulatinamente, alcança maior tempo de sobrevida, necessitando de medidas de cuidados de suporte que os auxiliem a conviver melhor com suas $\mathrm{FNM}^{147}$.

Limitações do estudo referem-se à impossibilidade de cegamento dos produtos, o que se justifica pela natureza do fenômeno. Para diminuir esta limitação, procedeu-se à ratificação do alcance de hemostasia por outro profissional de saúde, retirando da pesquisadora principal a tarefa de definir isoladamente a eficácia do hemostático. Nesse sentido, outra ação realizada no estudo foi o "cegamento" da tela do cronômetro digital à pesquisadora principal, mesmo sendo informada do decorrer cronológico de tempo enquanto o processo de hemostasia ocorria. Ambas serviram como ações de mascaramento frente à natureza peculiar dos produtos envolvidos no estudo e possível interferência, ainda que inconsciente, da pesquisadora principal que exerceu a pressão digital em todos os casos do estudo.

É importante acrescentar que os instrumentos aqui utilizados para avaliação do sangramento e das feridas não foram adaptados culturalmente e validados para o Brasil, particularmente, aquele empregado na avaliação das FNM. Este já vem sendo usado sistematicamente no INCA, após tradução livre, desde 200557,147. Já a escala para classificação de sangramento foi traduzida livremente pela pesquisadora 
principal, necessitando de adaptação cultural e validação. Apesar da ausência de adaptação cultural e validação e como se trata de um instrumento clínico, optou-se por sua utilização apenas traduzida buscando sitematização nesse processo avaliativo e redução de riscos de uma avaliação mais subjetiva.

O estudo incluiu pacientes que recebiam medicações coagulantes por via sistêmica, o que poderia interferir nos desfechos. No entanto, estas não foram excluídas do estudo pelo fato de que, no cenário real, constituem os principais pacientes que se utilizam dos produtos testados nos experimentos aqui conduzidos. Adicionalmente, o sangramento em FNM é pouco frequente, e a captação de pacientes sem uso de medicações coagulantes ou anticoagulantes aumentaria demasiadamente o tempo para a coleta de dados. Para minimizar esse problema, variáveis de confusão foram definidas e controladas nas análises estatísticas.

Outra limitação do estudo se deu em relação à técnica de compressão manual que foi associada à aplicação dos produtos, onde a força manual exercida não foi mensurada. Para minimizar este viés, a pesquisadora principal do estudo assumiu a função de exercer compressão em todas as feridas incluídas no estudo, de modo que pudesse ser seguido um certo padrão de compressão executado sempre pela mesma pessoa.

O pequeno tamanho amostral resultou de seu planejamento ter sido fundamentado em estudos de hemostasia cirúrgica, projetando-se a detecção de uma diferença média de tempo de hemostasia bastante superior àquela mensurada e obtida durante o estudo. Reitera-se que o evento investigado é raro, imprevisível quanto à sua ocorrência, forma de apresentação, intensidade e controle.

Ao finalizar esta tese, inúmeras recomendações advêm, algumas das quais já mencionadas anteriormente.

O desenvolvimento de ECR futuros de eficácia hemostática em FNM é recomendável, incluindo amostras maiores qu permitam considerar subgrupos de sangramento, em diferentes e múltiplos centros oncológicos, considerando FNM de outras etiologias, bem como estudos observacionais que possam contribuir para a caracterização do perfil do sangramento delineando de maneira mais consistente e a associação entre o sangramento e variáveis pouco ou não discutidas neste estudo, como o perfil de plaquetas, coagulação, comorbidades, HAS, DM, estadiamento de FNM e níveis de Ki 67. 
Estudos de adaptação cultural dos instrumentos utilizados nesta pesquisa, quais sejam o Sistema de Estadiamento das FNM e da Escala de Avaliação de Sangramento, são desejáveis.

Adicionalmente, recomenda-se estudos de custos para norterar a melhor tomada de decisão e o aprimoramento de protocolos clínicos considerando o uso de hemostáticos mais avançados para sangramentos que ultrapassem o tempo limite de 10 minutos, para além do uso de AC e COR. 


\section{CONCLUSÃO}

Os resultados do presente ECR, conduzido com 28 mulheres em vigência do sangramento de FNM decorrentes de câncer de mama, mostraram que:

- Não houve evidência estatística de diferença entre os grupos COR e AC quanto ao tempo total de hemostasia;

- Aos 30 segundos, a probabilidade de alcançar hemostasia foi, aproximadamente, $50 \%$ em ambos os grupos; a partir do 5\%. minuto, a probabilidade de não se obter hemostasia foi inferior a $10 \%$, utilizando qualquer um dos dois produtos testados;

- Dentre as pacientes do estudo, duas apresentaram ressangramento quando expostas ao tratamento pela COR; e

- Houve consumo de produtos hemostásticos quatro vezes maior no grupo que utilizou COR.

Não houve evidência de diferença de eficácia da COR versus $A C$ na hemostasia das FNM mamárias quanto ao tempo de hemostasia e proporção de pacientes que a alcançaram. A avaliação de eficácia quanto ao número de ressangramentos e quantidade de produtos utilizados, na comparação com o AC, tradicionalmente empregado, foi inconclusiva. 


\section{Referências}

1 Seaman S, Bates-Jensen M. Skin disorders. Malignant wounds, fistulas, and stomas. In: Ferrell BR, Coyle N, Paice JÁ, editors. Oxford Textbook of Palliative Nursing.4 ${ }^{\mathrm{a}}$ Ed. New York: Oxford University Press; 2015. p:325-40.

2 Mayer JE, Maurer MA, Nguyen HT. Diffuse cutaneous breast cancer metástases resembling subcutaneous nodules with no surface changes. Cutis ${ }^{\circledR}$. 2018;101(3):21923.

3 Gao RW, Edlund S, Yun J. Dramatic Regression of a Fungating Breast Lesion Treated with Radiation Therapy. Cureus [Internet]. 2017 [cited 2018 Nov. 10]; 9(6):e1360. Available https://www.ncbi.nlm.nih.gov/pmc/articles/PMC5510970/pdf/cureus-0009from: 00000001360.pdf.

4 Watanabe M, Matsuoka R, Ichimura Y, Takagaki T, Litsuka Y. Papillotubular carcinoma with an invasive micropapillary carcinoma componente of the breast, characterized by a rapid increase in size due to intra-tumoral hemorrhage: a case report. Int J Surg Case Rep. 2017;38:189-91.

5 Kelati A, Gallouy S. Dermoscopy of skin metastases from breast cancer: two case reports. J Med Case Rep. [Internet]. 2018 [cited 2018 Dez 02]; 12:273.Available from:

https://www.ncbi.nlm.nih.gov/pmc/articles/PMC6151035/pdf/13256_2018_Article_180 3.pdf

6 Tilley C, Lipson J. Ramos M. Palliative wound care for malignant fungating wounds. Holistic considerations at end-of-life. Nurs Clin N Am. 2016; 51:513-31.

7 Lo SF, Hayter M, Hu WY, Tai CY, Hsu MY, Li YF. Symptom burden and quality of life in patients with malignant fungating wounds. JAN. 2011;68(6);1312-1321.

8 Alexander SJ. An intense and unfogettable experience: the lived experience of malignant wounds from the perspectives of patients caregivers and nurses. Int Wound J. 2010;7:456-65.

9 Rowan S, Moffatt C. Olden A. Researching the lived experiences of cancer patients with malignant fungating wounds. Int J Palliat Nurs. 2015;21(12):579-85.

10 European Oncology Nursing Society - EONS. Education. Recommendations for the Care of Patients with Malignant Fungating Wounds. [Internet]. London: EONS; 2015 [cited 2016 Out 16]. Available from: http://www.cancernurse.eu/documents/EONSMalignantFungatingWounds.pdf. 
11 Maida V, Ennis M, Kuziemsky C, Trozzolo L. Symptoms associated with malignant wounds: a prospective case series. J Pain Symptom Manage. 2009;37(2):206-11.

12 Probst S, Arber A, Trojan A, Faithfull S. Caring for a loved one with a malignant fungating wound. Suupport Care Cancer 2012;20:3065-70.

13 Probst S, Arber A, Faithfull S. Malignant fungating wounds: a survey of nurses'clinical practice in Switzerland. Eur J Oncol Nurs 2009;13:295-98.

14 Azevedo IC, Costa RKS, Miranda de Holanda CS, Salvetti MG, Torres GV. Conhecimento de enfermeiros da Estratégia Saúde da Família sobre avaliação e tratamento de feridas oncológicas. Revista Brasileira de Cancerologia. 2014(2):11927.

15 Burratini ACB, Piteri RCO, Ferreira LF, Silveira JR VF, Broetto J, Richter CA. Segurança e viabilidade de um novo formato de retalho toracoepigástrico na reconstrução da parede torácica em câncer de mama localmente avançado: um estudo transversal. Rev.Bras.Cir.Plast. 2016;31(1):2-11.

16 Simos D, Clemons M, Ginsburg O, Jacobs C. Definition and consequences of locally advanced breast cancer. Curr Opinn Support Palliat Care. 2014;8:33-8.

17 Vempati P, Knoll MA, Dharmarajan K, Green S, Tiersten A, Bakst RL. Palliation of ulcerative breast lesions with radiation. Anticancer Res. 2016. 36:4701-5.

18 Rocha FBC, Formigoni MC, Lima BSS, Filassi JR, Baracat EC. Avaliação de incidência do câncer de mama localmente avançado no Instituto de Câncer do Estado de São Paulo. Rev. Latinoamericana de Mastología [Internet]. 2012 [citado em 2018 Dez. 02];9: 6(2). Disponível em: http://www.flamastologia.org/rlamastologia/index.php/journal/article/view/27.

19 Flores-Balcázar CH, Flores-Luna L, Villarreal-Garza C, Mota-Gárcia A, BargallóRocha E. Impact of delayed adjuvant radiotherapy in the survival of women with breast cancer. Cureus[Internet].2018 [cited 2018 Dez. 02];10(7):e3071.Available from: https://assets.cureus.com/uploads/original_article/pdf/12917/154360006220181130-5124-ifwuwp.pdf.

20 Panchal HP, Pilewskie ML, Sheckter CC, Albornoz CR, Razdan SN, Disa JJ. National trends in contralateral prophylactic mastectomy in women with locally advanced breast cancer. J Surg Oncol. 2019;119(1):79-87.

21 Kakimoto M, Toketa H, Okamura T, Yoshino K. A chemical hemostatic technique for bleeding from malignant wounds. J Palliat Med. 2010; 13(1):11-3.

22 Instituto Nacional de Câncer José Alencar Gomes da Silva [Internet]. Rio de Janeiro; 2018. [atualizado s/d citado 2018 dez. 5] Disponível em: http://www1.inca.gov.br/estimativa/2018/introducao.asp. 
23 GLOBOCAN. Global Cancer Observatory. Cancer today [Internet]. Lyon:France; [atualized 2018; cited 2018 Dez. 5]. Available from: https://gco.iarc.fr/today/home.

24 Ferlay J, Colombet M, Soerjomataram I, Mathers C, Parkin DM, Piñeros M, Bray F. Estimating the global câncer incidence and mortality in 2018: Globocan source and methods. Int J Cancer [internet] 2018 [cited 2018 Dez. 5]; Oct 23. [Epub ahead of print]. Available from: https://onlinelibrary.wiley.com/doi/epdf/10.1002/ijc.31937.

25 Abood RA. Breast cancer in Basra Oncology Center: a clinico-epidemiological analysis. Asian Pac J Cancer Prev. 2018;19(10):2943-6.

26 Falato C, Taylor SK, Szulkin R, Nordblom A, Erilsson L. Sofiadis A, et al. Prognosis inpatients diagnosed with loco-regional failure of breast cancer: 34 years longitudinal data from the Stockholm-Gotland cancer registry. Breast Cancer Res. Treat. 2018; 172:703-12.

27 Cazap E. Breast cancer in Latin America: a map of the disease in the region. Merican Society of Clinical Oncolgy - Asco. Educational Book. ASCO [Internet]: 2018 [cited 2018 Dez. 05]:451-6. Available from: http://ascopubs.org/doi/pdf/10.1200/EDBK_201315.

28 Fayer WA, Guerra MR, Cintra JRD, Bustamante-Teixeira MT. Sobrevida de dez anos e fatores prognósticos para o câncer de mama na região Sudeste do Brasil. Rev Bras Epidemiol. 2016;19(4):766-78.

29 Guerra MR, Zevedo e Silva G, Nogueira MC, Leita ICG, Carvalhaes de Oliveira RV, Cintra JRD, et al. Sobrevida por câncer de mama e iniquidade em saúde. Cad. Saúde Pública, Rio de Janeiro. 2015;31(8):1673-84.

30 Word Health Organization (WHO) [Internet]. Geneva. Switzerland. 2018 [cited 2018 Dez. 02]. Available from: http://www.who.int/cancer/en/.

31 Diaz EEF, Saito RF, Chammas R. Introdução ao câncer. In: Saito RF, Lana MVG, Medrano RFV, Chammas R. Fundamentos de Oncologia Molecular. São Paulo:Atheneu; 2015. p. 1-13.

32 Brentani, MM. Receptores de estrógeno e progesterona em câncer de mama. In: Brentani MM, Coelho FRG, lyeyasu H, Kowalski LP. Bases da Oncologia. São Paulo: Lemar, 2003, p:129-36.

33 Pang-Kuo Lo, Ji Shin Lee, Liang X, Sukumar S. The dual role of FoxF2 in regulation of DNA replication and the epithelial-mesenchymal transition in breast câncer progression. Cell Signal. 2016;28(10):1502-19.

34 Foxson SB, Lattimer JG; Felder B. Breast cancer. In: Yarbro CH, Wujcik D, Gobel $\mathrm{BH}$. Cancer Nursing. Principles and Practice. 7a․ Ed. USA:Jones and Bartlett Publishers; 2010. p: 1092-1145.

35 Stafim I, Caponi LGF, Torres TP, Araujo JN, Guedes VR. Fatores prognósticos no câncer de mama. HU Revista, Juiz de Fora. 2012;38(3 e 4):193-201. 
36 Buitrago F, Uemura G, Sena MCF. Fatores prognósticos em câncer de mama. Com. Ciências Saúde. 2011;Supl 1:S69-S82.

37 Yanli Yan, Long Zhang, Li Tau, Xiaowei MA, Yong Zhang, Shuai S, et al. Endocrine therapy for ductal carcinoma in situ (DCIS) of the breast with breast conserving surgery (BCS) and radiotherapy (RT): a meta-analysis. Pathol Oncol Res [Internet]. 2018 [cited 2018 Dez. 02]; Nov 29. [Epub ahead of print]. Available from: https://link.springer.com/content/pdf/10.1007\%2Fs12253-018-0553-y.pdf.

38 Pondé N, Brandão M, EL-Hachem G, Werhouck E, Piccart M. Treatment of advanced HER-positive breast cancer:2018 and beyond. Cancer Treat Rev. 2018; 67:10-20.

39 Zhi-Bin Wan, Hong-YI Gao, Lian Wei, An-Qin Zhang, Jian-Yu Zhang, Yi Wang, et al. Expression of strogen receptor, progesterone receptor, human epidermal growth fator receptor 2, and Ki-67 in ductal carcinoma in situ (DCIS) and DCIS with microinvasion. Medicine [Internet]. 2018 [cited 2018 Dez. 05];97:44:e13055. Available from: https://www.ncbi.nlm.nih.gov/pmc/articles/PMC6221707/pdf/medi-97e13055.pdf.

40 Catani JPP, Riechelmann RP. Inovação terapêutica. In: Fundamentos de Oncologia Molecular. São Paulo:Atheneu; 2015. p:409-23.

41 Shen S, Wu G, Xiao G, Du R, Hu N, Xia X, et al. Prediction modelo $f$ lymphovascular invasion based on clinicopathological factors in Chinese patients with invasive breast cancer. Medicine [Internet]. 2018 [cited 2018 Dez. 02];97(43):e12973. Available from: https://insights.ovid.com/pubmed?pmid=30412123.

42 Goto W, Kashiwagi S, Takada K, Asano Y, Takahashi K, Fujita H, et al. Significance of intrinsic breast cancer subtypes on the long-term prognosis after neoadjuvant chemotherapy. J Transl Med [Internet]. 2018 [cited 2018 Dez. 02]:16:307. Available from: https://www.ncbi.nlm.nih.gov/pmc/articles/PMC6230295/pdf/12967_2018_Article_167 9.pdf.

43 Fromantin I, Watson S, Baffie A, Rivat A, Falcou MC, Driegel I,et al. A prospective, descriptive cohort study of malignant wound characteristics and wound care strategies inpatients with breast cancer. Ostomy Wound Manage. 2014;60(6):38-48.

44 Measume S, Fromantin I, Teot L. Neoplastic wounds and degenerescence. J Tissue Viability. 2013;22:122-130.

45 Hu SC, Chen GS, Lu YM, Wu CS, Lan CC. Cutaneous metastases from different internal malignancies: a clinical and prognostic appraisal. J Eur Acad Dermatol Venereol. 2008;22:735-40. 
46 Vigano A, Bruera E, Jhandri GS, Newman SC, Fields AI, Suarez-Amazor ME. Clinical survival predioctors in patients with advanced cancer. Arch Intern Med. 2000;27:160(6):861-8.

47 Lam PT, Leung MW, Tse CY. Identifying prognostic factors for survival in advanced cancer patients: a prospective study. Hong Kong Med J. 2007;13(6):453-9.

48 Maida M, Ennis M, Kuziemsky C, Corban J. Wounds and survival in cancer patients. Eur J Cancer. 2009;45:3237-44.

49 Dowsett $\mathrm{C}$. Malignant fungating wounds: assessment and management. $\mathrm{Br} \mathrm{J}$ Commnunity Nurs. 2002;7(8):396-400.

50 Gethin G, Mclntosh C, Probst S. Complementary and alternative therapies for management of odor in malignant fungating wounds: a critical review. Chronic Wound Care Management and Research. 2016:3:51-7.

51 Mercier D, Knevitt A. Using topical aromatherapy for the management of fungating wounds in a palliative care unit. J Wound Care. 2005;14(10):497-501.

52 Vilela-Castro DL, Santos VLCG, Woo K. Polyhexanide versus Metronidazol for odor management in malignant (fungating) wounds: a double-blinded, randomized, clinical trial. J Wound Ostomy Continence Nurs. 2018;45(50):413-8.

53 Instituto Nacional de Câncer - INCA. Ministério da Saúde. Indicadores de unidade de cuidados paliativos: Hospital de Câncer IV do Instituto Nacional de Câncer [Internet]. Rio de Janeiro: INCA; 2009 [cited 2017 Jan 18]. Available from: http://www1.inca.gov.br/inca/Arquivos/HclV/IndicadoresHCIV_2009.pdf.

54 Lisboa IND, Valença MP. Caracterização de pacientes com feridas neoplásicas. Estima. 2016;14(1):21-8.

55 Santos PL, Canadas NF, Aguilar RG, Turrado MMA, Fernandez GGA, Moreno $\mathrm{NM}$, et al. Guía de Práctica Clínica para el Cuidado de Personas com Úlceras Neoplásicas [internet]. 1ª̣. Ed. Andalucía: Hospital Univesitário Reina Sofía. Complejo Hospitalario Torrecádenas. Servicio Andaluz de Salud. Consejería de Igualdad, Salud y políticas Sociales; 2015 [cited 2018 Dec 24]. Available from: http://www.aeev.net/guias/GuiadePractica\%20u\%20neoplasicas\%20sas\%202015.pd f.

56 da Costa Santos CM, de Mattos Pimenta CA, Nobre MR. A systematic review of topical treatments to control the odor of malignant fungating wounds. J Pain Symptom manage. 2010;31(6):1065-76.

57 Brasil. Ministério da Saúde. Instituto Nacional de Câncer. Tratamento e controle de feridas tumorais e úlceras por pressão no câncer avançado [Internet]. Série Cuidados Paliativos. Rio de Janeiro: INCA, 2009 [citado em 201802 dez]. Disponível em: http://bvsms.saude.gov.br/bvs/publicacoes/inca/Feridas_Tumorais.pdf. 
58 Quackenbusch K, Amini A, Fischer CM, Rabinovitch R. Regression of a fungating tumor after hypofractionated radiation therapy in a patient with nmetastatic breast cancer. Cureus [internet]. 2017 [cited 2018 Dez 02];9(7). Available from: https://www.ncbi.nlm.nih.gov/pmc/articles/PMC5580970/pdf/cureus-0009-

00000001417.pdf.

59 Lund-Nielsen B. Malignant wounds in patients with advanced stage cancer [Internet]. Copenhagen, Denmark: Faculty of Health Sciences University of Copenhagem; 2011 [cited 2017 Jan 18]. Available from: http://www.ucsf.dk/documents/31204/33223/Lund-

Nielsen+2011.+Malignant+wounds+in+patients.pdf.

60 Gozzo TO, Tahan FP, Andrade M, Nascimento TG, Prado MAS. Ocorrência e manejo de feridas neoplásicas em mulheres com câncer de mama avançado. Esc Anna Nery. 2014;18(2):270-6.

61 Tamai $N$, Mugita $Y$, Iketa $M$, Sanada $H$. The relation-ship between malignant wound status and pain breast câncer. Eur J Oncol Nurs. 2016;24:8-12.

62 Haisfield-Wolfe ME, Baxendale-Cox, 1999. Staging of malignant cutaneous wounds: a pilot study. Oncol Nur Forum. 1999; 26(6): 1055-64.

63 Manning, MP. Metastase to skin. Semin Oncol Nur. 1998;14(30):240-3.

64 Nielsen J, Fogh K. Clinical utility of foam dressings in wound management: a review. Chronic Wound Care Management and Reseach [Internet] 2015 [cited 2018 Dez 5];2:31-8. Available from: https://www.dovepress.com/clinical-utility-of-foamdressings-in-wound-management-a-review-peer-reviewed-fulltext-article-CWCMR.

65 Tamai N, Horii M, Takehara K, Kato S, Yamamoto Y, Naito A, et al. Morphological characteristics of and factors related to moisture-associated dermatites surrounding malignant wounds in breast cancer patients. Eur J Oncol Nurs. 2013;17(5):673-80.

66 Tamai N, Akase T, Minematsu T, Higashi K, Toida T, Igarashi K, et al. Association between componentes of exsudates and periwound moisture-associated dermatites in breast cancer patients with malignant fungating wounds. Biol Res Nurs. 2016;18(2):199-206.

67 Paiva CJK, Cesse EAP. Aspectos relacionados ao atraso no diagnóstico e tratamento do câncer de mama em uma unidade hospitalar de Pernambuco. Revista Brasileira de Cancerologia. 2015: 61(1):23-30.

68 Maida V, Alexander S, Case AA, Fakhraei P. Malignant wound management. Public Health Emerg. 2016;1(12): 1-14.

69 Ellis LM, Liu WF, Fan F, Reinmuth N, Shaheen RM, Jung YD, et al. Role of angiogenesis inhibitors in cancer treatment. Oncology. 2011; 15(7-Suppl 8):39-46.

70 Addison $\mathrm{H}$, Richard S. Fungating metastatic breast cancer, a challenging case report of bleeding control and palliative wound care. EPJM 2014; 2(3):29-32. 
71 Viera IL, Tamura RE, Chammas R. Angiogênese tumoral. In: Saito RF, Lana MVG, Medrano RFV, Chammas R. Fundamentos de Oncologia Molecular. São Paulo:Atheneu, 2015, p. 225-41.

72 Pinho MSL. Angiogenese: o gatilho proliferativo. Rev Bras Coloproct. 2005;25(4):396-402.

73 Neto M AA, Cardim SGB, Mothê CMA, Andrade LNS. Introdução ao microambiente tumoral. In: Fundamentos de Oncologia Molecular. São Paulo: Atheneu; 2015. p. 187-203.

74 Zhang Z, Luo G, Tang H, Cheng C, Wang P. Prognostic Significance of High VEGF-C Expression for Patients with Breast Cancer: An Update Meta Analysis. PLOS ONE [Internet] 2016 [cited $2018 \mathrm{dez}$ 5];11(11): e0165725. Available from: https://doi.org/10.1371/journal.pone.0165725.

75 Liu H, Tang L, Li X, Li H. Triptolide inhibits vascular endotelial growth fator mediated angiogenesis in human breast cancer cells. Exp Ther Med. 2018;16:830836.

76 Lewis KM, Li Q, Jones DW, Corrales JM, Du H, Spiess PE, et al. Development and validation of na intraoperative bleeding severity scale for use in clinical studies of hemostatic agentes. Surgery. 2017;161(3):771-81.

77 Oxford Centre for Evidence-Based Medicine. OCEBM [Internet]. UK; 2016-2019 [atualized 2019 cited 2019 Jan 11]. Available from: https://www.cebm.net/wpcontent/uploads/2014/06/CEBM-Levels-of-Evidence-2.1.pdf.

78 Grondin SC, Schieman C. Evidence-Based Medicine: Levels of Evidecne and Evaluation Systems. In: Ferguson MK. Difficult Decisions in thoracic Surgery na Evidence-Based Approach. 2a․ Ed. London:Springer-Verlag; 2011. p:13-22.

79 Simann R, Reynolds D. Bedside bleeding control, review paper and proposed algorithm. J am Coll Clin Wound Spec. 2013;4(2):40-4.

80 Monléon-Just M, García YR, Ruiz-López D, Borrego AS, Crespo AA, Jiménez GC. Cuidados em el deterioro de la integridade cutánea secundaria a carcinoma ductal. Med Paliat. 2012;19(4):155-9.

81 Tsukada T, Nakano T, Matoba M, Matsui D, Sasaki S. Locally advanced breast cancer made amenable to radical surgery after a combination of systemic therapy and Mohs paste: two case reports. J Med Case Rep [Internet]. 2012 [cited 2019 Jan 9]; 6:360. Available from: https://jmedicalcasereports.biomedcentral.com/track/pdf/10.1186/1752-1947-6-360.

82 Kakimoto M, Toketa H, Okamura T, Yoshino K. A chemical hemostatic technique for bleeding from malignant wounds. J Palliat Med. 2010; 13(1):11-3. 
83 Adebamowo CA. Topical formalina for management of bleeding malignant ulcers. Word J Surg. 2000; 24:518-20.

84 Woo K, Santos VLCG, Alam T. Optimising quality of life for people with nonhealing wounds. Wounds International [Internet]. 2018 [cited 2019 Jan 11];9(3):6-47. Available from: https://www.woundsinternational.com/journals/issue/549/articledetails/optimising-quality-of-life-for-people-with-non-healing-wounds.

85 Soares RS, Cunha DAO, Fuly PSC. Cuidados de enfermagem com feridas neoplásicas. J Nurs UFPE online [Internet]. 2018 [citado em 2018 dez 5];12(12):3456-63. Disponível https://periodicos.ufpe.br/revistas/revistaenfermagem/article/view/236438.

86 Domansky RC, Chimentão DMN. Prevenção de lesões de pele associadas a umidade. In: Domansky Rc, Borges EL. Manual para prevenção de lesões de pele: recomendações baseadas em evidências. Rio de Janeiro: Rubio; 2014.p: 93-150.

87 Jones RE, Foster DS, Longaker MT. Management of chronic wounds. Clinical Review \& Education. JAMA Insights/Clinical UpDate. JAMA. 2018;30(14):1481-2.

88 Thuleau A, Dugay J, Dacremont C, Jemmali Z, Elard J, De Ricke Y, Cassoux N, Watson S, Escande MC, Fromantin I. Volatile organic compounds of malignant breast cancer wounds: identification and odors. Wounds [Internet]. 2018 [cited 2019 Jan 2]Aug 23;30(11):337-344. Available from: https://www.woundsresearch.com/article/volatile-organic-compounds-malignantbreast-cancer-wounds-identification-and-odors.

89 Chiara O, Cimbanassi S, Bellanova G, Chiarugi M, Mingoli A, Olivero G, et al. A systematic review on the use of topical hemostats in trauma and emergency surgery. BMC Surg [Internet]. 2018 [cited 2019 Jan 2];18(1):68. Available from: https://www.ncbi.nlm.nih.gov/pmc/articles/PMC6116382/pdf/12893_2018_Article_398 .pdf

90 Ozawa S. Patient blood management: use of topical hemostatic and sealant agents. AORN Journal. 2013;98(5):461-78.

91 Velásquez-Avina J, Monkmuller K, Sakai P, Sulbaran M, Chávez-Vargas C, Javé $E M$, et al. Hemostatic effect of oxidized regenerated cellulose in an experimental gastric mucosal resection model. Endoscopy. 2014; 46:878-82.

92 Schonauer C, Tessitore E, Barbagallo G, Albanese V, Moraci A. The use of local agentes: boné wax, gelatina, collagen, oxidized celulose. Eur Spine J. 2004;13:S-89S96.

93 Kaneyuki D, Mogi K, Sakata T, Takahara Y. Surgice ${ }^{\circledR}$ packing remnants mimicking mediastinitis after adult cardiac surgery. Interact Cardiobasc Thorac Surg. 2018. 26;(6):1035-6. 
94 Okushi T, Yoshikawa M, Otori N, Matsuwak Y, Asaka D, Nakayama T, et al. Evaluation of symptoms and QOL with calcium alginate versus chitin-coated gauze for middle meatus packing after endoscopic sinus surgery. Auris Nasus Larynx. 2012;39(1):31-37.

95 Williams $\mathrm{C}$. Algosteril calcium alginate dressing for moderate/high exsudate. $\mathrm{Br} \mathrm{J}$ Nurs 1999;8(5):313-7.

96 Carvalho MV, Machi E, Pantoroto M, Rossini M, da Silva DM, Teodoro LFF, et al. Agentes hemostáticos locais e adesivos teciduais. Rev. Col. Bras. 2013;40(1):066071.

97 Hutchinson RW, George K, Johns D, Craven L, Zhang G, Shnoda P. Hemostatic efficacy and tissue reaction of oxidized regenerated celulose hemostats. Cellulose 2013; 20:537-45.

98 Carvalho MVH, Dias BVB, Marchi E. A escolha do agente hemostático tópico e do adesivo tecidual. RBM. 2014; 7(9):334-8.

99 Franzt VK, Clarke HT, Lattes R. Hemostasis with absorbable gauze (oxidized celulose). Ann Surg [Internet]. 1944 [cited 2019 Jan 13];120(2): 181-198.Available from: https://www.ncbi.nlm.nih.gov/pmc/articles/PMC1617952/.

100 Mello LR, Machado FCN, Haas LJ, Zacchi V, Luzzi R, Zoschke J, et al. Efeitos hemostático e estrutural da esponja de celulose liofilizada. Arq Neuropsiquiatr. 1998;56(3-B):613-20.

101 Lewis KM, Spazierer D, Urban MD, Lin L, Rdi H, Goppelt A. Comparison of regenerated and non-regenerated oxidized cellulose hemostatic agents. Eur Surg. 2013;45:213-20.

102 Tartaglia N, Lascia AD, Lizzi V, Cianci P, Fersini A, Ambrosi A, et al. Haemostasis in thyroid surgery: collange-fribrinogen-thrombin patch versus cellulose gauze - our experience Surg Res Pract [Internet]. 2016 [cited 2019 Jan 13]. Available from: https://www.hindawi.com/journals/srp/2016/3058754/.

103 Lagman R, Walsh D, Day K. Oxidized celulose dressings for persistente bleeding from a superficial malignant tumor. Am $\mathrm{J}$ Hosp. Palliat Care. 2002;19(6):417-8.

104 Pinheiro LS, Borges EL, Donoso MTV. Uso de hidrocolóide e alginato de cálcio no tratamento de lesões cutâneas. Rev Bras Enferm. 2013;66(5):760-70.

105 Azad S, Sacks L. Modified application of alginate dressings on graft donor sites. Br J Plast Surg. 2002;55(2):177-8.

106 Taskin AK, Yasar M, Ozaydin I, Kaya B, Balt O, Ankarali S, et al. The hemostatic effect of calcium alginate in experimental splenic injury model. Ulus Travma Acil Cerrahi Derg. 2013;19(3):195-9. 
107 Thomas S. Alginate dressings in surgery and wound managemen - part 1 . J Wound Care.2000;9(2):56-60

108 Timmons J. Alginates and hydrofiber dressings. The history of alginates. Prof Nurs. 1999;14(7):496-503.

109 Pudner R. Wound Management: alginate and hydrofibre dressings in wound management. J Clin Nurs. 2001;15(5):1-7.

110 Aydin O, Tuncal S, Kilicoglu B, Onalan AK, Gonultas MA, Ozer H, et al. Effects of Ankaferd Blood Stopper and calcium alginate in experimental modelo of hepatic parenchymal bleeding. Braatisl Lek Listy. 2015;116(2):128-131.

111 Blaine, G. Experimental observations on absorbable alginate products in surgery. Ann Surg. 1947;125:102-14.

112 Woo KY, Krasner DL, Kennedy B, Wardle D, Moir D. Palliative wound care management strategies for palliative patients and their circles of care. Adv Skin Wound Care. 2015;28(3):130-40.

113 Dumville JC, Samantha JK, Liu A, Stubbs N, Walker RM, Fortham M. Alginate dressings for treating pressure ulcers. Cochrane Highlights. São Paulo Med J. 2015;133(5):455.

114 Grocott P, Gethin G, Probst S. Malignant wound management in advanced illness: new insights. Curr Opin Support Paliat Care 2013;7(1):101-5.

115 Bensenor IM, Lotufo PA. Epidemiologia Abordagem Prática. 2a. Ed. São Paulo:Sarvier; 2011. p:30-39.

116 Vieira RAC, Formenton A, Bertolini SR. Breast cancer screening in Brazil. Barriers related to the health system. Rev Assoc Med Bras. 2017;63(5):470-8.

117 Conselho Nacional de Saúde - CONEP. Resolução no. 422 de 12 de dezembro de 2012. Aprova diretrizes e normas regulamentadoras de pesquisa envolvendo seres humanos [Internet]. Brasília;2012 [citado em 2019 Jan 13]. Disponível em: http://conselho.saude.gov.br/resolucoes/2012/reso466.pdf.

118 Instituto Nacional de Cancer. Normas e recomendações do INCA/MS. Controle de sintomas do cancer avançado em adultos. Revista Brasileira de Cancerologia. 2000;46(31):243-56.

119 Ministério da Saúde. Instituto Nacional de Cancer. Cuidados Paliativos Oncológicos. Controle de Sintomas. Rio de Janeiro:INCA,2001.

120 Oliveira Filho PF. Epidemiologia e bioestatística. Fundamentos para a leitura crítica. Rio de Janeiro:Rubio, 2015.

121 Nedel WL, Silveira F. Os diferentes delineamentos de pesquisa e suas particularidades na terapia intensiva. Rer Bras Ter Intensiva. 2016;28(3):256-260. 
122 Conselho Nacional de Saúde - CONEP. Resolução n. 346, de 13 de janeiro de 2005. Estabelece a regulamentação para tramitação de projetos multicêntricos no sistema Comitês de Ética em Pesquisa - CEP-CONEP [Inernet] Brasília;2005 [citado em 2019 Jan 13]. Disponível em: http://bvsms.saude.gov.br/bvs/saudelegis/cns/2005/res0346_13_01_2005.html.

123 Qerimi B, Baumann P, Husing J, Knaebel HP, Schumacher H. Collagen hemostat significantly reduces time to hemostasis compared with celllose: COBBANA, a single-center, randomized trial. Am J Surg 2013;205:636-41.

124 Genyk Y, Kato T, Pomposelli JJ, Wright Jk JR, Sher LS, Tetens V. Fibrin Sealant Patch (TachoSil) vs Oxidized Regenerated Cellulose Patch (Surgicel Original) for the Secondary Treatment of Local Bleeding in Patients Undergoing Hepatic Resection: A Randomized Controlled Trial. J Am Coll Surg. 2016;222(3):261-8.

125 Verhoef C, Singla N, Moneta G, Muir W, Rijken A, Lockstad H, et al. Firbrocaps for surgical hemostasis: two randomized, controlled phase II trials. J Surg Res 2015;194:679-687.

126 Moench C, Mihaljevic AL, Hermanutz V, Thasler WE, Suna K, Diener MIK, et al. Randomized controlled multicenter trial on the effectiveness of the collagen hemostat Sangustop ${ }^{\circledR}$ compared with a carrier-bound fibrina sealant during liver resection (ESSCALIVER study, NCT00918619). Langenbecks Arch Surg 2014;399;725-33.

127 Sintler MP, Mahmood MRCS, Simon RG, Smith FRCS, Malcom H, Simms FRCS, et al. Randomized trial comparing Quixil Surgical Sealant with kaltostat Hemostatic Dressing to control suture line bleeding after carotid endarterctomy eith ePTFE Patch Reconstruction. Word J Surg 2005; 29:1259-62.

128 Gupta NY, Chetter I,Hayes P, Yourvati AHD, Moneta GL, Shenoy S, et al. Randomized trial of a dry - powder, fibrin sealant in vascular procedures. J Vasc Surg 2015;62(5):1288-95.

129 Coloplast do Brasil. Coloplast. Biatain alginato. Informação do produto. Descrição do produto. Composição do produto [Internet]. São Paulo/SP; S/D[citado em 2019 Jan 13]. Disponível em: http://www.coloplast.com.br/biatain-alginate-ptbr.aspx\#section=product-description_3.

130 Agência Nacional de Vigilância Sanitária (ANVISA) [Internet]. 2018 [citado em 2019 jan 12]. Disponível em: https://www.smerp.com.br/anvisa/?ac=prodDetail\&anvisald=10430310091.

131 Johnson \& Johnson do Brasil [Internet]. São Paulo/SP. 2016 [citado 2019 Jan 13]. Disponível em: http://br.ethicon.com/profissionais-dasaude/produtos/hemostaticos-e-selantes/familia-de-hemostaticos-absorviveissurgicel/surgicel-hemostatico-absorvivel-orginal. 
132 Agência Nacional de Vigilância Sanitária (ANVISA) [Internet]. 2018 [citado em 2019 jan 12]. Disponível em: Registro ANVISA. 2018. https://consultas. anvisa.gov.br/\#/saude/250010381086/?numeroRegistro=101325900 56

133 Cormio L, Cormio G, Di Fino G, Scavone C, Sanguedolce F, Loizzi V, et al. Surgice| ${ }^{\circledR}$ granuloma mimicking ovarian cancer: a case report. Oncol Lett 2016;12:1083-4.

134 Bhalla RK, Murphy J, Jones TM, Roland NJ. Foreign body reaction to calcium alginate fibre mimicking recurrent tumour of the submandicular salivar gland. $\mathrm{Br} \mathrm{J}$ Oral Maxillofac Surg 2002;40:172-4.

135 Bajay HM, Jorge AS, Dantas SRPE. Curativos e coberturas para o tratamento de feridas. In: Jorge AS, Dantas SRPE. Abordagem multiprofissional do tratamento de feridas. São Paulo: Atheneu; 2003. p: 89.

136 Dorterler ME, Ayangil HR, Turan C, Deniz K. Comparison of the hemostatic effects of oxidized celulose and calcium alginate in na experimental animal modelo of hepatic parenchymal bleeding. Int J Crit IIIn Inj Sci. 2016; 4(6): 167-71.

137 Singh A, Jai S, Ganpule S, Ganpule A. Bolster material granuloma masquerading as recurrent renal cell carcinoma following partial nephrectomy. Indian J Radiol Imaging. 2016;26(3):352-5.

138 Martins J, Sousa Lm, Oliveira AS. Recomendações do enunciado CONSORT para o relato de estudos clínicos controlados e randomizado. Medicina (Ribeirão Preto) [Internet]. 2009 [citado em 2019 jan 13];42(1):9-21. Disponível em: http://revista.fmrp.usp.br/2009/vol42n1/Simp_Recomendacoes_Enunciado_CONSO RT_1.pdf.

139 CONSORT. CONsolidated Standards Of Reporting Trials.Transparent Reporting of Trials (Internet). Ottawa, Canada. 2010 [atualized 2019, cited 2019 Jan 13]. Available from: http://www.consort-statement.org/.

140 Fischer CP, Bochicchio G, Shen J, Patel B, Batiller J, Harte JC. A propsepctive, randomized, controlled trial of the efficacy and safety of fibrina pad as na adjunct to control soft tissue blleding during abdominal, retroperitoneal, pelvic, and thoracic surgery. J Am Coll Surg 2013; 217(3):385-93.

141 Kakaei F, Sadeghi MSS, Sanei B, Hashemzadeh S, Habibzadeh A. A randomized clinical trial comparing the effect of different haemostatic agents for haemostasis of the liver after hepatic resection. HPB Surg [Internet]. 2013 [cited 2019 Jan 13]. Available from: https://www.ncbi.nlm.nih.gov/pmc/articles/PMC3789495/.

142 Hanks JB, Kjargard HK, Hollingsbee DA. A comparison of the haemostatic effect of Vivostat ${ }^{\circledR}$ patient-derived fibrina sealant with Oxidised Cellulose (Surgice ${ }^{\circledR}$ ) in multiple surgical procedures. Eur Surg Res. 2003;35:439-444. 
143 Lakshan S, Aqua K, Stefanovic A, Djurdjevic S, Nyirády P, Davis R, et al. A prospective, single-blind, randomized, phase III study to evaluate the safety and efficacy of fibrin sealant Grifols as an adjuncto to hemostasis during soft tissue open surgery. J Invest Surg [Internet]. 2018 [cited 2019 Jan 13]. 10 Oct [Epub ahead of print].

144 Schenk WG, Burks SG, Gagne PJ, Kagan AS, Lawson JH, Spotnitz WD. Fibrin sealant imporves hemostasis in peripheral vascular surgery: a randomized prospective trial. Ann Surg.2003;237(6):871-6.

145 Blair SD, Backhouse CM, Harper R, Matthews J, McCollum CN. Comparison of absorbable materials for surgical haemostasis. Br. J. Surg. 1988; 75:969-71.

146 Rembe J-D, Bohm JK, Fromm-Dornieden CF, Schafer N, Maegele M, Frohlich $\mathrm{M}$, et al. Comparison of hemostatic dressings for superficial wounds using a new spectrophotometric coagulatoin assay. J Transl Med [Internet].2015 [cited 2019 Jan 13);13:375. Available from: https://www.ncbi.nlm.nih.gov/pmc/articles/PMC4666077/.

147 Firmino F. Pacientes portadores de feridas neoplásicas em serviços de cuidados paliativos: contribuições para a elaboração de protocolos de intervenções de enfermagem. Revista Brasileira de Cancerologia [Internet]. 2005 [citado em 2019 jan. 13];347-359. Disponível

em: http://www1.inca.gov.br/rbc/n_51/v04/pdf/revisao6.pdf. 
APÊNDICES 
Apêndice A - Quadro de Distribuição do número de artigos pelas bases de dados consultadas na busca de artigos referentes à hemostasia clínica de feridas neoplásicas malignas. São Paulo, 2018

\begin{tabular}{|c|c|c|c|c|c|c|}
\hline $\begin{array}{l}\text { Base/ } \\
\text { Portal }\end{array}$ & Estratégia & Indicados & Selecionados & Repetidos & Excluídos & Incluídos \\
\hline PubMed & $\begin{array}{l}\text { Advanced Search Builder. Builder. All fields /show index list: Search } \\
\text { \#1: breast neoplasms: } 269.282 \text { records; search \#2: breast cancer: } \\
245.190 \text { records; search \#3: malignant fungating wounds: } 26 \text { records; } \\
\text { search \#4: malignant wounds: } 71 \text { records; search \#5: bleeding: } 183.283 . \\
\text { Boolean operators: \#1 OR \#2 AND \#3 OR \#4 AND \#5: } 16 \text { records. } \\
\text { ((("breast neoplasms"[All Fields] OR "breast cancer"[All Fields]) AND } \\
\text { "malignant fungating wounds"[All Fields]) OR "malignant wounds"[All } \\
\text { Fields]) AND "bleeding"[All Fields] }\end{array}$ & 16 & 6 & 0 & 14 & 02 \\
\hline
\end{tabular}


Apêndice A - Quadro de Distribuição do número de artigos pelas bases de dados consultadas na busca de artigos referentes à hemostasia clínica de feridas neoplásicas malignas. São Paulo, 2018

\begin{tabular}{|c|c|c|c|c|c|c|}
\hline $\begin{array}{l}\text { Base/ } \\
\text { Portal }\end{array}$ & Estratégia & Indicados & Selecionados & Repetidos & Excluídos & Incluídos \\
\hline Scopus & $\begin{array}{l}\text { Search (Aff fields): Search \#1: breast neoplasms: } 248.434 \text { records; } \\
\text { search \#2: breast cancer: } 1.212 .180 \text { records; search \#3: malignant } \\
\text { fungating wounds: } 211 \text { records; search \#4: malignant wounds: } 412 \\
\text { records; search \#5: bleeding: } 527.180 \text { records. } \\
\text { Boolean operators: \#1 OR \#2 AND \#3 OR \#4 AND \#5: } 44 \text { records. } \\
\text { ( ALL ( "BREAST NEOPLASMS")) OR ( ALL ( "BREAST } \\
\text { CANCER" ) ) AND ( ALL ( "MALIGNANT FUNGATING } \\
\text { WOUNDS") ) OR ( ALL ("MALIGNANT } \\
\text { WOUNDS") ) AND ( ALL ("BLEEDING" ) ) }\end{array}$ & 44 & 15 & 4 & 41 & 3 \\
\hline $\begin{array}{l}\text { Web } \\
\text { of } \\
\text { Science }\end{array}$ & $\begin{array}{l}\text { Advanced research. Search \#1: TS=(breast neoplasms): } 19.224 \text { records; } \\
\text { research \#2: TS=(breast cancer): } 522.516 \text { records; research \#3: TS } \\
\text { (malignant fungating wounds): } 64 \text { records; research \#4: TS(malignant } \\
\text { wounds): } 2.689 \text { records; research \#5: TS=(bleeding): } 161.634 \text { records. } \\
\text { Boolean operator: \#1 OR \#2: } 525.066 \text { records (\#6); \#3 OR \#4: } 2.689 \\
\text { records (\#7); \#6 AND \#7: } 398 \text { records (\#8); \#8 AND 5\#: } 15 \text { records. }\end{array}$ & 15 & 3 & 3 & 15 & 0 \\
\hline $\begin{array}{l}\text { Portal } \\
\text { BVS }\end{array}$ & $\begin{array}{l}\text { (tw:(breast neoplasms)) OR (tw:("breast cancer")) AND (tw:(malignant } \\
\text { fungating wounds)) OR (tw:(malignant wounds)) AND (tw:("bleeding")) }\end{array}$ & 16 & 3 & 3 & 16 & 0 \\
\hline Total & 6 Bases + 1 Portal consultados & 111 & 42 & 12 & 106 & 5 \\
\hline
\end{tabular}

conclusão 


\section{Apêndice $B$}

\section{TERMO DE CONSENTIMENTO LIVRE E ESCLARECIDO (TCLE)}

"Eficácia da celulose oxidada regenerada no controle do sangramento de feridas neoplásicas malignas decorrentes do câncer de mama: Ensaio Clínico Randomizado"

Convido o Sr ou a Sra (a) a participar de uma pesquisa denominada acima citada porque você está sendo atendido (a) nesta instituição teve diagnóstico de câncer de mama e tem uma ferida em seu peito com risco de apresentar sangramento.

Você só deve aceitar participar desta pesquisa depois de ter entendido este documento que se chama Termo de Consentimento Livre e Esclarecido. Leia as informações com atenção, converse com o pesquisador responsável para retirar todas as suas dúvidas; com seus familiares, amigos e com a equipe médica antes de tomar uma decisão. Se você tiver dúvidas depois de ler estas informações entre em contato com o pesquisador responsável identificado ao final desse documento. Você poderá cancelar sua participação na pesquisa ou retirar seu consentimento a qualquer momento, sem nenhuma penalidade, e sem nenhum dano ao seu tratamento, à sua assistência integral, ou aos seus direitos como paciente da instituição.

\section{PORQUE A PESQUISA VAI SER FEITA}

A pesquisa vai ser feita para testar materiais que possam oferecer a melhor forma de parar o sangramento da sua ferida. O objetivo é saber qual tipo de curativo controla mais rápido o sangramento.

\section{O QUE VAI SER FEITO COM VOCÊ NA PESQUISA}

1‥ Passo: quando a sua ferida apresentar sangramento, você será submetido à coleta de sangue para exames de laboratório. 2․ Passo: o pesquisador irá abrir o seu curativo, lavar a sua ferida com soro e colocar o produto a ser testado, apertar e contar o tempo que leva para parar o sangramento. Em seguida seu curativo será finalizado. 3 Passo: você será entrevistado sobre sua idade, seu tratamento, e as medicações que você toma. Essa entrevista tem tempo previsto de 20 minutos. 4. Passo: você deverá permanecer na instituição até ser liberado pelos pesquisadores. 
Nos casos em que você nos informar que sempre ao trocar o curativo a sua ferida sangra você será submetido ao procedimento de coleta de sangue, mas haverá o risco do seu sangue ser descartado se o sangramento não acontecer quando o enfermeiro trocar seu curativo.

\section{MÉTODOS ALTERNATIVOS}

Você estará sendo submetido a um procedimento de rotina na instituição. Esse procedimento será feito utilizando produtos que são diferentes entre si, mas que são utilizados para o controle do sangramento das feridas decorrentes do câncer de mama. Estando participando ou não da pesquisa, você poderia estar sendo submetido ao mesmo tipo de tratamento.

\section{BENEFÍCIOS, ACOMPANHAMENTO E ASSISTÊNCIA}

Você não será remunerado por sua participação e esta pesquisa não poderá oferecer benefícios diretos a você. Você não receberá dinheiro. O benefício principal da sua participação é possibilitar que no futuro os resultados alcançados com esta pesquisa beneficiem outros pacientes.

Durante a pesquisa você será acompanhado (a) pelos pesquisadores até o momento em que o médico avaliar seu exame de sangue, e nesse momento encerra-se a sua participação na pesquisa. Após a sua participação na pesquisa seu acompanhamento, tratamento, assistência integral e seus direitos como paciente na instituição serão mantidos de forma rotineira

\section{RISCOS}

Não existem riscos físicos adicionais a você relacionados ao uso dos produtos envolvidos na pesquisa porque eles já são utilizados como rotina na instituição. De maneira geral você estará exposto aos riscos comuns da coleta de sangue, que podem incluir desmaio, dor, mancha roxa na pele. De maneira mais rara poderá ocorrer infecção no local da picada da agulha.

No entanto todas as cautelas técnicas serão tomadas para minimizar esses riscos como: descontinuidade do procedimento se você apresentar palidez e/ou referir mal estar inespecífico, cuidados com a sua pele ao colocar o garrote, escolha de veia de maior calibre para diminuir sua dor, compressão firme e com duração de ao menos cinco minutos para diminuir o risco de ficar a mancha roxa sobre sua pele.

Se você fizer uso de cateter você será exposto aos mesmos riscos da coleta de sangue que você faz de rotina: a dor da punção da pele sobre o cateter e o risco de obstrução do dispositivo. Para diminuir a dor da punção da pele você será 
condicionado a fazer movimentos respiratórios que tornam o dispositivo mais superficial e contribui para que a punção seja sentida como a menos dolorida possível. Irrigação adicional com $20 \mathrm{ml}$ de soro fisiológico minimiza o risco de obstrução, conforme protocolo institucional.

\section{CUSTOS E RESSARCIMENTOS}

Você não terá quaisquer custos ou despesas pela sua participação nessa pesquisa. Você não pagará por nenhum procedimento e por nenhum produto utilizado como parte desta pesquisa. Uma vez que a pesquisa irá acontecer quando você estiver nas dependências do hospital por outros motivos, não haverá ressarcimento de nenhuma despesa que você tenha relacionada à sua presença no hospital.

\section{CONFIDENCIALIDADE}

As informações sobre a sua saúde e seus dados pessoais serão mantidas de maneira confidencial e sigilosa. Seus dados somente serão utilizados sem identificação. Apenas os pesquisadores autorizados terão acesso aos dados. Mesmo que estes dados sejam utilizados para divulgação e/ou publicação científica, sua identidade permanecerá em segredo.

\section{INDENIZAÇÃO E TRATAMENTO MÉDICO EM CASO DE DANOS}

Todo e qualquer dano decorrente do desenvolvimento desta pesquisa, e que necessite de atendimento médico, ficará a cargo da instituição. Seu tratamento e acompanhamento médico independem de sua participação nesta pesquisa. Se você e sofrer qualquer tipo de dano decorrente diretamente desta pesquisa você será indenizado conforme as leis e direitos de pacientes vigentes no país.

\section{GARANTIA DE ESCLARECIMENTOS}

Você terá garantia de acesso, em qualquer etapa da pesquisa, sobre qualquer esclarecimento de eventuais dúvidas e inclusive para tomar conhecimento dos resultados desta pesquisa. Neste caso, por favor, ligue para a enfermeira Flávia Firmino no telefone (21) 3259-1754 ou 98207-9470 a qualquer horário nas 24 horas do dia.

Esta pesquisa foi aprovada pelo Comitê de Ética em Pesquisa (CEP) da Universidade de São Paulo (USP) e do INCA, que são formados por profissionais de diferentes áreas, que revisam os projetos de pesquisas que envolvem seres humanos, para garantir os direitos, a segurança e o bem-estar de todas as pessoas que se voluntariam a participar destes. Se tiver perguntas sobre seus direitos como 
participante de pesquisa, você pode entrar em contato com o CEP da USP Endereço: Av. Dr. Enéas de Carvalho Aguiar, 419 - Cerqueira Cesar - São Paulo/SP CEP 05403-000, telefone: (11): 3061-8858, e-mail: cepee@usp.br de segunda a sexta de 9:00 a 17:00 h, ou no INCA na Rua do Resende №128, Sala 203, de segunda a sexta de 9:00 a 17:00 h, nos telefones (21) 3207-4550 ou 32074556, ou também pelo e-mail: cep@inca.gov.br.

O principal pesquisador é a Sra. Flávia Firmino, enfermeira do INCA, que pode ser encontrada no endereço: Rua Visconde de Santa Isabel 274. Vila Isabel. Rio de Janeiro/RJ. CEP 20560-121. E-mail: flaviafir@hotmail.com. Telefone: 21 3207-3874 ou 21 3207-3872 (atendimento 24 horas/dia).

Este termo está sendo elaborado em duas vias, sendo que uma via ficará com você e outra será arquivada com os pesquisadores responsáveis. Ele será rubricado em todas as suas páginas e assinado por você e pelo pesquisador nas duas vias.

Esta pesquisa atende todas as especificações da Resolução 466, de 12 de dezembro de 2012 que aprova as diretrizes e normas regulamentadoras de pesquisas envolvendo seres humanos.

\section{CONSENTIMENTO}

Eu, por intermédio deste, dou livremente meu consentimento para participar nesta pesquisa.

Nome e Assinatura do participante/representante legal

$\frac{1 /}{\text { Data }}$

$\frac{1 /}{\text { Data }}$


Apêndice C

FICHA DE COLETA DE DADOS

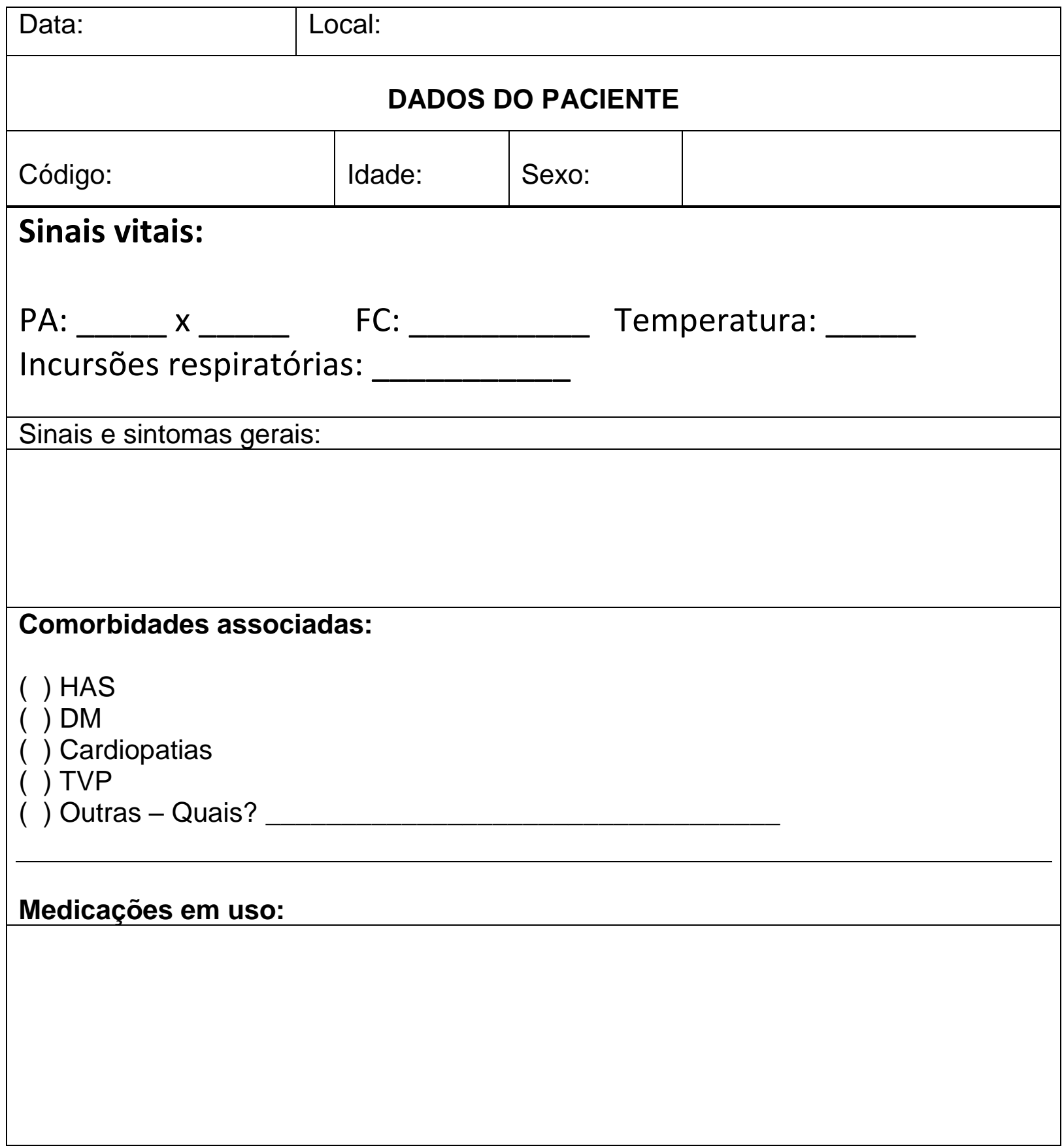




\section{DADOS DO TUMOR}

\section{Histologia do tumor:}

Estadiamento do tumor:

Tratamento oncológico em curso

( ) QT

( ) RXT

( ) Hormonioterapia

( ) Seguimento/ Informar o tempo de seguimento:

( ) Cuidados Paliativos

Tratamento oncológico pregresso

( ) QT / última sessão:

( ) RXT /última sessão:

( ) Hormonioterapia/última dose:

( ) Cirurgia:

Data: 
DADOS DA FERIDA

\section{Estadiamento da ferida neoplásica maligna (vide anexo)}

( ) Estadiamento IN

( ) Estadiamento II

( ) Estadiamento III

( ) Estadiamento IV

\section{Sinais e sintomas da ferida:}

( ) Secreção

( ) Exsudato

( ) Odor

( ) Dor

( ) Sangramento

Cobertura em uso:

\section{DADOS DO SANGRAMENTO}

1) O sangramento é: ( ) Espontâneo ( ) Induzido

2) Localiza-se na ferida: ( ) área delimitada ( ) difuso ( ) de fundo

3) Grau de intensidade/caracterização: (vide escala de intensidade)

( ) $0 \quad$ ( ) 1

( ) 2 ( ) 3 ( ) 4

Tratamento local/sistêmico do tratamento

Faz uso de medicação/produto específico: ( ) Sim ( ) Não

Quais:

Tempo de uso: 


\section{DADOS DA INTERVENÇÃO}

Houve medicação trombolítica antes da intervenção?

( ) Sim Quais:

( ) Não

Alocação no estudo: ( ) G1: Alginato （ ) G2: Celulose

Tempo de hemostasia:

Profissional que atestou a hemostasia:

Assinatura:

1ํㅡㄹ Avaliação de Ressangramento:

( ) Sim Tempo:

( ) Não 


\begin{tabular}{|l|}
\hline \multicolumn{1}{|c|}{ DADOS DOS EXAMES LABORATORIAIS } \\
\hline Hemograma \\
\hline Hemácias: \\
\hline HB: \\
\hline HT: \\
\hline Plaquetas: \\
\hline Bioquímica \\
\hline Cálcio: \\
\hline Albumina: \\
\hline Coagulograma \\
\hline Tempo de Protrombina: \\
\hline INR: \\
\hline Tempo de Tromboplastina Ativa: \\
\hline
\end{tabular}

\section{Pesquisador responsável pela coleta dos dados:}

Nome: Contato telefônico: 


\section{Apêndice D}

Escala de intensidade de sangramento

\begin{tabular}{|c|c|c|c|c|}
\hline Grau & $\begin{array}{c}\text { Apresentação } \\
\text { visual }\end{array}$ & $\begin{array}{l}\text { Aparência } \\
\text { anatômica }\end{array}$ & $\begin{array}{l}\text { Descrição } \\
\text { qualitativa }\end{array}$ & $\begin{array}{l}\text { Média visualmente } \\
\text { estimada da perda } \\
\text { sanguínea ( } \mathrm{mL} / \mathrm{min})\end{array}$ \\
\hline 0 & $\begin{array}{c}\text { Sem } \\
\text { sangramento }\end{array}$ & $\begin{array}{c}\text { Sem } \\
\text { sangramento }\end{array}$ & $\begin{array}{c}\text { Sem } \\
\text { sangramento }\end{array}$ & $<-1.0$ \\
\hline 1 & $\begin{array}{l}\text { Escorre ou } \\
\text { goteja em fluxo } \\
\text { intermitente }\end{array}$ & $\begin{array}{l}\text { Sangramento } \\
\text { capilar }\end{array}$ & Leve & $>1.0-5.0$ \\
\hline 2 & $\begin{array}{l}\text { Fluxo contínuo } \\
\text { ou jato rápido } \\
\text { controlável }\end{array}$ & $\begin{array}{l}\text { Sangramento de } \\
\text { Vênula ou } \\
\text { arteríola }\end{array}$ & Moderado & $>5.0-10.0$ \\
\hline 3 & $\begin{array}{l}\text { Escoamento, } \\
\text { jato ou } \\
\text { esguicho com } \\
\text { fluxo } \\
\text { aumentado }\end{array}$ & $\begin{array}{c}\text { Sangramento } \\
\text { Venoso não } \\
\text { central e /ou } \\
\text { arterial }\end{array}$ & Intenso & $>10.0-50.0$ \\
\hline 4 & $\begin{array}{l}\text { Escoamento, } \\
\text { jato ou } \\
\text { esguicho } \\
\text { incontrolável ou } \\
\text { inacessível }\end{array}$ & $\begin{array}{l}\text { Sangramento } \\
\text { arterial central } \\
\text { ou venoso }\end{array}$ & $\begin{array}{c}\text { Ameaçador da } \\
\text { vida }\end{array}$ & $>50.0$ \\
\hline
\end{tabular}

Fonte: Modificado de: Lewis KM, Li Q, Jones DW, Corrales JM, Du H, Spiess PE, et al. Development and validation of na intraoperative bleeding severity scale for use in clinical studies of hemostatic agentes. Surgery. In press 2016. Available from: http://www.surgiournal.com/article/S00396060(16)30605-5/abstract. 
ANEXOS 


\section{Anexo A}

\section{Aprovação do Comitê de Ética em Pesquisa do Instituto Nacional do Câncer}

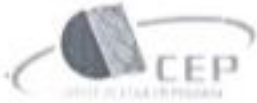

Memo 104/10-CEP-INCA

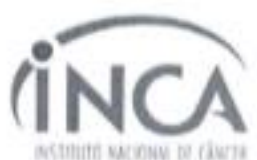

Rio de Janeiro, 3 de março de 2010.

$\mathrm{A}(\mathrm{o})$ : Enf' Laisa Figueiredo Ferreira

Pesquisador(a) Principal

Registro CEP n* 132/09 (Este $n^{\circ}$, deve ser citado nas correspondências referentes a este estudo)

Titulo do Estudo: A mulher portadora de câncer de mama e sua ferida neoplásica: subsidios para as intervençōes de enfermagem

Prezado(a) Pesquisador(a),

Informo que o Comitê de Ética em Pesquisa do Instituto Nacional de Câncer aprovou após re-análise o estudo intitulado: $\mathbf{A}$ mulher portadora de câncer de mama e sua ferida neoplásica: subsidios para as intervençôes de enfermagem, bem como o seu Termo de Consentimento Livre e Esclarecido versâo 2 para a paciente, Termo de Consentimento Livre e Esclarecido versão 2 para o familiar/cuidador principal e Termo de Consentimento Livre e Esclarecido versfo 2 para o profissional de eneformagem, em 3 de março de 2010.

Ressalto que conforme descrito na folha de rosto (item 49), o(a) pesquisador(a) responsável deverá apresentar relatórios semestrais a respeito do seu protocolo que estâo previstos para as seguintes datas: setembro/2010 e março/2011.

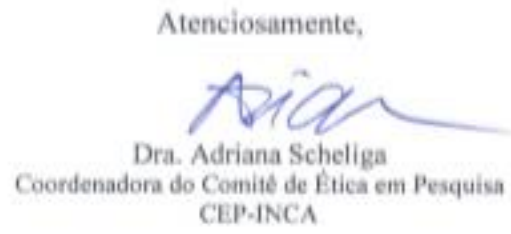

C/e - Eaf Maria Cristina Caldas - Chefe da Divisaso de Eafermagem - HC III Dr. Cesar Lasmar - Direter do IIC III 
Anexo B

\section{Parecer Consubstanciado do CEP Escola de Enfermagem USP}

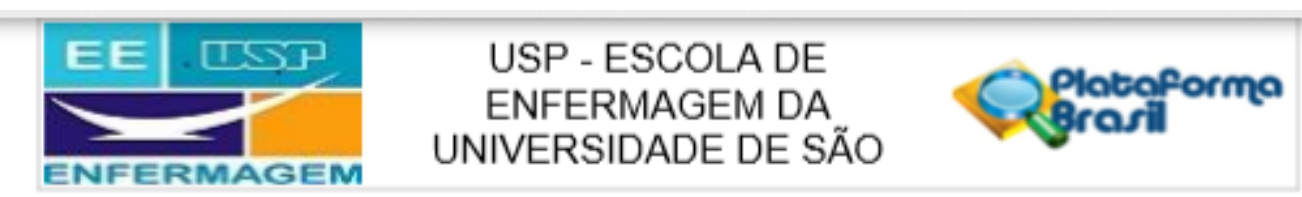

\section{PARECER CONSUBSTANCIADO DO CEP}

\section{DADOS DO PROJETO DE PESQUISA}

Titulo da Pesquisa: Eficácia da Celulose Oxidada Regenerada versus Alginato de Cálcio no Controle do Sangramento de Feridas Malignas Decorrentes do Câncer de Mama: Ensaio Clínico Randomizado.

Pesquisador: FLAVIA FIRMINO

Área Temática:

Versão: 4

CAAE: 64956317.7 .0000 .5392

Instituiçäo Proponente: Escola de Enfermagem da Universidade de Såo Paulo - EEUSP

Patrocinador Principal: Financiamento Próprio

\section{DADOS DO PARECER}

Número do Parecer: 2.157.193

Apresentaçäo do Projeto:

O projeto é tema de Tese de Doutorado da aluna Flávia Firmino sob a orientação da Dra. Vera Lúcia Conceição de Gouveia Santos.

Trata-se de ensaio Clínico Randomizado aberto, controlado, paralelo, envolvendo pacientes acometidos pelo câncer de mama com presença de ferida neoplásica maligna sangrantes, distribuídos em dois braços com três estratos alocados para receberem qualquer uma das intervenções hemostáticas do estudo: seja a aplicação do tratamento padrão que é feito pelo curativo de alginato de cálcio ou pela intervenção teste que é a aplicação do hemostático tópico à base de celulose oxidada regenerada quando apresentarem sangramento de intensidade leve, moderada e/ou severa, na ferida maligna.

O estudo parte da hipótese de que em pacientes com feridas malignas sangrantes decorrentes do câncer de mama, há diferença no tempo necessário para se obter hemostasia quando se utiliza o hemostático tópico à base de celulose oxidada regenerada comparado ao uso padrão do curativo de alginato de cálcio.

A amostra será composta por 24 pacientes sendo 12 no grupo 1 (Alginato de ć́lcio) e 12 no grupo 2 (celulose oxidada regenerada). As pacientes serão recrutadas em dois hospitais do Instituto Nacional de Câncer José Gomes de Alencar da Silva - INCA, a saber: em suas unidades de

Enderego: Av, Dr. Eneas de Carvalho Aguiar, 419
Bairro: Cerqueira Cesar
$\begin{aligned} & \text { UF: SP } \\ & \text { Telefone: (11)3061-8858 }\end{aligned}$




USP - ESCOLA DE
ENFERMAGEM DA
ENIVERSIDADE DE SÃO

Cortinuscas do Parncer; 2.157 193

tratamento especializado no cânoer de mama (conhecido pela sigla HC III) e na de ouidados paliativos (conhecida pela sigla HC IV).

Cada sujeito será submetido à realizaçăo de curativo sendo avaliado o tipo de sangramento e o tempo gasto para o aloance da hemostasia. Os dados serăo colhidos através de instrumentos próprios de avaliação em forma de oheck-list e a hemostasia será atestada por pesquisador independente. Análise de dados: será feita utilizando Teste de regressão de Cox, teste nảo paramétrioo de Kruskal-Wallis para comparaçăo das variáveis com distribuiçŏes medianas, e Man-Whitney para avaliar a signnifioância estatístios.

Objetivo da Pesquisa:

Objetivo geral:

- Avaliar se o grupo que recebeu a celulose oxidada regenerada alcança o menor tempo para obter hemostasia até o limite de 20 minutos.

Objetivos Secundários:

- Comparar o tempo necessário para a obtenção de hemostasia em ambos os grupos:

- Avaliar se a proporçăo de pacientes que alcançaram hemostasia foi maior no grupo que recebeu a celulose oxidada regenerada;

- Identificar e comparar intra e intergrupos o perfil de sangramento, de coagulação, comorbidades, tipo histopatológico, estadiamento tumoral, estadiamento da ferida, e tratamento oncológico pregresso e atual com os tempos de hemostasia apresentados.

Avaliąăo dos Riscos e Benefícios:

Näo existem risoos físicos adicionais relacionados ao uso dos produtos envolvidos na pesquisa porque eles já são utilizados como intervenções hemostátioas na rotina da instituiçăo onde pretende-se fazer a ooleta de dados. De modo geral geral os risoos serão relativos à ooleta de sangue, que podem incluir desmaio, dor. mancha roxa na pele e de modo mais raro infeç̧ăo no local da picada da agulha. Pacientes em uso de cateter venoso central terăo riscos de obstruçăo do dispositivo, sensação de dor pela picada a agulha sobre a pele e infeoçäo.

Os risoos associados aos materiais das intervençöes de controle e teste dizem respeito aos riscos já existentes no dia-a-dia da rotina institucional de aplioaçăo desses mesmos produtos: formaçăo de corpo estranho na ferida, levando a processo inflamatório mais intenso, inefioácia do produto = o que inoorrerá em aumento da perda sanguínea. Esses riscos serăo minimizados pela inspeção direta da ausência, diminuiçăo ou aumento do sangramento pelo pesquisador em tempo

Endereço: Av. Dr. Eneas de Carvaho Aguiar, 419

Bairro: Cerqueira Cesar CEP: 05.403-000

UF: SP MUnicipio: SAOPAULO

Telefone: (11)3061-8858

E-mall: cepee@usp br 


\begin{tabular}{|c|c|c|}
\hline$\equiv$ & पsp & $\begin{array}{c}\text { USP - ESCOLA DE } \\
\text { ENFERMAGEM DA } \\
\text { UNIVERSIDADE DE SÃO }\end{array}$ \\
\hline
\end{tabular}

Continusçao do Parecer; 2.157.193

determinado pelo protocolo de pesquisa (20 minutos) e comunicação ao serviço médico de situações que envolvam aumento de risco para os participantes, o que implicará em retirada imediata da pesquisa $e$ aplicação de medidas terapêuticas apropriadas que já são desenvolvidas pelo protocolo de tratamento existente na instituição onde se almeja coleta dos dados.

\section{Beneficios:}

Serão benefícios para os sujeitos da pesquisa: o exame de sangue - que nem sempre é solicitado quando das intervenções hemostáticas de rotina, a orientaçäo mais criteriosa acerca do evento sangramento na ferida tumoral maligna e a participação em prol do desenvolvimento de melhorias acerca dos cuidados prestados $\mathrm{na}$ instituição.

\section{Comentários e Considerações sobre a Pesquisa:}

Pesquisa descrita de maneira extremamente detalhada, com cuidado de descrição dos critérios de inclusão e exclusão e de todas as etapas que abrangem o estudo.

Cronograma detalhado, com estudo tendo tido seu início em 2015. mas com previsão de início da coleta de dados em setembro-2017.

Orçamento detalhado, com custo total previsto de $69.874,40$. A pesquisadora justificou que o projeto será encaminhado à agência de fomento e que as despesas pessoais e aquelas referentes à participaçäo em eventos científicos, pagamento de taxas para publicaçăo e revisão de texto ficarão inicialmente a cargo da pesquisadora.

\section{Consideraçöes sobre os Termos de apresentação obrigatória:}

A pesquisadora corrigiu a frase do TCLE e anexou a nova versão ao final do projeto, além de encaminhar o documento separadamente.

\section{Recomendaçöes:}

Näo há.

Conclusöes ou Pendências e Lista de Inadequaçöes:

Näo há mais pendências.

\section{Consideraçöes Finais a critério do CEP:}

- Este CEP informa a necessidade de registro dos resultados parciais e finais na Plataforma Brasil;

- Esta aprovação não substitui a autorizaçäo da instituição coparticipante, antes do inicio da coleta de dados.

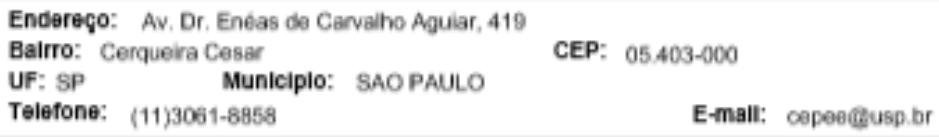




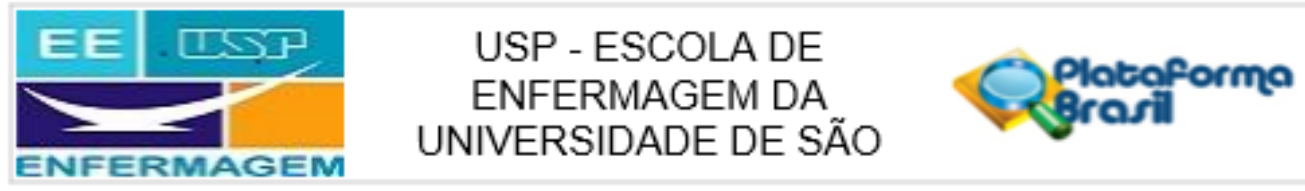

Continusçao do Parecer: 2.157.193

Este parecer foi elaborado baseado nos documentos abaixo relacionados:

\begin{tabular}{|c|c|c|c|c|}
\hline Tipo Documento & Arquivo & Postagem & Autor & Situação \\
\hline $\begin{array}{l}\text { Informações Básicas } \\
\text { do Projeto }\end{array}$ & $\begin{array}{l}\text { PB_INFORMAÇOEES_BÁSICAS_DO_P } \\
\text { ROJETO 862703.pdf }\end{array}$ & $\begin{array}{c}09 / 06 / 2017 \\
15: 11: 17\end{array}$ & & Aceito \\
\hline $\begin{array}{l}\text { Projeto Detalhado / } \\
\text { Brochura } \\
\text { Investigador }\end{array}$ & ProjetocomnovoTCLEVersao4.doc & $\begin{array}{c}09 / 06 / 2017 \\
15: 09: 30\end{array}$ & FLAVIA FIRMINO & Aceito \\
\hline $\begin{array}{l}\text { TCLE / Termos de } \\
\text { Assentimento / } \\
\text { Justificativa de } \\
\text { Ausência }\end{array}$ & REVISADOTCLEVersao4.docx & $\begin{array}{c}09 / 06 / 2017 \\
15: 05: 18\end{array}$ & FLAVIA FIRMINO & Aceito \\
\hline Cronograma & $\begin{array}{l}\text { QUARTAVERSAONOVO_Cronograma. } \\
\text { docx }\end{array}$ & $\begin{array}{c}09 / 06 / 2017 \\
15: 01: 24 \\
\end{array}$ & FLAVIA FIRMINO & Aceito \\
\hline Cronograma & Nova_carta_ao_comite.docx & $\begin{array}{c}09 / 06 / 2017 \\
14: 55: 53 \\
\end{array}$ & FLAVIA FIRMINO & Aceito \\
\hline $\begin{array}{l}\text { Declaração de } \\
\text { Instituiçắo e } \\
\text { Infraestrutura }\end{array}$ & Termo_de_anuencia_HC_4.pdf & $\begin{array}{c}30 / 03 / 2017 \\
17: 54: 38\end{array}$ & FLAVIA FIRMINO & Aceito \\
\hline $\begin{array}{l}\text { Declaração de } \\
\text { Instituiçắo e } \\
\text { Infraestrutura }\end{array}$ & Responsabilid_pes_HC_3.pdf & $\begin{array}{c}30 / 03 / 2017 \\
17: 15: 01\end{array}$ & FLAVIA FIRMINO & Aceito \\
\hline $\begin{array}{l}\text { Declaração de } \\
\text { Instituiçắo e } \\
\text { Infreestrutura }\end{array}$ & Assinaturas_HV_4.pdf & $\begin{array}{c}30 / 03 / 2017 \\
16: 51: 01\end{array}$ & FLAVIA FIRMINO & Aceito \\
\hline $\begin{array}{l}\text { Declaração de } \\
\text { Pesquisadores }\end{array}$ & Formulario_para_submissao.pdf & $\begin{array}{c}30 / 03 / 2017 \\
16: 49: 26\end{array}$ & FLAVIA FIRMINO & Aceito \\
\hline $\begin{array}{l}\text { Declaração de } \\
\text { Pesquisadores }\end{array}$ & Compromisso_pesquisador.pdf & $\begin{array}{c}30 / 03 / 2017 \\
16: 47: 49 \\
\end{array}$ & FLAVIA FIRMINO & Aceito \\
\hline $\begin{array}{l}\text { Declaração de } \\
\text { Pesquisadores }\end{array}$ & Declaracao4_de_privacidade.pdf & $\begin{array}{c}30 / 03 / 2017 \\
16: 45: 28\end{array}$ & FLAVIA FIRMINO & Aceito \\
\hline $\begin{array}{l}\text { Declaração de } \\
\text { Pesquisadores }\end{array}$ & Declaraca05_de_recrutamento.jpg & $\begin{array}{c}30 / 03 / 2017 \\
16: 42: 58\end{array}$ & FLAVIA FIRMINO & Aceito \\
\hline $\begin{array}{l}\text { Declaração de } \\
\text { Pesquisadores }\end{array}$ & Declaracao3_de_suspensao_ou_enc.pdf & $\begin{array}{c}30 / 03 / 2017 \\
16: 40: 41\end{array}$ & FLAVIA FIRMINO & Aceito \\
\hline $\begin{array}{l}\text { Declaração de } \\
\text { Pesquisadores }\end{array}$ & Declaracao2_sobre_despesas.pdf & $\begin{array}{c}30 / 03 / 2017 \\
16: 39: 04\end{array}$ & FLAVIA FIRMINO & Aceito \\
\hline $\begin{array}{l}\text { Declaração de } \\
\text { Pesquisadores }\end{array}$ & Declaracao1_de_publicicolade.pdf & $\begin{array}{c}30 / 03 / 2017 \\
16: 38: 15 \\
\end{array}$ & FLAVIA FIRMINO & Aceito \\
\hline $\begin{array}{l}\text { Declaração de } \\
\text { Instituiçå̃o e } \\
\text { Infreestrutura }\end{array}$ & Termo_de_snuencia_HC_3.pdf & $\begin{array}{c}16 / 02 / 2017 \\
19: 26: 52\end{array}$ & FLAVIA FIRMINO & Aceito \\
\hline $\begin{array}{l}\text { Declaração de } \\
\text { Instituiçâo e } \\
\text { Infraestrutura }\end{array}$ & Responsabilid_pes_HC4.pdf & $\begin{array}{c}16 / 02 / 2017 \\
19: 25: 16\end{array}$ & FLAVIA FIRMINO & Aceito \\
\hline $\begin{array}{l}\text { Declaração de } \\
\text { Instituiçắo e } \\
\text { Infraestrutura }\end{array}$ & Assinaturas_HC3.pdf & $\begin{array}{c}16 / 02 / 2017 \\
19: 04: 23\end{array}$ & FLAVIA FIRMINO & Aceito \\
\hline
\end{tabular}

Endereģo: Av. Dr. Eneas de Carvalho Aguiar. 419

Balrro: Cerqueira Ceser

CEP: $05,403-000$

UF: SP

MUnICIPIO: SAOPAULO

Telefone: (11)3061-8858

E-mall: cepee@itusp.br 


\begin{tabular}{c|c|c|c|c|} 
EE DSP - ESCOLA DE \\
ENFERMAGEM DA \\
UNIVERSIDADE DE SÃO
\end{tabular}

Continusçao do Parecer: 2.157.193

\begin{tabular}{|l|l|c|l|c|}
\hline Folha de Rosto & Folha_rosto.pdf & $\begin{array}{c}16 / 02 / 2017 \\
18: 58: 14\end{array}$ & FLAVIA FIRMINO & Aceito \\
\hline
\end{tabular}

Situação do Parecer:

Aprovado

Necessita Apreciação da CONEP:

Na๊o

SAO PAULO, 05 de Julho de 2017

Assinado por:

Marcelo José dos Santos

(Coordenador)

Enderego: Av. Dr. Eneas de Carvalho Aguiar, 419

Bairro: Cerqueira Ceser

CEP: $05,403-000$

UF: SP

Municiplo: SAO PAULO

Telefone: (11)3051-8858

E-mall: cepeegusp br 


\section{Anexo C}

\section{Parecer Consubstanciado do CEP Instituto Nacional de Câncer José Alencar Gomes da Silva- INCA}

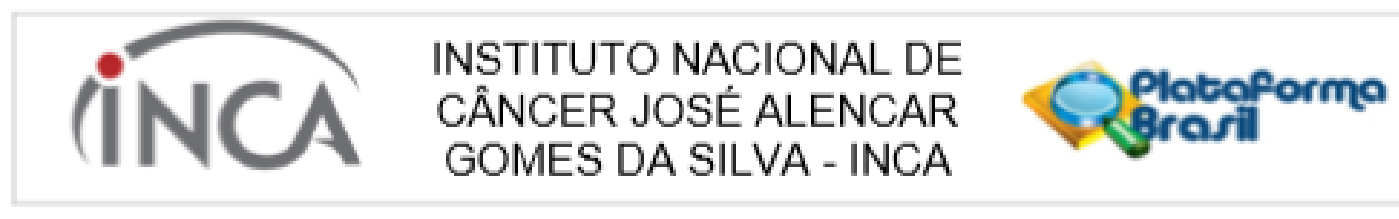

\section{PARECER CONSUBSTANCIADO DO CEP}

Elaborado pela Instituição Coparticipante

DADOS DO PROJETO DE PESQUISA

Titulo da Pesquisa: "Eficácia da Celulose Oxidada Regenerada versus Alginato de Cálcio no controle do sangramento de feridas malignas decorrentes do câncer de mama: ensaio clínico randomizado".

Pesquisador: FLAVIA FIRMINO

Área Temática:

Versão: 1

CAAE: 75440717.4 .3001 .5274

Instituiçăo Proponente: Escola de Enfermagem da Universidade de Säo Paulo - EEUSP

Patrocinador Principal: Financiamento Próprio

\section{DADOS DO PARECER}

Número do Parecer: 2.288 .858

\section{Apresentaçäo do Projeto:}

Conforme descrito no Parecer Consubstanciado CEP/NCA N 2186186 .pdf de 25/07/17.

Objetivo da Pesquisa:

Conforme descrito no Parecer Consubstanciado CEP/NCA No 2186186.pdf de 25/07/17.

Avaliação dos Riscos e Beneficios:

Conforme descrito no Parecer Consubstanciado CEP/NCA No 2186186.pdf de 25/07/17.

Comentários e Considerações sobre a Pesquisa:

Conforme descrito no Parecer Consubstanciado CEP/NCA No 2186186.pdf de 25/07/17.

Consideraçöes sobre os Termos de apresentação obrigatória:

Conforme descrito no Parecer Consubstanciado CEP/INCA N0 2188186.pdf de 25/07/17.

Recomendações:

Sem recomendaçōes.

Conclusỏes ou Pendências e Lista de Inadequaçöes:

Respostas ao Parecer Consubstanciado CEP/INCA N 2186186. pdf de 25/07/17.

Pendência 1 - Quanto à Folha de Rosto: No campo Apoio Financeiro do documento

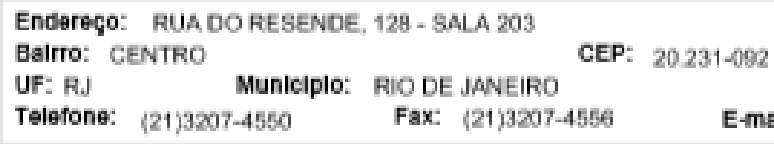


INSTITUTO NACIONAL DE CÂNCER JOSÉ ALENCAR GOMES DA SILVA - INCA

"PB_INFORMAÇŐES_BÁSICAS_DO_PROJETO_802703.pdf' de 09/06/2017 foi informado "Financiamento Próprio". Entretanto, no documento "ProjetocomnovoTCLEVersao4.doc" postado em 00/00/2017 lê-se "7 CUSTOS DO ESTUDO: O estudo terá efetivamente baixo ousto para a instituiçăo tendo em vista que os materiais a serem utilizados fazem parte da rotina da instituiçắo". Assim sendo, o campo "Patrocinador Principal" na Folha de Rosto deve ser assinado pelo Responsável Institucional (Coordenador de Assistênoia ou Diretor Geral). Ressalta-se que a Folha de Rosto é um documento que dá consistência jurídica ao projeto e. portanto, firma o compromisso assumido pelo responsável legal em nome da Instituiçăo (Norma Operacional CNS $n^{\circ} 001$ de 201, item 3.3.a).

Resposta: a aba 5 na Plataforma Brasil só abre para projetos na modalidade "estudos multicêntricos". Assim. o projeto foi reapresentado na Plataforma Brasil cadastrando o Instituto Nacional de Câncer como instituição coparticipante, de acordo com o desenho original do estudo - onde năo prevê ser pesquisa multicêntrica por não utilizar-se de "vários centros de pesquisa" e nem por disponibilizar um "pesquisador responsável em cada oentro" de acordo com a Resoluçắo No. 346, de 13 de janeiro de 2005, a qual definiu o termo "Projetos Multioêntricos' conforme descrito a seguir:

I - Definiçăo do termo: Projetos multicêntricos - projeto de pesquisa a ser conduzida de acordo com protocolo únioo em vários centros de pesquisa e, portanto, a ser realizada por pesquisador responsável em cada centro, que seguirá os mesmos procedimentos.

Análise: Pendência atendida

2 - Quanto ao Projeto de Pesquisa (documentos 'ProjetocomnovoTCLEVersao4.doo" postado em 09/00/2017 e "PB_INFORMAÇŎES_BÁSICAS_DO_PROJETO_862703.pdf' de 09/00/2017):

Pendência 2.1 - A expressäo "sujeitos" deve ser substituida por "participantes de pesquisa" sempre que for necessário, em atenção à Resoluçã̃o CNS 468/12.

Resposta: as alteraçőes foram feitas nos resumos, nas versỏes portuguesa e inglesa, e em outros trechos do texto a partir do tópioo "0.4 RECRUTAMENTO E SELEÇÄO DOS PARTICIPANTES" cito à página 38 até o subitem "Desfecho Primário" do tópico "6.12.2 Desfechos" cito à pağ. 58. Quando apropriado, foi utilizada a expressăo "pacientes".

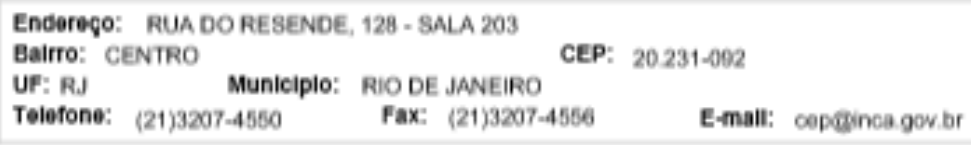




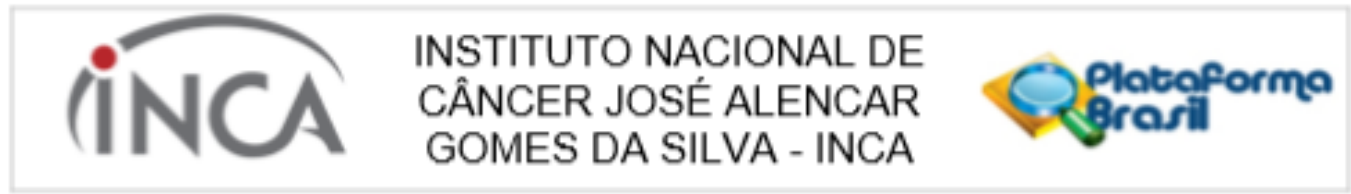

Continuscao do Parecer, 2 .288 868

Análise: Pendência atendida.

Pendência 2.2 - O Anexo 2 (Ficha de coleta de dados) apresenta dados identificadores dos participantes de pesquisa tais como nome, matrícula, endereço, etc. Ressalta-se que para fins de pesquisa, o anonimato deve ser garantido como procedimento ético. O pesquisador principal deverá assegurar a anonimização dos dados, garantindo assim o sigilo, através do uso de formulários específicos, de acesso exclusivo.

Resposta: O novo texto do projeto passou a constar a seguinte descriçäo no sub item ' 6.10 INSTRUMENTOS DE COLETA DE DADOS: Ficha demográfica e clínica: contendo dados de identificação anonimizados de modo a conter somente as iniciais do nome completo, e dados demográficos (número de registro hospitalar, nome, idade, sexo, endereço, telefone para contato), e demais dados clínicos como: estadiamento tumoral, tratamento oncológico pregresso e atual, comorbidades: medicações em uso (Apêndice 3). Após a coleta dos dados somente o pesquisador principal terá acesso à ficha de identificação dos pacientes. No momento em que os dados forem transcritos para planilhas de Excel o pesquisador criará uma lista de códigos para designar os pacientes por números arábicos minimizando, assim, o risco de identificação e preservando o anonimato dos participantes da pesquisa por ocasião da computaçăo, análise e discussão dos dados", O grifo em amarelo sinaliza as palavras incluídas na nova redação cito à pag. 48 . O impresso desenvolvido para coleta de dados foi alterado conforme abaixo:

Data:

Unidade de coleta:

Iniciais do nome completo:

Número na pesquisa/ID: (campo a ser preenchido somente pelo pesquisador principal) Matricula:

Contato fone:

Análise: Pendência atendida parcialmente, deverá ser retirado o número da Matrícula por equivalente gerado pela Pesquisadora.Solicita-se adequaçăo.

Pendència 2.3-No item Beneficios" do documento "PB_INFORMAÇÕES_BÁSICAS_DO_PROJETO_862703.pdf" de 09/06/2017 lề-se: "Seräo benefícios para os sujeitos da pesquisa: O EXAME DE SANGUE - que nem sempre é solicitado quando das

Endereģo: RUA DO RESENDE, 128 - SALA 203

BaIrTO: CENTRO MUnICIPIO: RIO DE JANEIRO

Telefone: (21)3207-4550 Fax: (21)3207-4556 E-mall: cepegincagow br 
INSTITUTO NACIONAL DE CÂNCER JOSÉ ALENCAR GOMES DA SILVA - INCA

intervenções hemostáticas de rotina, A ORIENTAÇÃO MAIS CRITERIOSA acerca do evento sangramento na ferida tumoral maligna e a participação em prol do desenvolvimento de melhorias acerca dos cuidados prestados na instituição" (destaque nosso). Considera-se que as informações apresentadas não representam, de fato, benefícios diretos da pesquisa para os participantes, pois estes procedimentos também fazem parte da rotina assistencial de enfermagem durante a realizaçäo dos curativos. Recomendase que seja informado: "O benefício principal da participação é possibilitar que no futuro os resultados alcançados com esta pesquisa beneficiem outros pacientes" (ou similar).

Resposta: foi acatada a sugestão de trocar a redação original para a seguinte redação: "Não haverá benefícios diretos, exceto o fato de que a participaçäo do paciente irá possibilitar que no futuro, com os resultados alcançados com a pesquisa, o controle do sangramento, embasado em pesquisas, beneficie outros pacientes", conforme consta no item "Detalhamento do estudo", redigido diretamente na Plataforma Brasil.

Análise: Pendência atendida.

3 - Quanto so TCLE, documento "REVISADOTCLEVersao4.docx", postado em 09/06/2017:

Pendência 3.1 - No item "BENEFíCIOS, ACOMPANHAMENTO E ASSISTÊNCIA" lề-se "Durante a pesquisa você será acompanhado (a) pelos pesquisadores até o momento da liberaçäo dos resultados de seu exame de sangue. Após a sua participação na pesquisa VOCÊ NÃO IRÁ RECEBER NENHUMA FORMA DE ACOMPANHAMENTO ADICIONAL" (destaque nosso). Cabe lembrar que segundo a Resolução CNS 468/12 - Pesquisador deverá assegurar aos participantes da pesquisa os beneficios resultantes do projeto, seja em termos de retorno social, acesso aos procedimentos, produtos ou agentes da pesquisa; e também assegurar as condições de acompanhamento, tratamento, assistência integral a que terão direito, inclusive considerando benefícios e acompanhamentos posteriores ao encerramento e/ ou a interrupção da pesquisa.

Resposta: foi refeita a redação original, passando a constar à página 79 o seguinte texto informativo no TCLE: "... $/$ O benefício principal da sua participação é possibilitar que no futuro os resultados alcançados com esta pesquisa beneficiem você e/ou outros pacientes através de programas de educaçäo dos profissionais de saúde e melhorias nos cuidados das feridas tumorais sangrantes. Durante a pesquisa você será acompanhado (a) pelos pesquisadores até o momento

Endereģo: RUA DO RESENDE, 128 - SALA 203

BalrTo: CENTRO

UF: RJ MUnICIPlo: RIO DE JANEIRO

Telefone: (21)3207-4550 Fax: (21)3207-4556

CEP: $20.231-092$ 


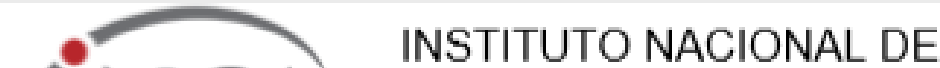 CÂNCER JOSÉ ALENCAR GOMES DA SILVA - INCA

em que o médico avaliar seu exame de sangue, e nesse momento encerra-se a sua participaçăo na pesquisa. Após a sua participação na pesquisa seu acompanhamento, tratamento, assistência integral e seus direitos como paciente na instituiçăo seräo mantidos de forma rotineira".

Análise: Pendência atendida.

Pendência: 3.2 - $O$ documento não informa a garantia de liberdade ao participante da pesquisa de recusarse a participar ou retirar o consentimento, em qualquer fase da pesquisa, sem penalização alguma.

Resposta: Na primeira página do TCLE, cito à pág. 78 do projeto, passou a constar a seguinte redação: "Você poderá cancelar sua participação na pesquisa ou retirar seu consentimento a qualquer momento, sem nenhuma penalidade, e sem nenhum dano ao seu tratamento, à sua assistência integral, ou aos seus direitos como paciente da instituiçäo*

Análise: Pendência atendida.

Pendência 4 - Quanto aos membros da equipe de pesquisa No documento "ProjetocomnovotCLEVersao4.doc" (postado em 09/06/2017) lê-se" "A etapa de randomizaçăo, alocação e mascaramento irăo requerer um ESTATÍSTICO, e DOIS PROFISSIONAIS DE SAÚDE; sendo um o colaborador da pesquisa, que irá realizar a randomização (manipulação dos envelopes), e outro que irá atestar a hemostasia" ; "Nos casos em que o sangramento for causa principal pela busca do atendimento especializado, o pesquisador principal ou SEUS COLABORADORES certificarse-ão se haverá intervenção sistêmica prescrita pelo médico plantonista antes de proceder à troca do curativo"; "Os COLABORADORES DA PESQUISA nas salas de atendimento de enfermagem, nutrição, psicologia e atendimento médico identificarão os pacientes elegíveis"; "Os COLABORADORES DA PESQUISA das enfermarias, sendo um colaborador por enfermaria no plantäo diurno, ficarão encarregados de identificar ao pacientes elegiveis para o estudo e prosseguir a coleta de dados": "[...] no momento em que for aplicado o material hemostático e conferida pressão manual o pesquisador irá solicitar ao SEU AUXILIAR DE PESQUISA para acionar o cronômetro digital", etc. Já no item "Outras informações, justificativas ou consideraçóes a critério do pesquisador" do documento "PB_INFORMAÇÕ̃ES_BÁSICAS_DO_PROJETO_862703.pdf" de 09/06/2017 foi informado

Endereģo: RUA DO RESENDE, 128 - SALA 203

Bairro: CENTRO R.J MUniciplo: RIO DE JANEIRO

Telefone: (21)3207-4550 Fax: (21)3207-4556 E-mall: ceperenca gow br 


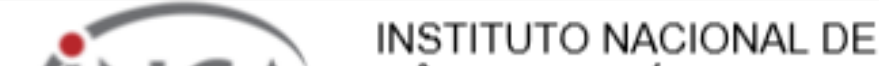 CÂNCER JOSÉ ALENCAR GOMES DA SILVA - INCA

Cortinuscas do Parncer: 2.288 .86

"Considerou-se equipe de 5 pesquisadores (pesquisador principal + 4 auxiliares) para o cálculo de materiais permanentes e capital porque este é o número estimado de PROFISSIONAIS QUE IRA̋O EXECUTAR A INTERVENÇA̋O EXPERIMENTAL após o treinamento pelo pesquisador principal* (destaque nosso). Todos os membros da equipe envolvida, adequadamente informados sobre o protocolo, o(s) produto(s) da pesquisa e suas tarefas e funçōes, deverão ser inseridos no oadastro do projeto de pesquisa na Plataforma Brasil e assinar o Formulário para Submissăo de Estudos no INCA, a fim de garantir o cumprimento dos requisitos e diretrizes estipulados na Resoluçăo CNS 466/12 e toda a regulamentaçăo complementar relativa à ética em pesquisa envolvendo seres humanos.

Resposta: O número de colaboradores foi redimensionado contando com enfermeiras diaristas e enfermeiras plantonistas de ambos os locais onde ocorrerá a coleta de dados (HC III e HC IV). Manteve-se o total de cinco membros participantes da Equipe de Pesquisa, que foram inseridos no cadastro do projeto da Plataforma Brasil e assinaram o Formulário de Submissão de Estudos no INCA (Vide anexo I).

Análise: Pendência atendida

5 - Quanto ao Formulário para Submissão de Estudos no INCA:

Pendência: 5.1 - O documento deverá incluir a assinatura da chefia do Laboratório Clínico, Serviço envolvido na execução da Pesquisa.

Resposta: Assinatura foi incluida (Vide anexo 2).

Análise: Pendência atendida.

5.2 - O documento deverá incluir a assinatura de todos os membros da equipe envolvida na execuçăo da Pesquisa.

Resposta: Todas as assinaturas estăo incluídas e foram incluídas. Houve mudança da Chefia de Enfermagem do HC III e assinatura da nova ohefia foi providenciada (Vide anexo 2)

Análise: Pendência atendida

EndoreqQ: RUA DO RESENDE, 128 - SALA 20:

BaIrTo: CENTRO

UF: R.J MUniciplo: RIODE JANEIRO

CEP: $20.231-092$

Telefone: (21)3207-4550 Fax: (21)3207-4556 E-mall: coperincagovibr 


\section{(iNCA \\ INSTITUTO NACIONAL DE CÂNCER JOSÉ ALENCAR Plotoforma GOMES DA SILVA - INCA}

Continuscáa do Parecer; 2 .288 868

Consideraçöes Finais a critério do CEP:

Diante do exposto, o Comitê de Ética em Pesquisa do Instituto Nacional de Câncer (CEP-INCA), de acordo com as atribuições definidas na Resoluçăo CNS No 466/2012 e na Norma Operacional CNS N0 001/2013. manifesta-se pela aprovação do projeto de pesquisa proposto.

Ressalto o(a) pesquisador(a) responsável deverá apresentar relatórios semestrais a respeito do seu estudo.

Este parecer foi elaborado baseado nos documentos abaixo relacionados:

\begin{tabular}{|c|c|c|c|c|}
\hline Tipo Documento & Arquivo & Postagem & Autor & Situação \\
\hline $\begin{array}{l}\text { Informações Básicas } \\
\text { do Projeto }\end{array}$ & $\begin{array}{l}\text { PB_INFORMAÇŌES_BÁSICAS_DO_P } \\
\text { ROJETO } 969003 \text {.pdf }\end{array}$ & $\begin{array}{c}04 / 09 / 2017 \\
21: 35: 43\end{array}$ & & Aceito \\
\hline Outros & Carta_ao_CEP_EEUSP_docx & $\begin{array}{c}04 / 09 / 2017 \\
21: 27: 52\end{array}$ & FLAVIA FIRMINO & Aceito \\
\hline $\begin{array}{l}\text { Recurso Anexado } \\
\text { pelo Pesquisador }\end{array}$ & Carta_resposta_ao_CEP_INCA_doc & $\begin{array}{c}04 / 09 / 2017 \\
21: 27: 27\end{array}$ & FLAVIA FIRMINO & Aceito \\
\hline $\begin{array}{l}\text { Declaração de } \\
\text { Pesquisadores }\end{array}$ & Equipe_de_Pesquisa2.jpg & $\begin{array}{c}04 / 09 / 2017 \\
21: 01: 00 \\
\end{array}$ & FLAVIA FIRMINO & Aceito \\
\hline $\begin{array}{l}\text { Declaração de } \\
\text { Pesquisadores }\end{array}$ & Equipe_de_Pesquisa1.jpg & $\begin{array}{c}04 / 09 / 2017 \\
21: 00: 30\end{array}$ & FLAVIA FIRMINO & Aceito \\
\hline Outros & Servicos_HV_4.pdf & $\begin{array}{c}04 / 09 / 2017 \\
20: 57: 46\end{array}$ & FLAVIA FIRMINO & Aceito \\
\hline Outros & Servicos_HClII.pdf & $\begin{array}{c}04 / 09 / 2017 \\
20: 56: 37\end{array}$ & FLAVIA FIRMINO & Aceito \\
\hline Outros & $\begin{array}{l}\text { Assinatura_servico_Patologia_Chefia_E } \\
\text { nf HClll.pdf }\end{array}$ & $\begin{array}{c}04 / 09 / 2017 \\
20: 55: 18\end{array}$ & FLAVIA FIRMINO & Aceito \\
\hline $\begin{array}{l}\text { TCLE / Termos de } \\
\text { Assentimento / } \\
\text { Justificativa de } \\
\text { Ausência }\end{array}$ & TCLE_REVISADO.docx & $\begin{array}{c}04 / 09 / 2017 \\
20: 44: 46\end{array}$ & FLAVIA FIRMINO & Aceito \\
\hline Orçamento & Orcamento_Revisado.docx & $\begin{array}{c}04 / 09 / 2017 \\
20: 43: 32 \\
\end{array}$ & FLAVIA FIRMINO & Aceito \\
\hline $\begin{array}{l}\text { Declaração de } \\
\text { Pesquisadores }\end{array}$ & Declaracao5_de_recrutamento.jpg & $\begin{array}{c}04 / 09 / 2017 \\
20: 24: 51\end{array}$ & FLAVIA FIRMINO & Aceito \\
\hline $\begin{array}{l}\text { Declaração de } \\
\text { Pesquisadores }\end{array}$ & Declaracao4_de_privacidade.pdf & $\begin{array}{c}04 / 09 / 2017 \\
20: 23: 43\end{array}$ & FLAVIA FIRMINO & Aceito \\
\hline $\begin{array}{l}\text { Declaração de } \\
\text { Pesquisadores }\end{array}$ & Declaracao3_de_suspensao_ou_enc.pdf & $\begin{array}{c}04 / 09 / 2017 \\
20: 23: 13\end{array}$ & FLAVIA FIRMINO & Aceito \\
\hline $\begin{array}{l}\text { Declaração de } \\
\text { Pesquisadores }\end{array}$ & Declaracao2_sobre_despesas.pdf & $\begin{array}{c}04 / 09 / 2017 \\
20: 22: 36\end{array}$ & FLAVIA FIRMINO & Aceito \\
\hline $\begin{array}{l}\text { Declaração de } \\
\text { Pesquisadores }\end{array}$ & Declaracao1_de_publicicdade.pdf & $\begin{array}{c}04 / 09 / 2017 \\
20: 22: 14\end{array}$ & FLAVIA FIRMINO & Aceito \\
\hline
\end{tabular}

Endereço: RUA DO RESENDE, 128 - SALA 203

Bairro: CENTRO RJ MUniciplo: RIO DE JANEIRO

Telefone: (21)3207-4550 Fax: (21)3207-4556 E-mall: ceperincagow br 


\section{(iNCA \\ INSTITUTO NACIONAL DE CÂNCER JOSÉ ALENCAR GOMES DA SILVA - INCA

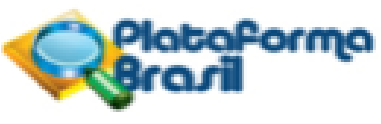

Continuscaso do Parecer: 2 2as a68

\begin{tabular}{|c|c|c|c|c|}
\hline $\begin{array}{l}\text { Declaração de } \\
\text { Pesquisadores }\end{array}$ & $\begin{array}{l}\text { Termo_de_compromisso_pesquisador.p } \\
\text { df }\end{array}$ & $\begin{array}{c}04 / 09 / 2017 \\
20: 21: 49\end{array}$ & FLAVIA FIRMINO & Aceito \\
\hline $\begin{array}{l}\text { Declaração de } \\
\text { Instituiçấo e } \\
\text { Infraestrutura }\end{array}$ & Termo_compromisso_HC_IV.pdf & $\begin{array}{c}04 / 09 / 2017 \\
20: 16: 16\end{array}$ & FLAVIA FIRMINO & Aceito \\
\hline $\begin{array}{l}\text { Declaraç̃o de } \\
\text { Instituição e } \\
\text { Infreestrutura }\end{array}$ & Termo_compromisso_HC_III_pdf & $\begin{array}{c}04 / 09 / 2017 \\
20: 14: 56\end{array}$ & FLAVIA FIRMINO & Aceito \\
\hline $\begin{array}{l}\text { Declaração de } \\
\text { Instituiçắo e } \\
\text { Infreestrutura }\end{array}$ & Termo_anuencia_HC_IV.pdf & $\begin{array}{c}04 / 09 / 2017 \\
20: 10: 51\end{array}$ & FLAVIA FIRMINO & Aceito \\
\hline $\begin{array}{l}\text { Declaração de } \\
\text { Instituiçắo e } \\
\text { Infreestrutura }\end{array}$ & Termo_anuencia_HC_III.pdf & $\begin{array}{c}04 / 09 / 2017 \\
20: 09: 08\end{array}$ & FLAVIA FIRMINO & Aceito \\
\hline Cronograma & QUINTAVERSAO_Cronograma_docx & $\begin{array}{c}04 / 09 / 2017 \\
20: 07: 16\end{array}$ & FLAVIA FIRMINO & Aceito \\
\hline $\begin{array}{l}\text { Projeto Detalhado / } \\
\text { Brochura } \\
\text { Investigador }\end{array}$ & Projeto_Versao5.doc & $\begin{array}{c}04 / 09 / 2017 \\
20: 06: 38\end{array}$ & FLAVIA FIRMINO & Aceito \\
\hline Folha de Rosto & Folha_de_Rosto_assinada.pdf & $\begin{array}{c}04 / 09 / 2017 \\
20: 01: 00\end{array}$ & FLAVIA FIRMINO & Aceito \\
\hline
\end{tabular}

Situação do Parecer:

Aprovado

Necessita Apreciação da CONEP:

Nåo

RIO DE JANEIRO, 21 de Setembro de 2017

Assinado por:

Carlos Henrique Debenedito Silva

(Coordenador)

Enderego: RUA DO RESENDE, 128 - SALA 203

BalrTO: CENTRO

UF: RJ

MunIcIplo: RIO DE JANEIRO

CEP: $20.231-092$

Telefone: (21)3207-4550 Fax: (21)3207-4556 E-mall: cepersinca.gowbr 


\title{
Anexo D
}

\section{Estadiamento classificatório das feridas neoplásicas}

\begin{abstract}
Estádio 1 - Pele íntegra. Tecido de coloração avermelhada e/ou violácea. Nódulo visível e delimitado. Encontra-se em estado assintomático.

Estádio $1 \mathrm{~N}$ - Ferida fechada ou com abertura superficial por orifícios de drenagem de secreção límpida, amarelada ou de aspecto purulento. Tecido avermelhado ou violáceo, lesão seca ou úmida. Pode haver dor e prurido. Não apresenta odor e configura-se sem tunelizaçōes e/ou formação de crateras.

Estádio 2 - Ferida aberta, envolvendo derme e epiderme. Ulceraçōes superficiais podendo apresentar-se friáveis, sensíveis à manipulaçấo, com secreçẩo ausente (lesōes secas) ou em pouco quantidade (lesões úmidas). Intenso processo inflamatório ao redor, em que o tecido exibe coloração vermelha e/ou violácea e o leito da ferida configura-se com áreas secas e úmidas. Pode haver dor e odor. Não formam tunelizaçōes, pois não ultrapassam o tecido subcutâneo.

Estádio 3 - Feridas que envolvem derme, epiderme e subcutâneo. Têm profundidade regular, mas com saliências e formação irregular. São friáveis, com áreas de ulceraçōes e tecido necrótico liquefeito ou sólido e aderido. Fétidas, secretivas, já com aspecto vegetativo, mas que não ultrapassam o subcutâneo. Podem apresentar lesỗes satélites em risco de ruptura iminente. Tecido de coloração avermelhada, violácea. O leito da lesão é predominantemente de coloração amarelada.

Estádio 4 - Feridas invadindo profundas estruturas anatômicas. Têm profundidade expressiva, por vezes não se visualiza seus limites. Têm secreçấo abundante, odor fétido e dor. Tecido ao redor exibe coloração avermelhada, violácea. O leito da lesão é predominantemente de coloração amarelada.
\end{abstract}

Fonte: Haisfield-Wolfe, Baxendale-Cox. Staging of Malignant Cutaneous Wounds: a pilot study. ONS, 26 (6):1055-56, 1999 


\section{Anexo E}

\section{View Letter}

\section{Close}

$\begin{array}{ll}\text { Date: } & 30 / 11 / 2018 \\ \text { To: } & \text { "Flavia Firmino" flavia.firmino@inca.gov } \\ \text { From: } & \text { "JWC Editorial Office" jwc@markallengroup.com } \\ \text { Subject: } & \text { Your Submission - jowc.2018.0112R1 }\end{array}$

Ref.: Ms. No. jowc.2018.0112R1

Study Protocol

Regenerated oxidized cellulose versus calcium alginate in the control of bleeding from malignant wounds from breast cancer: a randomized controlled trial

Journal of Wound Care

Dear Mr Flavia Firmino,

I am pleased to tell you that your work has now been accepted for publication in Journal of Wound Care.

It was accepted on $30 / 11 / 2018$

The next step is for the article to be copy-edited and formatted into the journal's house-style. In due course, you will receive another email from us asking you to check a proof copy of the edited article.

Thank you for submitting your work to this journal.

With kind regards

Rachel Webb

Editor

Journal of Wound Care

$x * \approx * ; * ;: * * ;$

In compliance with data protection regulations, please contact the publication office if you would like to have your personal information removed from the database. 